PACIFIC LINGUISTICS

Series B - No. 26

\title{
PIDGINIZATION AND SIMPLIFICATION OF LANGUAGE \\ by
}

$P$. Mühlhäusler

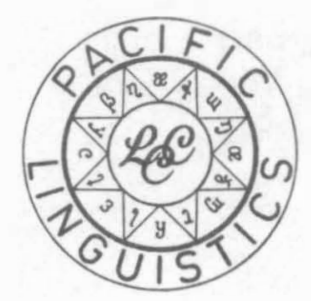

Department of Linguistics

Research School of Pacific Studies

THE AUSTRALIAN NATIONAL UNIVERSITY 
PACIFIC LINGUISTICS is issued through the Linguistic Circle of Canberra and consists of four series:

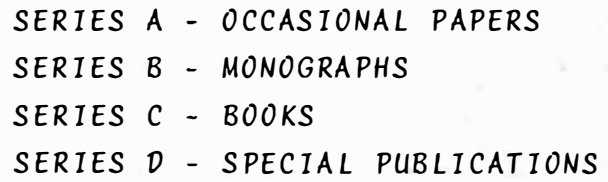

EDITOR: S.A. Wurm.

ASSOCIATE EDITORS: D.C. Laycock, C.L. Voorhoeve, D.T. Tryon, T.E. Dutton. EDITORIAL ADVISERS:

B. Bender, University of Hawaii

D. Bradley, University of Melbourne

A. Capell, University of Sydney

S. Elbert, University of Hawaii

K. Franklin, Summer Institute of Linguistics

w.w. Glover, Summer Institute of Linguistics

G. Grace, University of Hawaii

M.A.K. Halliday, University of Sydney

A. Healey, Summer Institute of Linguistics

L. Hercus, Australian National University N.D. Liem, University of Hawaii

J. Lynch, University of Papua New Guinea

K.A. McElhanon, University of Texas

H. McKaughan, University of Hawaii

P. Mühlhäusler,

G.N. O'Grady, University of Victoria, B.C.

A.K. Pawley, University of Hawaii

K. Pike, University of Michigan; Summer Institute of Linguistics

E.C. Polomé, University of Texas

G. Sankoff, Université de Montréal

W.A.L. Stokhof, National Center for Language Development, Jakarta; University of Leiden

J.W.M. Verhaar, University of Indonesia, Jakarta

ALL CORRESPONDENCE concerning PACIFIC LINGUISTICS, including orders and subscriptions, should be addressed to:

The Secretary,

PACIFIC LINGUISTICS, Department of Linguistics,

Research School of Pacific Studies,

The Australian National University,

Canberra, A.C.T. 2600.

Australia.

Copyright (C) P. Mühlhäusler.

First published 1974. Reprinted 1978 and 1981.

The editors are indebted to the Australian National University for help in the production of this series.

This publication was made possible by an initial grant from the Hunter Douglas Fund.

National Library of Australia Card Number and ISBN 0858831139 


\section{INTRODUCTION}

This mongraph was originally presented as a thesis which was a partial requirement for the degree of M.Ph1l. of the University of Reading. It was written under the joint supervision of Dr I.P. Warburton and Dr P.J. Trudgill of the Department of Linguistic Sclence during the 1971/72 academic year.

There has been significant progress in the field of pidgin and creole studies since. Furthermore, the author has had the opportunity to carry out extensive fleldwork on New Guinea Pldgin in 1973 and 1974 which has led him to a reappraisal of some of the 1deas proposed in the original thesis. However, changes have only been made where this seemed absolutely essential.

Finally the author wants to apologize for the idiosyncracies in the use of the English language resulting from German and Afrikaans substratum influences.

Canberra, October 1974. 
TABLE OF CONTENTS

1. THE PREDICAMENT OF THE PIDGINIST 1

1.1. PROLEGOMENA 1

1.2. THE NATURE OF THE DATA 3

1.3. GRAMMATICAL THEORY AND PIDGINS 6

1.4. DIACHRONIC STUDIES OF PIDGINS AND CREOLES 6

1.5. SYNCHRONIC STUDIES OF PIDGINS AND CREOLES 9

2. THE DEFINITION OF THE TERMS 'PIDGIN', 'PIDGINIZATION', 11

'CREOLE' AND 'CREOLIZATION'

2.1. INTRODUCTION 11

2.2. A LOOK AT EARLIER DEFINITIONS 12

2.3. THE RELATIVITY OF THE TERMS 'PIDGIN' AND 'CREOLE' 14

2.4. DEFINITIONS IN PURELY LINGUISTIC TERMS 18

2.5. FOUR CRITERIA FOR THE DEFINITION OF PIDGIN 22

3. SOCIOLINGUISTIC PARAMETERS OF PIDGINIZATION AND 27 CREOLIZATION

3.1. SOME EARLIER PROPOSALS 27

3.2. A PRELIMINARY LIST OF PARAMETERS 29

3.3. A CLOSER LOOK AT SOME PARAMETERS 29

3.4. ADDITIONAL PARAMETERS 45

3.5. SOME CONCLUSIONS 48

4. THE CONNECTION BETWEEN LINGUISTIC AND SOCIOLINGUISTIC 49 FACTORS

4.1. INTRODUCTORY REMARKS 49

4.2. CORRELATES OF SIMPLIFICATION 50

4.3. IMPERFECT LEARNING OF A FOREIGN LANGUAGE 53

4.4. THE SOCIOLINGUISTIC CORRELATES OF IMPOVERISHMENT 61

4.5. SOCIOLINGUISTIC PARAMETERS OF UNINTELLIGIBILITY 62 
4.6. SOCIOLINGUISTIC PARAMETERS OF STABILITY 63

4.7. SUMMARY OF CHAPTER FOUR 64

5. SIMPLIFICATION OF LANGUAGE 67

5.1. INTRODUCTION 67

5.2. DIFFERENT USES OF THE NOTION OF SIMPLICITY

5.3. THE DISCUSSION OF SIMPLIFICATION IN THE 69

5.4. SIMPLIFICATION AND IMPOVERISHMENT 73

5.5. MARKED CATEGORIES AND THEIR LOSS IN 76 PIDGINIZATION

5.6. SIMPLIFICATION OF THE MORPHOPHONEMIC COMPONENT 84

5.7. STRICT ORDER OF SURFACE STRUCTURE ELEMENTS AND 92 SIMPLIFICATION

5.8. SIMPLIFICATION IN THE LEXICON I 97

5.9. SIMPLIFICATION IN THE LEXICON II 103

6. THE DETERMINATION OF FORM CLASSES IN PIDGINS 111

6.1. PROBLEMS IN PRETHEORETICAL CLASSIFICATION 111

6.2. FORM CLASSES IN GENERATIVE THEORY 118

6.3. DERIVATION VERSUS CROSS-CLASSIFICATION 129

7. CONCLUSIONS 135

BIBLIOGRAPHY 141 


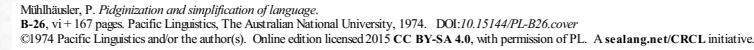




\section{CHAPTER 1}

\section{THE PREDICAMENT OF THE PIDGINIST}

\subsection{PROLEGOMENA}

Progress in linguistics depends on two main factors: the development of an explicit linguistic theory and the avallability of data that are rellable enough to be used in the testing of these theorles. A look at the present state of pidgin studies will show that both conditions are far from belng met. Most of the studies that have been done were undertaken without any theoretical framework and even those studies that were made within the framework of structuralist linguistics were of ten made on a limited and unreliable corpus of data.

One of the reasons for this is that pidgins and similar 'marginal' languages were of marginal interest for most linguists. Although they are mentioned in most standard textbooks, only a few pages were devoted to them, and earlier opinions about pidgins were often uncritically taken over in otherwise critical studies. The same holds for creole languages, which were often considered as a varlation of the same phenomenon.

"The study of creoles and pidgins has galned 1mpetus only during the last fifteen years. These languages, long viewed as the product of linguistic miscegenation and therefore beneath the dignity of scholars of the more traditional schools, have for too long gone unregarded." (Hancock 1971a: p.117). Th1s does not mean that some excellent work has not been done by scholars such as Schuchardt, R.A. Hall, LePage and Taylor, work that is a valuable foundation for further research. But the success of most earlier work is due to the personal devotion of a few scholars and their insistance on particular problems. Today, pidgin studies havereached a degree of maturation that should make it possible to leave behind the pre-theoretical phase of investigation and develop 
a theory that can accommodate the observations made during that phase. This will necessarlly be beyond the power of a single scholar. The work of many scholars will be needed as well as interdisciplinary collaboration between linguists, sociolinguists, and sociologists.

The aim of this thesis is to examine certain present-day tendencies in pidgin and creole studies, to discuss some of the questions that must be asked in this field, and to make some suggestions about how grammatical theory can help in understanding the phenomena under debate. Most of the results will seem tentative and unsatisfactory, but some may indicate the direction to be taken by further investigations. Before any discussion, however, I want first to mention some difficulties of a more general nature in some detall - difficulties that are responsible for the predicament in which the present-day pidginist finds himself. In this discussion the term creole will be used as well as the term pidgin. The reasons for this will become clear later.

As mentioned above, many linguists have held the view that pidgins are not worthy objects for a scientific investigation, but rather mere curlosities. This view has been discussed at some length (e.g. Hall: review Sayer; Hall 1954; Hymes 1971: preface Schuchardt 1909 and elsewhere) and little therefore remains to be sald here. However, some prejudices that were exposed by Hall and others are still with us. They are, perhaps, more subtle today, but no less dangerous for that. Labov has recently criticized the first generative account of a creole (Balley 1966) on very similar grounds, namely that the language is described in terms of 1 ts deviation from the standard language: "The description of a non-standard language is to be a kind of grammaire des fautes, a pedagogical caricature of the language rather than a portrait of 1t. Whatever value such constructions have for the teachers or learners, they cannot contribute anything to our study of the adequacy of languages. If such "pure" creoles are not used, they are not used for some good reason. We can only argue from grammars that are used for the serious purpose of communication in everday life." (Labov 1971a: p.41). This means that creoles and pidgins cannot be regarded as maximally divergent versions of a lexically related standard language, but have to be described as they are actually used by their speakers, as versions that are sometimes heavily influenced by the presence of a model language, sometimes impervious to such influences. The names Jamałcan English, Pidgin English, Cape-Dutch, etc. suggest that these languages are merely some sort of deviant form (the term dialect is frequently used in this connection) of a related upper language. Such labels are very misleading and I shall have more to say on this point in a discussion of the genetic relationship that holds between languages 
such as Jamaican Creole and English. Another point that needs to be mentioned is that pidgins are second languages, and that any deficiencies, inconsistencies etc. that may be found in these languages $c$ an be explained partly in terms of second-language learning. Those who describe pidgins as being the result of some mental inferiority on the part of their speakers (Jourdain 1956; Bos 1880, and others,) e.g. "l'esprit borné de ces races incapables de saisir bien les nuances du franca1s" (Bos, 1880: p.571) 1gnore the fact that although certain concepts may be absent in a pidgin, this says nothing about the concepts that the user of a pidgin may have in his first language. The development of pidgins into creoles has shown again and again that this impoverishment will be repalred as soon as a pidgin becomes the native language of a community (excellent examples are to be found in Labov 1971a). Pidgins, therefore, reflect the ability of human beings to simplify language for certain purposes rather than any propensity to conceptual impoverishment in certain races.

\subsection{THE NATURE OF THE DATA}

Even in the very recent literature on pidgins the lack of data is recognized as one of the main obstacles (e.g. Hymes 1971: p.3): "the scientific significance of pidgins and creoles was recognized by a few pioneers - ... - but avallable descriptions seldom want beyond vocabularies and occasional texts, most often attempting to represent the language in some other language's conventional orthography." One of the reasons was certainly that pidgins were spoken in geographically marginal areas, and another perhaps more immediate reason was that the necessity for syntactic description was not seen: "It will prove scarcely worth while to formulate the rules of grammar of this speech" (Church1ll, 1911: p.27).

Even less attention has been pald to another aspect of pidgins: their nonsegmental properties. Prosodic features play an important part in these languages. Only recently, Labov (1971a) has mentioned that the tempo of a spoken pidgin may be one of the universals of pidgins. Loudness is often mentioned in an unsystematic way as a parameter of pidgins (the widespread belief that one can make up for imperfect competence by speaking louder). It is further known that nonlinguistic features such as the use of parts of the body other then the vocal organs, e.g. hands or chin, is used as a means of disambiguating or even producing information. An investigation of this field would seem to me to be very promising. (cf. also Goodman (1964: p.44)): "This great intelligibility, however, was by no means the result of the pidgin alone; a great deal was accomplished by the use of the language with 
gestures, tricks of volce quality and volce dynamics, exaggerated facial expressions, and a social atmosphere of amused friendliness." Hall (1943: p.39): "Although not absolutely necessary (for example conversatlons may be held in Pidgin on the telephone, etc.) nonlinguistic devices are often used to furnish further explanatory practical context for an utterance, e.g. pointing (w1th the chin), descriptive gesture with the hand, shrugging the shoulders, etc." and S1lverstein (1971: p.191) for a discussion of extralinguistic features in Chinook jargon.

In spite of some fairly extensive descriptions in structuralist terms (e.g. Hall's account of Chinese Pidgin English, New Guinea Pidgin and Haltian Creole), even today "perhaps the greatest need is the elementary one of adequate linguistic descriptions of pidgins and creoles." (Hymes, 1971: p.6). Of the pidgins mentioned in the appendix in Hymes, (1971) only a handful are well known, although much remains to be done even in the description of these languages. Other pldgins like the Pidgin Portuguese of Timor (mentioned in Wurm, 1971b: p.1003), Pidgin Siass 1 (Hymes 1971: p.523) and many others are practically unknown. It is concelvable that an investigation into an existing Pidgin Portuguese could provide us with answers to many questions that have been posed in connection with the relexification theory (e.g. Whinnom 1965, 1971; Thompson 1961). For a number of pidgins it is true there are notes, sketchy material or partial descriptions of various degrees of reliability, but these are all insufficient to serve as a foundation for a study that aims at the establishment of "pldgin universals".

As unsatisfactory as the general lack of data is the degree of reliability of what data there is. Two sources of unreliability seem to characterize most available descriptions.

Many generalizations about pidgins are based on a very small sample of observations. The informants are often not really representative of the dialectal variations that may occur in a pidgin. In some cases it is even assumed that falrly different pidgins are one and the same language, e.g. Rogge (1957) who does not account for the fact that the three languages called Pidgin English, namely those spoken on the China Coast, that on the Islands of Melanesia and that in Hawa11 are, in fact, three different pidgins that just happen to have the same name: Zusammenfassend se1 festgestellt: P1dgin 1st ins English übersetzte Chinesisch and hatte noch nach dem Ersten Weltkrieg elne grosse Bedeutung in Ostasien" (Rogge 1957: p.325). Th1s tendancy to neglect all regional differences is attacked severely by Spears (review of Schneider: p.60): West African Pidgin is a complex linguistic phenomenon consisting of the varieties of speech spoken by individuals in a multilingual situation. A single individual may use a number of different 
varieties, depending on specific situations. It is, of course, evident to linguists and laymen alike that Cameroon Pldgin, Sierra Leone Krio and the varieties spoken in Liberia and Nigeria resemble one another markedly. To brand all of these varleties dialects of a separate and distinct language is to conceal the real nature of pidgins, however. To most Creolists, it is, in addition to descriptive studies, an examination of the social, cultural, political, and linguistic considerations surrounding the development and uses of the varieties of a derived language that is of interest. To the extent that a linguistic description attempts to make pidgin fit a rigid language/dialect scheme, the description is inexact and uninformative."

This quotation also indicates the second source of unreliability: the socio-linguistic parameters that determine different varieties of the same pidgin. That the pidgin spoken by the speakers of the superstrate language often differs considerably from the pldgin in the mouth of speakers of substrate languages is not only true for European-based pidgins: the same phenomenon can be found in indigenous pidgins, e.g. In Police Motu (Wurm 1971: p.1015): "In 1ts present day form, Police Motu is spoken in two dialects, one of them the Central Dialect, used by speakers of Motu proper when speaking

the Central District natives living in the nelghbourhood of the Motu area 1tself whose local languages are Austronesian. The other dialect, the Non-Central Dialect, is found in all other areas where Police Motu is spoken, and the form used in the Western District is regarded as standard."

Nevertheless most descriptions are abstractions from social and regional varieties or take into consideration only a single restricted variety (e.g. Pldgins as spoken by European speakers: Hall: Chinese Pidgin English and most of his Melanesian Pidgin).

There is a falr amount of uneasiness about this state of affairs. It is felt that in the case of pidgins abstraction from actual use is not enough, particularly since the notion of an ideal speaker-hearer's competence is applicable to pidgins only in a limited sense. A pidgin, by definition, is a language that has been learnt as a second language and even full competence in a pidgin is less than competence in one's first language. Interference phenomena may affect more than just performance. (I shall not go into much more detall here, but the problem is dealt with extensively in the following papers: Tsuzaki 1971: Coexistent systems in language variation, Decamp 1971: Analysis of a post-creole speech continuum, Hymes 1971: p.199 ff., Labov 1971a: p.42 ff. Labov modifies and expands on some of Tsuzaki's arguments). 
A theoretical framework for the description of pidgins must account for the kind of data that has just been discussed. It remains to be seen how those theorles of grammatical description that are currently avallable lend themselves to this purpose.

\subsection{GRAMMATICAL THEORY AND PIDGINS}

It is generally agreed that a scientific theory should be exhaustive, free of contradiction and adequate to deal with some given subject matter. In recent years, progress in this direction has been made in the fleld of grammatical theory, including transformational-generative theory. The discussion that follows will be couched mainly in terms of transformational-generative grammar and I shall try to define some of the pre-theoretical descriptive terms in common use among pidginists in terms of this theory. I shall also look at some of the more problematic areas of transformational-generative theory, especially the status of the 'parts of speech'. Most of the examples will be drawn from languages where the pretheoretical stages of investigation - the gathering of the data and their preliminary analysis - have been more or less completed.

The step which I am attempting to take here is the step from a pretheoretical to a theoretical stage of investigation. Some terms have been re-defined and integrated into the theory in question. For this reason much of this work will be concerned with terms such as pidgin, creole, simplicity, and impoverishment - terms that are widely and frequently inconsistently used in the literature on these languages. One of the main reasons why these terms have not yet been sufficiently well defined is the stress laid in most studies on diachronic aspects of pidgins and creoles. The question of historical origins has been the focus of attention, while the internal structure of pidgins and creoles, in so far as it does not relate to diachronic developments, has been given much less attention.

\subsection{DIACHRONIC STUDIES OF PIDGINS AND CREOLES}

It is sometimes not realised that the terms pidgin and creole refer to two different fields of linguistic investigation: pidgin studies are concerned in the first place with description, with synchronic analysis, whilst the term creole presupposes that we have information on the development of the language. Whereas it may be possible to define a pidgin on internal evidence alone, this is not possible with a creole: "Linguistically, pidgins have certain distinguishing features.. ..Synchronically the most obvious characteristic is that they make use of limited resources, and lack certain types of complexity. While this might be a useable criterion for identifying pidgins, it is not much 
help in 1dentifying creoles, since these are usually normal full-sized languages in all respects." (Southworth 1971: p.260). Thus, all efforts to describe a language as a creole simply because it has, for example, little morphology and much syntax (cf. Bickerton and Escalante 1970: p.262) who say that these properties could qualify a language as a creole 'by the most stringent criteria') are misdirected.

I think that one can agree with Winford (1972: p.82): "The plain truth of the matter seems to be that there are no structural criteria as such which will enable us to define a creole precisely, so that it is perhaps impossible to lay down any clear line of demarcation between a creole and any other language." (cf. also Tsuzak1, 1971: p.331).

Salient features may emerge in a comparison of creoles to their antecedents, but even here one must be careful not to make too strong assumptions about their importance for a definition of a creole. A look at an actual instance of creolization (e.g. Labov 1971a) w1ll show that many routes can be followed in the expansion of an impoverished pidgin so that, in the tense system for example, there may be more than one solution and some competing solutions may coexist for a long time. Thus, a standard language and its lexically related creole are distinguished by two kinds of restructuring: the loss of rules and simplifications during pidginization and the introduction of new rules during creolization. The rules of a standard language and its corresponding creole will, therefore, not demonstrate the relatively straightforward kind of similarity and correspondences one finds between related dialects. Transformational grammar has made some valuable suggestions on how the ordering of rules in a grammar can reflect the historical development of a language (Chafe 1968; King 1969; Kiparsky 1970 and 1970a), but in the case of creoles there may be some special difficulties. The rapid development of creoles has of ten been noted and this means that in a comparatively short time much restructuring has taken place and that many of the underlying forms are different in creoles and their mother languages. These differences can affect rules very early in a derivation. This kind of relationship is therefore different from what is normally understood by genetic relationship.

For this reason, the isolation of 'salient' features of a creole, even relative to 1 ts related standard languages, may be very complex. Certainly, there will be features that are shared by a standard European language and a lexically related language. The reasons for these affinities may be of very different kinds. They may be due to some kind of a "common core" of language-independent universals, or they may be a result of a particular historical development. The original language may have been only partially pldginized and subsequently creolized. The same possibilities exist when it comes to explaining the obvious similarities 
between all European-based creoles. Even if one assumes that they all originated in a Pidgin Portuguese it is not obvious why the subsequent independent creolization should have ylelded such similar results. (e.g. Gáld1, 1969, reconsideres his earlier assumptions of universal tendencies in favour of a theory that takes into consideration the influence of African languages). The part that languages other than European languages played in the development of creoles will need much more investigation. The lack of data that characterizes the fleld of creole studies and especially diachronic studies makes it impossible to make definite statements.

Most writers are not unaware of this: "One of the greatest problems in the study of contact languages is the tantalizing paucity of historical information (emphasis mine). Of actual linguistic evidence we rarely have, before the nineteenth century, more than an odd phrase quoted, usually with the intention of showing how comic these languages are." (Whinnom 1965: p.511).

Dillard (1970) exposes the dangers that lie in assuming certain principles about the origin of contact languages ('paradox', 'virginity' and 'cafeteria') and stresses the importance of analysing the existing data. Although the data for most creoles are very unreliable there are some exceptions. The project on Sranan, mentioned by Voorhoeve (1961) is a case in point and the findings of the 'Project for the Study of Creole Language History in Surinam' may clarify many points.

It is, perhaps, unfortunate that the diachronic aspect has been over-stressed in pidgin and creole studies. Comparatively little synchronic work has been done, and hardly any theoretical framework for pidginization or creolization has been proposed. (Some proposals have been made by Hjemlslev, Gáldi, Voorhoeve and several participants of the Second Mona Conference, but the results are far from conclusive). The interrelationship between sociolinguistic and linguistic factors is certainly very important and worth investigating, but the social context will not be the cause for the actual appearance of pidgins. It will trigger off linguistic processes, such as simplification, which eventually lead to pidgin. A large part of this paper will be devoted to the question of what the possible universals of simplification of language are. 


\subsection{SYNCHRONIC STUDIES OF PIDGINS AND CREOLES}

A synchronic study of pidgins and creoles would deal with two aspects: the grammatical structure of these languages, especially pidgins in the case of this investigation, and their actual use, variability etc. Although I realize the extreme theoretical importance of such aspects as variability, continua and the difficulties that are faced when an attempt is made to distinguish between these aspects and the abstract structure of these languages, I shall actually only deal with questions that are independent of variation and use. In other words, I shall deal with possible universals of pidgins and how they can be explained in terms of grammatical theory. Most of the attention will be devoted to the notion of simplification of language, this being present in all pldgins to varying degrees. The alm is to define a simplified language by internal linguistic criteria alone. A notion such as simplification is of use only when it becomes part of a grammatical theory. It is only then that we will be able to answer questions such as: Is a pidgin a simplified version of one language? or Is it the result of some language independent processes? A synchronic study would then have as 1 ts aim the definition of the amount of simplification that is present in any given pidgin.

It lies in the nature of this work that suggestions rather than solutions will be offered. I shall, however, attempt to make these suggestions in the form of empirical hypotheses about the nature of pidgins, hypotheses whose validity can be tested in further research. 



\section{CHAPTER 2}

2. THE DEFINITION OF the terms 'PIDGIN', 'PIDINIZATION', 'CREOLe', AND 'CREOLIZATION'.

\subsection{INTRODUCTION}

Much of the confusion in the discussion of pidgins and related languages is due to a loose and unsystematic use of the terms pidgin, pidginization, creole, creolization. Perhaps the best approach to this problem is to look first at the aim of definitions of one's terms. Apparently many of the earlier definitions were concerned with the sociolinguistic rather than the linguistic aspects of pidgin languages. Furthermore, earlier definitions tended to be made in everyday language or by means of what were considered to be sufficiently well-known sclentific terms such as 'mixed language', 'sharply-reduced language', 'simple language' etc. Such definitions are known as descriptive definitions and it was, and still is, assumed that continuous refinement and redefinition might lead to an acceptable and universally valid definition. of 'pidgin' etc.

Unfortunately this does not seem to be a very satisfactory approach. First most of the scientific terms are not well enough known (they are part of a pre-scientific rather than a scientific vocabulary) and secondly, they are not integrated into a theory of language which is explicit enough to make empirical claims. As it is, there is no way of deciding whether a given language is a pidgin or not, why it is a pidgin, or what constitutes simplicity of language etc. This is particularly true of non-European based (indigenous) pidgins and of other cases where the historical facts are not known. (It is an empty claim, for example, to say that Afrikaans is a partly creolized language; there is no way of either confirming or disconfirming this. Nevertheless, this has of ten been sald of Afrikaans). 
What we need is a principled way of deciding whether a given definition is correct. The only way to do this is to work within an explicit grammatical theory such as transformational-generative grammar. The aim of this and the following sections is to give a tentative definition within the framework of generative grammar, to discuss earlier proposals, and to look at the relevance of non-linguistic data to the definition of pidgin.

\subsection{A LOOK AT EARLIER DEFINITIONS}

The most convenient point of departure seems to be the definition of Bloomfield (1969: p.474 ff.) which was taken up and developed by Hall. Hall characterizes a pidgin as (1966: p.XII): "a variety whose grammar and vocabulary are very much reduced", an additional criterion is that "the resultant language must be native to no one" (1bidem): a creole arises when a pidgin becomes native and is characterized by a re-expansion of grammatical and lexical resources.

The definition given by Hall uses a linguistic and a non-linguistic criterion. Berry (1971a: p.510) thinks that "pidgin and creole have proved useful terms and there is a large measure of agreement in their use. They are not, however, general enough on the one hand, or precise enough on the other, to ensure that there is not any doubt." Similarly, we can read (Mafen1 1971: p.95): "While this (distinction between a pidgin and a creole language) is a useful distinction, it does not always prove possible to make such a neat separation. This is the case w1th English-based pidgin which is spoken in Nigeria. Nigerian Pidgin is a lingua franca for many, and thus a true pidgin in Hall's sense; it is also a mother tongue for a number of families in certain areas and communities, and as such might, in these cases, be defined as a creole language," or further on (1bidem: p.96): "West African Pidgin... runs the gamut all the way from true creole - as a mother tongue and home language - to what one might call 'minimal pidgin', the exiguous jargon often used between Europeans and thelr domestic servants." (cf. also Tonkin 1971: p.131).

The same is true of New Guinea Pidgin since again we find a continuum of varieties which correlates with the age at which Pidgin is learnt. Whereas in some parts, notably in the towns and coastal areas, Pidgin is learnt elther together with another vernacular or on 1 ts own as a first language, in the more remote areas it is often not learnt before people are fully grown up. The age at which Pidgin is learnt and the proficiency acquired seem to be correlated with the time for which the respective areas have been under the influence of the administration and missions. 
If one accepts these facts one must assume a scale of"pidginness" and "creoleness" rather than an e1ther-or dichotomy. Apparently on the linguistic side 1t would be a scale of 'simplicity', 'defectiveness', 'minimalization', and any other feature which can been taken for a universal of pidgins. On the extra-linguistic side the nature of the scale is less clear; one might think in terms of restricted and expanded situational context. The criterion of native versus non-native language may be thought of as a scale as well. In areas where pidgins are spoken multilingualism is frequent and there are cases (perhaps even many) in which speakers cannot say what language their real native language is, cf. Mafeni (1971: p.112): "I have the feeling I speak Pidgin more fluently than any other Nigerian Language which I know and use. Although my mother tongue is Isoko, Yoruba seems to be the dominant substrate in my varlety of P1dgin." Therefore, to avold confusion, one may adopt the term primary language to designate the language which is best mastered. This is not necessarily the mother-tongue. All other languages of a bilingual individual are secondary languages; this is discussed in more detail in Heine (1970: p.16). The situation is very similar in New Guinea where the boundary between pidgin and creole (as defined by Hall) is not easy to draw. Nevertheless in the pre-theoretical stage of an investigation this definition is more acceptable than most other definitions given.

In some works on pidgins and creoles no distinction seems to be made between the two. Richardson (1963a: p.2) speaks of "A strange variety of Pidgin French known as Creole". In the discussion of the origin of Afrikaans, Valkhoff seems to treat pidginization and creolization as the same process. He speaks of the "breaking down (creolizing) the original Cape Dutch." (1971: p.456). The most popular belief is that pidgins are 'mixed languages'. All major German encyclopedias, for example, use the term 'Mischsprache' (Meyers Lexicon, Herder-Lexicon, Grosse Duden Lexicon and others).

Apart from being an explanation which defines one unknown term by another, it has other dangers as well. This has been realized in the recent literature on this subject, cf. Whinnom (1971: p.90): "The analogy of two languages 'mating' to produce a hybrid offspring (a pidgin or creole) is quite false, since it is to equate a language with a blotype which is (a) on a different hierarchical level, and (b) has, in fact, no linguistic equivalent." It is certainly true that pidgins are due to different languages which come into contact, but a term like 'mixing' is totally inadequate to describe the resulting pidgin. (a) a pldgin can have features which none of the contributing languages has, (b) the result of mixing need not be a pidgin at all, (c) pidgins do not 
need to be very mixed at all. It is more promising to replace a vague notion of mixing by a thorough investigation into interference phonemena in second language learning, especially in language learning, under extremely unfavourable conditions (for example, short time of contact, possibly the policy of European masters in the case of European-based pldgins not to teach their language to their slaves.)

A still less useful definition of pidgin is its characterization as a deteriorated European language, although this has been sald frequently in earlier work, e.g. Bodmer (p. 441): "everywhere the new speechproduct consists of more or less deformed European words strung together with a minimum of grammar." Bos (1880: p.577): "nous n'avons plus 1c1 du francals simplifié, mals bien du francals détraqué." A discussion of this view is in the review of Sayer by Hall, and in Hall 1954. Sayer used the terms 'a corrupted form of English speech', 'a quaint and crude macaronic jargon', 'a mongrel lingo', and similar terms in his discussion of pidgins. This scientific superstition should have died out at the very latest after the excellent descriptions of pidgins and creoles by Schuchardt at the end of the last century. In the preface to 'Die Lingua Franca', Schuchardt (1909: p.441) gives the following character1zation of the goal of his investigation "jede Arbeit ist eine wissenschaftliche, welche sich zum Ziel setzt, Umfang and Wesen einer Erscheinung zu bestimmen, die ihr anhaftenden falschen Vorstellungen $z u$ bese1tigen, ihr den gebührenden Platz innerhalb einer grösseren Gruppe von Erscheinungen anzuweisen."

This means that one should continuously test one's claims, revise when necessary and integrate one's findings in a larger theoretical framework.

As we have seen so far, all definitions given either in purely linguistic or linguistic and sociolinguistic historical etc. terms have proved to be inadequate in some cases at least.

\subsection{THE RELATIVITY OF THE TERMS PIDGIN AND CREOLE}

It has not yet been decided if 1 t is possible to define pidgin in purely intralinguistic terms. Most proposals made so far want to take a not yet well defined criterion of simplification as the defining criterion for pidgins. Whether this simplification is something like a universal simplicity, (as assumed by Hjelmslev; 1938; Coelho 1881-1883; Tonkin 1971; Gáld1 1938) or whether it is a 'simplification of a model or target language' as proposed by Voorhoeve and others is not clear. The rest of this paper will deal with possible universal simplications. One must, however, not forget that pidgin is not a static term but rather a term that covers a whole field of differently developed competences. 
One could think of scales such as the following:

SCALE

Pre-pidgin continuum. Initial contact.

Minimal pidgin.

Pidgin.

Highly sophisticated pidgin.

Inftial creole.

Extended creole.

Post-creole continuum.
Master-slave relation, household.

See discussion of 'nature of contact' in following chapter.

\section{EXAMPLES}

Varieties of Bush-Pidgin in New Guinea in areas that have only recently been opened.

Butler-English of Madras (Schuchardt 1881).

Chinese Pidgin English, Chinook, Police Motu.

\section{Use as medium of primary New Guinea Pidgin. education, in newspapers, administration. \\ Intertribal marriage. \\ New Guinea Pidgin, \\ Oral and written \\ literature, used in Hawaian Creole. higher education. \\ Sranan, Paplamento. \\ Diglossic situation. \\ English Creoles in the Caribbean.}

The scale implies that reduction of vocabulary and grammatical tools is a characteristic of the very early or primitive stage of a pidgin only and that expansion starts before the actual creolization takes place. If one accepts this scheme, it makes sense to speak of a "falrly complicated and involved pidgin". New Guinea Pidgin is a good example, its functions having increased continuously at the same time as a grammar that can handle all new situations satisfactorily has evolved. Not only have embeddings become more frequent but new grammatical categories have also been introduced. The more sophisticated varieties of New Guinea Pidgin are increasingly indepent of the situational context. The following scheme may be useful as well:

\section{fully fledged language \\ partial reduction expansion}

fully fledged language

This means that for a language to be creolized it is not necessary to undergo the stage of a minimum pidgin. (Tonkin 1971: p.131). "However, 
while it is in a sense true that a 'creole' must first have been a 'pldgin', they are not necessarily distinctive linguistically. The same variety can, in fact, be used either as 'first language' or as 'lingua franca. The processes of reduction and expansion will not really fit these uses if the pattern of development is not a simple linear one." (emphasis mine). Both schemes imply the acceptance of the terms 'pidginization' and 'creolization' (Samarin 1971) as opposed to 'pidgin' and 'creole', referring to reduction and expansion respectively. This still leaves us with a definition of pidginization and creolization.

Whinnom's recent discussion of pidgins (Whinnom 1971) seems to be promising in many regards. First of all he demonstrates that the similarities between imperfect learning and simplification of a language is not a sufficient explanation for a pidgin (Whinnom 1971: p.104). It appears to be true that no pidgin has ever consolidated itself in other than a multilingual situation. I.e. for a pidgin to become stable it is appropriate to say that it involves speakers of at least three different languages; an imperfectly learned superstrate language serves as means of communication for speakers of different substrate languages.

\section{Superstrate language A}

Imperfect learning by speaker of $B$

$B^{\prime}$
Imperfect learning by speaker of $\mathrm{C}$

$C^{\prime}$

Minimal pidgin language

$\mathrm{D}$

expansion etc. (see above)

Pldgins are now seen as the result of a mixing of imperfectly learned varieties of a target language. The simplification, therefore, takes place in various places in the model, namely between $A$ and $B^{\prime}$, between $A$ and $C^{\prime}$, between $B^{\prime}$ and $C^{\prime}$ ( $B^{\prime}$ being the imperfectly learned language $A$ in the mouth of $B$ ). $B^{\prime}$ and $C^{\prime}$ are instable, but once they are used in communication between speakers of $B$ and $C$ they will soon develop a stable norm. Labov (1971a: pp.1566) discusses the difference between a 'multilingual idiolect' - modes of expression worked out by individuals in a new environment which show that pidginization has taken place. They are, however, not pidgins. In order for such a language to become a pidgin it must be 'socially sanctioned'. "Pidgins are thus social rather than individual solutions to the problem of cross-cultural communication" (Labov 197la: p.15) (emphasis mine). 
The term 'pidginization' is a convenient term to refer to all kinds of simplification (this is done by Samarin). The result of pidginization is not necessarily a pidgin and perhaps this will only be the case in a small percentage of the actually-occurring instances. Factors that play a role here are the presence or absence of the target language and the willingness of its speakers to teach 1ts use. A continuous presence of the target language will make pidginization much less likely and no stable pidgin will develop in such a condition. I will return to this point after the discussion of the terms creole and creolized.

A creole language is, according to the definition given above, a pidgin which has been restructured and expanded. Labov (1971a: p.12): "When pidgins acquire native speakers, they change. As we will see, these changes follow a regular pattern, supplying a varlety of grammatical categories and syntactic devices which were missing in the pidgin." The question is which pidgin has been expanded. Is it the instable, imperfectly learned varlety $B^{\prime}$ and $C^{\prime}$, or is it the relatively stable varlety $D$ ? In the latter case one could expect that the creolized form would preserve many traits of the pidgin; in the former case one could expect that creolization will be a process in which the target language is approximated in a haphazard way. This is basically a cocoliche situation.

I think one is justified in referring to these two processes as creolization ${ }^{1}$ (of stable pldgin) and creolization ${ }^{2}$ respectively. It is only in the case of creolization ${ }^{1}$ that the elements of the earlier pidgin can be recovered - one may assume that this creolization consists mainly in the addition of rules and elements of the lexicon. In the case of creolization ${ }^{2}$ something different happens. A restructuring takes place in which rules of the target language replace and supersede the rules of the unstable simplified version. The result depends mainly on two factors; namely the relative instablity of the pidgin and the relative aggressive power or influence of the target language. In the most extreme case creolization ${ }^{2}$ will result in A again. There seems to be no way of recovering the intermediate processes by internal reconstruction. The only evidence may be written evidence which reflects the intermediate stages. To speak of a creole language in purely synchronic terms is the case where creolization ${ }^{2}$ is involved is much more problematic than in cases where the creole is the result of creolization.' I think this point is important in the discussion of such languages as Afrikaans. Valkhoff (1966: p.192) makes the following statement: "Undoubtedly Afrikaans has sprung from Dutch, just as Mauritian Creole has from French, or French from Latin..." Although Valkhoff (1966) does not mention Richardson (1963) or Goodman (1964) in his bibliography one 
might expect that he is aware of what they have to say about the origin of French creoles and in particular Mauritian creole. (Goodman: p.131): "It is most likely developed out of a slaver's jargon, whose French element (what up to now has been called pre-creole) may or may not have been the kind of dialectal melange which Falne suggests... The West African Jargon or pidgin then began to develop independently in the various colonial areas to which it has been transported and to become more stable..." Richardson (1963a: p.14): "Incompatibility of ancestor languages...led to the neutralization of the features of the already simplified dominant language...."

In both cases the type of creolization involved is creolization ${ }^{1}$. For Afrikaans this would mean the existence of a stable simplified Dutch Pidgin (or of a relexified Malayo-Portuguese) and a subsequent creolization ${ }^{1}$. There is no evidence that this has happened. It makes, in fact, much more sense to assume a creolization ${ }^{2}$ which resulted in a language which is in fact much more Dutch than Valkhoff wants to believe. When Kempen says (see discussion Valkhoff (1966: p.193)) that Afrikaans and Dutch are the same language he obviously refers to the underlying system and not to the phonetic output. The only valid counter-example against this claim is to show that the rules of Afrikaans can be shown to be related to some pidgin. One could think of an investigation similar to Cassidy's 'Tracing the Pidgin Element in Jamaican Creole' (in Hymes 1971). For the moment we can assume that creolization has not taken place in Afrikaans.

\subsection{DEFINITIONS IN PURELY LINGUISTIC TERMS}

The next point I want to discuss is the possibility of defining a pidgin or creole in purely linguistic terms. cf. Samarin (1971: p.123): "There might be considerable value, for example, in the establishment of a recognition procedure for pidgins." or (1bidem p.124) "If we can determine a set of linguistic characteristics that evince rapid (or traumatic) social changes, we may be able to increase our ability to reconstruct the history of societies." or (1bidem p.128) where Samarin proposes a possible recognition procedure: "Thus it should be possible to 1dentify pidginness on internal evidence alone. Be that as it may, we have in the reduction of options a means for characterizing historical pidginization."

One must be careful not to confuse sallent features (which are to be found in many or most of the known pidgins) with universals of pidgins. Salient features cannot be more than an indication that a suspicion of pidginization is justified. More often that not they have 
been taken as evidence that indeed pidginization has occurred in the history of a language. A typical example is reduplication, a salient feature which is often found in pidgins. Yet the mere fact that Afrikaans, for example, uses reduplication is no proof of an earlier pidgin stage. On the other hand, the fact that Pidgin-Sango does not use reduplication does not make it less pidgin-like. Another example is the notorious pluralizer in many creoles. I.e., the third person plural pronoun after a noun is an optional means of indicating plural where this is necessary. Valkhoff (1966: p.225 ff): "All students of creole know of a curlous phenomenon which is common to most Creole languages, namely the use of the personal pronoun of the third person plural...as a pluralizer for nouns and other words...hulle also occurs sporadically as a pluralizer for living beings in advanced Afrikaans... Hence...1t very much looks as if we have a construction taken over in Cape Dutch from the African variety of the lingua franca by speakers of that tongue." This is an overstatement. According to Goodman (1964: p.45) of all French Creoles only Haitian Creole and the Creole of Guayanas share this feature. Hesseling (1905: p.52 ff.) adduces the pluralizer as evidence against the hypothesis that pidgins and creoles are the result of a sort of universal simplification mechanism which operated independently in all pidgins. In attacking Coelho who proposed this, Hesseling writes (translated from Dutch): "In order to cast doubt on Coelho's theory he (L. Adam) asks how he could explain in terms of his point of view: plural formation by means of preceding or following third person plural personal pronoun and rendering the idea of a dative by means of a verb ("to give") used as a preposition. I quote these two questions because they constitute serious evidence against Coelho's explanation."

I would like to suggest why this need not be so. My point of departure is:

(a) plural is normally not indicated by means of a plural suffix in pidgin languages. The context is normally enough to disambiguate nominal constructions;

(b) there is a pronominal system where a third person plural is expressed;

(c) in constructing simple sentences the pronoun is often inserted between the noun and the verb. This seems to be extremely common in popular speech in most European languages (c $f$. Hesseling 1905: p.57 and the article by J.J. Salverda de Grave in 'Taal en Letteren' (1904) referred to by Hesseling). It is very common in most pidgins, perhaps in all; 
The reason may well be that this is a reflection of a deep structure which underlies all these languages. The common surface structure can then be explained by the non-application of a deletion transformation.

$$
\begin{aligned}
\text { Cf. The man he comes } & =\text { The man comes } \\
\text { The men they come } & =\text { The men come. }
\end{aligned}
$$

A combination of (a), (b) and (c) will yield the following result (which I shall demonstrate with examples from 'advanced' Afrikaans)

$$
\begin{array}{ll}
\text { Die skáp húlle wei in die Karoo } & \text { Afrlkaans } \\
\text { The sheep they graze in the Karoo } & \text { English gloss }
\end{array}
$$

(This is not a hypothetical example: Bouman (1962: p.61) mentions the absence of the plural suffix ascribing it to the influence of Bantu languages. "This feature is of very limited use, although well known from the speech of farmers who live in regular contact with the Bantu. In my opinion it is modelled on the prototype of Bantu 1diom").

The only thing that has to happen is a slight shift of the nucleus of the intonation unit

\section{Die skáp hulle wei in die karoo}

or rather a change in tonality, 1.e. one intonation unit instead of two, which is extremely likely to happen in rapid speech (according to Labov (1971a) the development of a pidgin into a creole means that the nativized pidgins "are spoken with much greater speed and fluency." (p.22). There will be fewer mainstresses, longer phonological phrases, a development of sandh1 phenomena and other types of morphophonemic condensation), to get

\section{Die skáp hulle wei in die Karoo}

In which construction skaap hulle (or spelled skaap-hulle) is the putative plural of skaap. There is no reason to assume that this construction has not originated in a similar way in creoles. A further point is that a sentence such as die skaap-hulle wei

does not exist in Afrikaans as far as I know. I doubt whether a corresponding construction (e.g. noun-dem dem verb in Jamaican Creole) exists in any creoles. To me it seems to be a very plausible explanation and possible a reflection of some kind of universal deep (or at least deeper) structure.

What cannot be explained in terms of this general principle is the second and more common meaning of the hulle construction in Afrikaans: 


\section{Afrikaans}

dominee-hulle gloss

minister-they: the minister and the people around him

Piet-hulle

Peter-they: Peter and his friends

This construction is interesting because a construction with exactly the same meaning can, or at least could, be found in New Guinea Pidgin. One of the earliest word lists (Borchardt 1926) gives:

\section{New Guinea Pidgin \\ ol pater \\ pater ol}

German

die Patres
der Pater und seine
Begleiter

I may add that I have found the same construction in a Swiss German dialect, but I do not at present want to attempt any explanation in terms of language universals.

What seemed to be a salient feature of certain creoles may now be explained in terms of a universal grammar. In a later chapter I shall come back to the scarcity of deletion transformations in pidgins and creoles.

The same may be true for the rendering of a dative idea by means of a verb to give. It is obvious that the dative idea cannot be equated with any function of a surface structure case dative. Rather one must assume some semantic deep case expressing (according to Fillmore 1970: p.24): "the animate being affected by the state or action identified by the verb."

It is very interesting that the correspondence dative-to give is expressed optionally in the surface of other languages, cf. German.

\section{GERMAN}

Er trägt mir (dat) auf

Er gibt mir den Auftrag

Er lässt mich verstehen

Er gibt mir zu verstehen

Er beleidigt mich mit seiner Antwort

Er gibt mir eine beleidigende Antwort

\section{GLOSS}

$$
\begin{aligned}
& \text { he orders me } \\
& \text { he gives me the order } \\
& \text { he makes me understand } \\
& \text { he gives me to understand } \\
& \text { he offends me with his answer } \\
& \text { he gives me an offending answer. }
\end{aligned}
$$

One can suspect that give as well as 1ts equivalents, is in reality a deep structure verb which appears independently in many unrelated languages to express an idea of dative. Given the reluctance of pidgins to delete elements from the surface structure, or given the alleged limited cholce of constructions in pidgins (less optional stylistic etc. transformations) the dative-give construction is perfectly plausible. 


\subsection{FOUR CRITERIA FOR THE DEFINITION OF PIDGIN}

In the above argumentation I have moved away from the question of definition. Let us come back to this point now.

Whinnom (1971: p.106) gave four defining criteria for an intentional definition of pidgins:

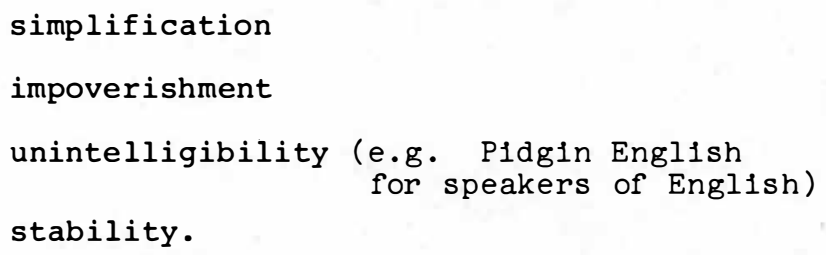

Only a combination of all four criteria will yield a pidgin. A combination of only some criteria will yield different language types.

\begin{tabular}{|c|c|c|c|c|}
\hline SIMPLIFIED & IMPOVERISHED & UNINTELLIGIBILITY & STABLE & $\begin{array}{l}\text { RESULTING } \\
\text { LANGUAGES }\end{array}$ \\
\hline+ & + & + & + & Pidgin \\
\hline+ & + & + & - & $\begin{array}{l}\text { Rudimentary } \\
\text { pidgin }\end{array}$ \\
\hline+ & + & - & - & $\begin{array}{r}\text { Imperfect } \\
\text { Language } \\
\text { learning }\end{array}$ \\
\hline+ & - & - & - & koine \\
\hline+ & - & + & + & Creole \\
\hline
\end{tabular}

(for the definition of koine see Nida and Fehderau 1970).

The pluses and minuses are idealizations and should be replaced by a scale of numbers whenever a precise characterization of the language type is needed; (the terminal language would be characterized by a sequence - - +; the fact that it is not simplified makes it different from all other language types in the above icheme).

What is needed now is a linguistic definition of 'simplification', 'Impoverishment', 'Intelligibility' and 'stability'. I shall look as the notion of simplification in later chapters. With regard to the other three one can make the following tentative statement: impoverishment means an actual loss of some part of the language - or more precisely a loss of some part of a component of the grammar without resulting complication of another component to make up for this loss. I am not certain what 'loss' could mean in the context of the phonological and syntactical components. One might think of a loss of euphony, rhyme words - strict word order would have similar consequences - (I refer 
here to the difficulties experienced by missionaries in the translation of religious songs). In the syntactic-component the loss of optional permutation transformations will yield similar results. The features of gender and surface case may be lost (although I am not certain what price one has to pay for this loss). The most obvious place, however, where impoverishment can take place is in the lexicon. There will be literally thousands of concepts which cannot be expressed in the first stages of a pidgin (and which will be introduced later); pidgins in the initial stage, and often as long as there is no need for 'filling up', may not function as a means of thought and self-expression. Chomsky refers to the lingua franca of the mediterranean coast - one of the oldest known pidgins - as an 'invented parasitic system' (Cartesian Linguistics, p.22). Attitudes of speakers, connotations, etc. will be the obvious victims. But before definite statements can be made one has to compare the semantic possibilities of various pidgins.

Unintelligibility is due to two main causes: (a) the shift of the meaning of lexical items and (b) restructuring of grammar. I.e. whereas in a koine the rules are the same as in the mother language, with the possible exception of some lower and very low rules, the restructuring in pidgins is much more far-reaching. Restructuring would mean, for instance (in terms of an 1tem-and-process approach) that the underlying forms in the systematic phonemic representation are different, that the order of rules is different, in short, that the grammars that generate the two languages are considerably different even at a rather deep level. An example of such a difference is the use of sequence of lexical elements for expressing sematic relations between them as opposed to inflexional categories and free word order. Most probably the meaningful sequence of elements is introduced somewhere rather deep in the grammar whereas the sequence of elements in an inflectional language is introduced by some late optional rule (cf. Staal 1967).

Stability is a relative measure. One is likely to find degrees of stability of rules and stability of competences. For most pidgins it is perfectly possible to have a written norm which is an indication of stability. This is not possible for the imperfectly learned language in the mouth of foreigners. The instability is furthermore unequally distributed in the various components of the grammar. The most obvious instability is in the phonetic output where speakers of pidgins are inclined to use the sounds of their vernacular languages. The syntactic component is much more stable. Not much is known about the stability of the semantic component, but one can assume that there is a common core of basic concepts - in any case large enough to serve the purposes of communication without much difficulty. To come back to phonological 
stab1lity: In Householder 1971 it is argued that the written text influences the spoken language to a high degree (primacy of writing). In pidgins where there is no written tradition or where the written tradition is heavily based on a European language, European. speakers will be inclined to pronounce the words of pidgin in terms of their own pronunciation. As soon as there is a spelling system which no longer relates the pidgin language to non-existing underlying forms via speaking, pronunciation may become more stable and unifled. I shall illustrate this with some examples (1t is a hypothesis rather than a statement but the empirical consequences can be tested in principle).

A comparison between earlier accounts of New Guinea with the new written tradition is very revealing:

First older examples:

all fellow meri, he cry

the women are singing

(Neverman 1929: p.257)

this fellow garden he belong you

this garden belongs to you

one day Eve she come along Adam

one day Eve comes to Adam

(Church1ll 1911: p.32)

you make him some water he boil

heat some water

he finish hot

it is already hot

(Schuchardt - MeZaneso Englisches p.159)

The striking similarity between pidgin and written English is evident. Now compare the following with the above examples:

tispela haus, em $i$ bilong tispela man

this house belongs to this man

(Fellow is now spelled pela)

mi ken i sapim tispela naip bilong yu

I shall sharpen this knife for you

yu save mekim paia bilong mi

can you make a fire for me

papa bilong mi i toktok pinis i tok, dok i mas kaikai

my father said the dog must eat

(examples from Wurm 1971a) 
Certainly the new spelling makes New Guinea Pidgin seem much less English and may indeed help its recognition as a fully fledged language. Mafeni discusses the difficulties of Nigerian pidgin because there is no unified spelling (Mafeni 1971: p.101): "I am of the opinion, from the tentative work I have done on the phonology of a few varieties of Nigerian Pidgin, that an orthography similar to that of Yoruba or Igbo would not only show clearly at least the phonetic/phonological difference between the base language and Pidgin but would emphasize the independent nature of the latter."

The account given on the last few pages is by no means a full account. It suggests, however, the general direction that one should take in the definition of pidgin in purely linguistic terms. In the discussion of simplicity these proposals will be refined below.

This does not mean, however, that the discussion of pidgins as socio-linguistic phenomena is superfluous. Rather it is complementary and, perhaps, decisive in the last instance. The role that context of situation plays in the impoverishment of pidgins is certainly very important. (cf. Firth who is of the opinion that a restriction of contexts results in restricted linguistic patterns). Therefore the second part of this chapter will be a discussion of the role of extralinguistic factors in the definition of pidgins and the interrelationship between the socio-linguistic and purely linguistic parameters. 


\section{CHAPTER 3}

\section{SOCIOLINGUISTIC PARAMETERS OF PIDGINIZATION AND CREOLIZATION}

\subsection{SOME EARLIER PROPOSALS}

The question I attempt to answer here is one that was asked by Grimshaw (1971: p.432): "What is 1t about the differential experience of language contact sites that has sometimes resulted in pidginization (variously culminating in creolization, in the maintenance and continued renewal of the pidgin, in the disappearance of the pidgin, or, in some few cases, the stabilization (standardization) of a pidgin) and in other cases has produced no speclal contact language at all..?"

This question is a result of the increasing uneasiness among pidginists and creolists about accepting the traditional definitions of pidgins and creoles, especially the key-cause hypotheses. It has been realized that pidgins develop in more than one sociolinguistic environment, that the factors that influence their origin and 'life cycle' are due to a combination of various parameters with different degrees of importance. The aim of a sociolinguistic characterization of pidgins and creoles must be to isolate possible parameters, to find a hierarchy among them, and to relate them to purely linguistic facts. One would further like to distinguish between salient and substantive parameters. Ideally the result would be a definition of pidgins and creoles that has predictive power, 1.e. given a certain combination of factors in the history of a language, one can assume that it has undergone pidginization and subsequent creolization. Hall has stressed the 1mportance of this factor in historical linguistics: the restructuring that characterizes the process of pidginization is likely to cause enormous difficulties in historical reconstructions. Grimshaw (1971: p.432) sets up a tentative list of factors that might be important in the process of pidginization and creolization: 
(a) patterns of conflict relations

(b) Industrial or commercial context

(c) numbers involved

Stewart (quoted from Grimshaw: 1bidem) recognizes another set:

(a) situation of culture contact with multilingualism

(b) relation primary-secondary speakers

(c) difference between languages in contact.

Elsewhere Stewart (quoted from Hart1g \& Kunz 1971: p.221) proposes a matrix for the classification of languages involving four parameters:

\section{PIDGIN CREOLE}
(a) standardization
(b) historicity
(c) vitality
(d) autonomy

Voorhoeve (1962) discusses the development of a creole language, Sranan, under the following four headings:
(a) numerical proportions between language groups
(b) social relation between linguistic groups
(c) geographical distribution of groups
(d) rise of a two-caste system.

The earliest attempt can be found in Reinecke (1964), who distinguishes between three groups of marginal languages according to socio-geographic context, namely:
(a) trade jargons
(b) plantation dialects
(c) settlers creoles.

Apart from these classifications, one finds numerous (often humorous) informal characterisations of pidgins, mostly involving both linguistic and sociolinguistic factors.

It is obviously not a very satisfying state of affairs when the same phenomenon is explained by a large number of more or less divergent definitions. It is even more dangerous to try to establish 'classes' of phenomena without making any claim as to the nature of these classes or their theoretical and empirical import. A possible way out would be: 
(a) to differentiate between causal and concomitant factors

(b) to differentiate between theories of the origin of pidgins and theories of the social function of pidgins

(c) to try to find sociolinguistic universals of pidginization and creolization.

\subsection{A PRELIMINARY LIST OF PARAMETERS}

At this stage, we are far from knowing enough to be able to formulate sociolinguistic theories of pidgins and creoles. What can be done is to take a closer look at all possible parameters of pidginization and creolization. These would include at least the following:

(a) nature of contact

(b) duration of contact

(c) 1lliteracy and second language learning

(d) cultural differences between groups

(e) prestige of target language

(f) prestige of pidgins and creoles

(g) number of speakers involved

(h) sex of speakers

(1) official language policy

(j) race relations

(k) group solidarity

(1) isolation versus contact with regard to target language and possible further factors.

This classification is falrly loose and purely pretheoretical, and it may be necessary to change it considerably. Nevertheless it will serve as a foundation for the discussion that follows.

\subsection{A CLOSER LOOK AT SOME PARAMETERS}

(a) Nature of contact

Wherever people of different languages come into contact the necessity for communication arises. Although in some cases verbal communication may not be necessary, it is the commonest form, as Reinecke (1964: p.534) notes: "If...contact is brief and discontinuous and limited to very simple transactions, speech may be dispensed with. Dumb barter is a form of accommodation reported from many parts of the world." On most occasions this is not enough, and, according to the nature of the contact, 
'lingua francas' of varying degrees of sophistication will be used. A 'lingua franca' is a language used between speakers of different languages, e.g. the Provencal language among the crusaders, English among many scientists, French among 19th century diplomats. If the topics which interest both parties involved are fairly sophisticated the lingua franca will remain the same without undergoing any simplification. The situation is different when the contact is of a restricted kind. The best-known cases are those of trade and masterslave contacts. Trade contact can be of different kinds:

1) between adjacent countries

11) between speakers of many different languages in a market situation

111) between European countries and peoples in other continents or between non-adjacent countries.

1) In the first case it is less likely that anything like a pldgin will originate or even that a lingua frarca will be used. The inhabitants of the border areas tend to be bilingual and mutual cultural contacts tend to be intensive. Since trade is on a relatively permanent basis it is worthwhile for the parties involved to learn each others language.

11) The contact in this case may be institutionalized, as it is the case in many trade centres in African countries, but there are speakers of a fairly large number of languages and it is therefore unlikely that they will all learn one another's language. Again, speakers of a given language want to maintain their identity and since learning and speaking someone else's language may mean that their native language loses prestige, there will be a pressure against this. Furthermore, other languages may be relatively difficult to learn. The obvious solution is the use of a fairly limited trade jargon that is noone's native language, and which is only used for trade relations. The type of language that is used in such a context is often referred to as an 'indigenous pidgin'. Some examples are Pidgin Sango, Pidgin Swahili and Kituba in Africa and Police Motu and Pidgin Siassi in New Guinea. A good description of the origin and function of Police Motu (Hiri Motu) can be found in Chatterton ( $1970 \mathrm{pp} .95 \mathrm{ff}$ ). It 1s likely that similar indigenous pidgins exist and existed elsewhere. They seem to be associated with certain economic systems and are prone to disappear with their conditioning factors. 
111) The trade between European countries and the rest of the world is closely related to the Portuguese explorations and voyages and the subsequent period of European colonialism. Since the Portuguese had trade relations with many peoples who had no relations whatsoever with each other, the Portuguese language in a pidginized form became the means of communication. Pidgin Portuguese was spoken along the sea routes between Europe and the Far East and in the coastal areas of Africa and Asia. In most cases P1dgin Portuguese has died out, but in some the continuous presence of the Portuguese and the establishment of stable settlements has resulted in a creolization of Pidgin Portuguese, presumably because the majority of the settlers were not native speakers of Portuguese (cf. Schuchardt 1888; Tonkin 1971). P1dgin Portuguese was used not only by the Portuguese in their contact with African and Asian peoples, but also by traders of other European nations. Later, after the decline of Portuguese power and Pidgin Portuguese, other European pidgins were used in trade relations, for example Pidgin English, Pidgin Dutch, Pidgin Danish and Pldgin French. Their linguistic relation to Pidgin Portuguese is claimed by some scholars, such as Whinnom and Thompson, but denied by others. Most of them have not survived elther as a result of relations being discontinued or considerably intensified. In the latter case a standard version of the European language tends to become the lingua franca. The trade contacts, and therefore the situational context, becomes so expanded that the original pidgin, used in a restricted context, no longer seems adequate.

A similar situation to the above is the migrant labour situation. This institution is part of the system of European colonialism. Typical examples are the mining centres of Katanga, the Copperbelt and the Witwatersrand where Africans from many countries were often forced to work. Two factors contribute to the use of a pidgin in such a situation: African workers speak many mutually unintelligible languages and the European supervisor has to communicate with the workers in a certain limited context. Several languages arose in this type of situation, of which Fanagalo san be sa1d to be the most 1mportant in that it has developed into a standardized and written language, and it fulfills a vital function in the context of mining-work in South Africa. It shares many properties with a slave-master language and becomes, therefore, the scapegoat of 1ts users in post-colonial days.

The master-slave languages developed mainly under the economic system of plantation industry. The work in the plantations necessitated a large number of unskilled workers recruited from most parts of Africa. 
As a precautionary policy the slave owners, especially in the West Indies, mixed Africans belonging to different tribes (cf. Taylor 1961: p. 612) in their plantations. Nevertheless many slaves seem to have already had a common means of communication in the form of a Europeanbased pidgin which they had acquired in the collecting centres in West Africa.

The following quotation contains the standard account of a plantation situation; it says all that seems to be relevant and $I$ am giving it in full: (review Turner: p.323/324): "The situation in which Gullah developed is a familiar type to those who have studied contact and creolized languages elsewhere. Negroes from various parts of Africa were brought to South Carolina and Georgia rice plantations, where white inhabitants were in decided minority, and opportunities to become famlliar with the standard language were limlted. Furthermore, the development and preservation of Gullah has been helped by geographical and cultural isolation. The coastal plantations were namely separated from the mainland by tidal streams or swamps; the institution of slavery till 1865, and the rigid Southern caste system since then.... have kept large proportions of Gullah Negroes from any contact with outside."

It is interesting to notice that the abolition of slavery did not change the situation of the plantation worker, or the African in general, since it was revived as a caste system.

As in the mining situation, two factors cooperate to bring about a pldgin: the necessity for the linguistically-diverse slaves to communicate with each other, and the language used between master and slave. As in the case of a European trade-pidgin the European language serves as the basis, the reason perhaps, being that it can be used in horizontal as well as vertical (master-slave) communication whereas indigenous pldgins are generally used in horizontal relations.

A last and perhaps minor variant of this type is a military alliance between two powers with the purpose of destroying a common enemy. There is a necessity to coordinate military actions and to communicate on a limited range of topics. Languages such as Korean Bamboo English (Algeo) 1960), English-Japanese P1dgin (Goodman 1967), various forms of 'pet1t nègre' and police languages in some colonies (Njanja, Police Motu) fall into this group. In many cases military pidgins are relatively shortlived and dependent entirely on non-normal relations. 
To summarize this section on the nature of contact I want to propose the following scheme:

Indigenous trade Plantation and pidgin mining pidgin
European colonial trade pidgin

\begin{tabular}{l|l|l|l}
\hline $\begin{array}{c}\text { Relative social } \\
\text { status }\end{array}$ & equals & master-slave & \multicolumn{1}{|c}{ equals } \\
\cline { 2 - 4 } $\begin{array}{c}\text { Pidgin spoken } \\
\text { between }\end{array}$ & $\begin{array}{l}\text { speakers of a } \\
\text { fairly large } \\
\text { number of indiv- } \\
\text { idual vernaculars }\end{array}$ & $\begin{array}{l}\text { European and } \\
\text { speakers of } \\
\text { various languages } \\
\text { between speakers } \\
\text { of these } \\
\text { languages }\end{array}$ & $\begin{array}{l}\text { Monolingual Euro- } \\
\text { peans and } \\
\text { speakers of a } \\
\text { vernaculars }\end{array}$ \\
\cline { 2 - 4 } Topics & Trade & $\begin{array}{l}\text { of } \\
\text { various Topics }\end{array}$ & Trade \\
\hline
\end{tabular}

One factor that has not been mentioned in the literature on pidgins, and which may be falrly important, is that there is a considerable difference between the pidgins of deported slaves in plantations and the language used on plantations in Africa 1tself. Whereas the American plantation languages are based on a European language, the means of communication in many places in Africa between European and African is an African-based pidgin. The presence of relatively simple lingua francas, such as Sango and Swahili, on the African continent may be a possible reason.

(b) Duration of contact

Whereas the formation of pldgins seems to be relatively uninfluenced by the duration of contact (as a result of the immediate need for communication pidgin's develop extremely quickly, generally within a few days) - the creolization of the simple pidgin seems to be much more affected by the duration of contact. The withdrawal of the target language may have many consequences. One of the most important consequences is that the former target language is no longer the model for extension. Under German administration the vocabulary of New Guinea Pidgin was extended by introducing German terms. With English being the new target language many German words have dropped out (e.g. Kirche, Speisezimmer, Junge, Stange, Schule etc.) and have been replaced by English 1tems. 
The life-cycle of a pidgin, on the other hand, seems to be dependent on presence or absence of maintained contact, whereas a creole will continue to exist even when the contact with the original target language has ceased (cf. Tonkin 1971: p.135).

Whereas continued contact is important for the viability of a pidgin, this is one of the main factors that cause the abandonment of creoles. The situation of a creole is given up in favour of the original European languages can be observed in many countries. Thus Sao Tome and Princips Creole, Goanese Creole and Macanese, all spoken in Portuguese territories, have been replaced or are being replaced by standard Portuguese. On the other hand Portuguese creoles still survive in non-Portuguese territories, e.g. Macanese in HongKong, Portuguese Creole in Malacca. Similar observations have been made on Jama1can English Creole. On the other hand the removal of the target language in Papiamento and Sranan has resulted in very stable creoles.

(c) Illiteracy and Second Language learning

Most pidgins are merely spoken languages and have never been reduced to writing. The most important task of a pidgin is to enable oral communication in a number of situations. The speakers involved in the communication are often illiterate, at least on one side. Writing systems for pidgins are invented only when there is a necessity for unambiguous and written documents. The translation of the bible by missionarles and the use of pidgin as the language of the government, at least for such official purposes as proclamations, or 1ts use in newspapers are examples of developments which lead to a standardized written form.

Written pidgins and even written creoles are an exception. Therefore the transmission of the language is purely oral. The development of pidgin is characterized by adult language learning. The implications are that the transmission of an already established pidgin to newcomers who want to acquire the pidgin will show the imperfections and interferences from other languages that are necessary attributes of adult language learning.

Let us consider the hypothetical case of a plantation pidgin: in its first stage a European pidgin serves as a means of communication between slaves from different language groups. After a while a relatively stable form of pidgin has developed which is spoken more or less fluently by all slaves; various factors, however, notably the high rate of death in the plantation, cause an inflow of new slaves possibly from other parts of Africa who have to learn the already established and probably creolized pidgin. This means that the creole 
is pidginized again, a process perhaps occurring several times. An actual instance is mentioned by Labov (1971: p.60): "One can see the process of re-pldginization at work as new speakers entering the community fall to grasp the condensed forms and return to the zeros with which the pidgin started." The language will thus inevitably suffer distortions as a result of repeated imperfect learning and may finally differ considerably from the original pidgin. (cf. Neuman 1966). The 1mplications for any theory of the origin of pidgins and creoles are that reconstruction is extremely difficult. A written tradition may delay the process of change in a pidgin or creole, but this need not be the case. A written creole, Negro Dutch, has died out in spite of its large amount of written material and in spite of the fact that the target language, Dutch, was not present.

(d) Cultural differences between groups

The more culturally different people are the less common experiences they share and the fewer the topics which will be of common interest. This is basically the view of Malinowski and 1t helps to explain certain facts about pidginization.

Where speakers of different languages belong to a common culture (e.g. the Christian-European culture) stable pldgins are less likely to arise in their mutual contacts. It is true that they do normally have a common lingua franca (e.g. Latin) but this is not a very simplified language. The lingua franca is intelligible to the speakers of the language from which it is derlved, as in the case of Greek koine and Greek for example.

Most pidgins arise in situations where the cultural differences are considerable, although there are exceptions such as Russo-Norsk, and where the interest in each other's culture is very limited. The maintenance of one's own cultural 1dentity is an objective of members of many countrles. To learn another language or have an outsider learn one's own language does not seem desirable. It is sald that this played an important role in the relations between the Chinese and Europeans.

A pldgin used by both sides is the solution in such a situation. Often even after the creolization of a pidgin the original culture of Its speakers remains unchanged. Whereas the words that are of interest to both parties come from the dominating language, words pertaining to the private and religlous sphere tend to come from other sources. The creoles that developed in the plantations conserved the African vocabulary concerned with their pagan religion and the whole gamut of religious vocabulary, songs and tales seems to have been preserved in 
this way. Earlier descriptions by Europeans often did not take this phenomenon into account and therefore tended to underestimate the African influences. (A discussion of Africanisms can be found in Turner 1949 and Voorhoeve 1971b).

This leads to the conclusion that one has to differentiate between two processes in the development of a creole: extreme change and restructuringof the language in general and extreme conservatism in the preservation of certain parts of the vocabulary.

Cultural differences tend to be reflected in the lexicon rather than anywhere else in the grammar. The list of lexical items will basically reflect concepts that are 1mportant in a culture. Many concepts that were of importance to the European discoverers did not exist in the contact languages. The number of concepts shared by both in the particular context of situation was, in any case, very limited.

It has been suggested that all European based creoles are basically relexifications of a Portuguese Pidgin. One of the reasons why this is doubtful is that Portuguese words seem to be limited to a rather small sub-group of the vocabulary, mainly the one of nautical and fisherman language. For an interesting discussion see J. Du P. Scholtz:

Uit die Geskiedenis van die naamgewing aan diere en plante in Afrikaans which deals in detail with the names for fish in Afrikaans. As in the case of religlous language the lexical items have been taken over in more or less their original form. This means that in the ease of the development of a creole, cultural differences were maintained after creolization and that a European language and the corresponding creole or pidgin do not only reflect two linguistically different systems, but also two culturally different systems.

The cultural system of the creole may be very heavily influenced by the cultural system of 1 ts original speakers (e.g. West-Africans in the case of the West Indies, Melanesian in the case of New Guinea Pidgin etc.) or 1t may reflect a break with the old culture without subsequent acceptance of the European culture, as in the case of Town Bemba.

The chances that cultural differences will continue to exist are highest in those areas where the original target language has been withdrawn. In these cases the pidgin (e.g. Bahasa Indonesa) or Creole (Papiamento, Sranan) becomes the vehicle of new national aspirations and serves as a means of expression of cultural independence. In all other cases where the target language continues to exist side by side with the creole or pidgin a process of acculturation in the direction of the European language takes place (cf. Alleyne 1971). Alleyne speaks of a scale of acculturation which parallels a scale of distinctness of the creole English language from English. The less the creole resembles English the more different are the two cultures. 


\section{(e) Prestige of the target language}

Closely connected with the question of cultural differences is the question of the prestige of the target language. It seems that in many cases the European language was a prestige language and this tendency has become stronger with the development of modern technology and communication. Mastery of the European language brings with it such privileges as having a share in the cultural possessions of the European, having access to written material, and being able to take part in political discussions etc. These motives have only relatively recently become significant, since in earlier times a policy, based on the presumed inferiority of the non-European, excluded everybody who didn't belong to the ruling European class from the European languages. Only where the mastery of the European language was a real stimulus and an instrument for upward social mobility was it a danger to coexisting other languages. This seems to have been far more the case in Spanish and Portuguese colonies that elsewhere. The Spanish system offered considerable reward to those who could speak Spanish. In fact in almost all Spanish colonies Spanish became the main language of most groups within the population. In the case of Portugal, although the situation was slightly different, the Portuguese also regarded people for their capacity to speak Portuguese: members of the ruling classes of Portuguese colonies were educated in Portugal, and until recently the ability to speak Portuguese was the criterion for full Portuguese citizenship in the African possessions Angola, Mocambique and Bissau-Guiné. It is interesting to note that the second criterion was the adherence to christian religion.

It seems, however, that Fanagalo is the exception rather than the rule. Although other pidgins have been used by the European colonizers they continue to be used after independence and there seems a fair chance that some of them will survive and develop into a national language. Although the attitudes towards pidgins are ambivalent in most cases the usefulness of the language seems to make up for the negative connotations. This seems to be the case with Nigerian Pidgin English and to an even higher degree with New Guinea Pidgin.

In New Guinea, although pidgin is used between Europeans and locals in master-servant situations, its use is not limited to these situations. Wurm (1971a: p.3) and others mention that Europeans of ten fall to differentiate between a broken English and.P1dgin. Pidgin languages are not unsystematic simplifications of the standard European language, but have a structure of thelr own and have to be learned. Nevertheless, a fair number of Europeans do not realise this and the language in which they address their servants is not the pidgin that is used among the 
natives. The latter in the case of New Guinea Pidgin is an adequate tool of communication among the speakers of the many New Guinea languages. Knowledge of Pidgin is equivalent to having access to modern 11 fe and being able to take part in all activities of full citizens and Pidgin is increasingly becoming a symbol of national unity. Some scholars reckon that it may well become the national language once New Guinea becomes independent. The two largest political parties in the Territory have advocated the use of New Guinea Pidgin as the National Language.

The difference between the pidgin as spoken by the Europeans as against that spoken by indigenous peoples is a common phenomenon. Mafen1 (1971: p.99) points out two functionally and formally distinct pidgins: "The majority of domestic servants, for instance almost certainly use two quite different varieties of Pidgin; one, a minimal variety, which they use to their employers - and which is the only kind of Pidgin most Europeans come across - and a fuller variety, Pidgin proper, which they use elsewhere."

Earlier literature often underestimates this dichotomy, but even recent treatments of pidgins such as Labov (1971b: p.447) continue to make statements such as "there are pidgins which show such a fluctuating and unsystematic character that one can question whether or not they are systems in the sense given above." We have seen that, in some cases, an. unsystematic language variety is not a pidgin at all, but only.considered to be a pidgin by people who know no better. It is the prejudice that pidgins have no grammar that seems to keep Europeans from learning pidgin languages as they learn any other language. This not only continues the prejudice, but also hinders the development of mutual understanding. Fortunately in the last two decades, a number of grammars of pidgins have been written, pidgin courses on tapes are avallable and a revaluation of pidgins takes place. This also holds true for the scientific description of, and investigation into, pidgins.

The days when pidgins and their simplicity were ascribed to the limited mental capacity of the negro brain are over, and it is generally accepted that: "In studying of pidgin language, as in studying most other subjects, the investigator will find just as much as he sets out to look for. If he has an a priori conviction it is a 'bastard, mongrel lingo' of only curlosity and comlc value, approaches it without adequate linguistic training, and tries to describe it in terms of the grammar of the standard language, then a mongrel, bastard lingo of only curiosity and comic value will be all that is evident from his description." (Hall review Sayer: p. 1973). 
(f) Number of speakers involved

As important as the relative social position of the speakers involved in pidgin communication is their numerical relation. Goodman (1967: p.43) holds the view that "Although practices somewhat like pidgins can be developed by as few as two people in very brief encounters and in very specific situations, it is best to limit the definition to the bodies of interlinguistic usages developed by reasonably large groups of linguistically differing peoples who find sustained interaction necessary in important social domains." The ideal pidgin situation seems to be one in which there is a large number of different small monolingual groups. If one of these groups is in a socially dominant position its language will determine the lexical character of the pidgin. This seems to have happened when European based pldgins first evolved. On the one side there was a dominant group of Europeans speaking Portuguese, English etc. and on the other hand a large number of speakers of many different languages, elther in more or less the same geographical area as on plantation, or in many geographically non-related places along the coasts of the African, American and Asian continents.

The number of speakers involved really refers to the number of people who actually communicate with each other. Thus in a trade relationship normally only a small number of traders and visitors to the market are involved, whereas in a plantation situation more or less everybody can be expected to have some knowledge of pidgin. Where trade relations are involved even a small number of speakers of one language is enough in relation to a large number of speakers of one or more other languages, to influence the pidgin language when they are the 'attacking' trade partner as in the case of European traders. Voorhoeve (1962: p.235) seems to imply that a pidgin which is based on or derived from a European language is more likely to develop when the number of the Europeans is relatively high. (In Surinam the proportion of English speaking Europeans - African Slaves was 2:1 in the beginning and the English were the largest single language community). In most plantation areas this seems to have happened. At the beginning - and presumably at the time when the pidgin came into being - the Europeans were the largest, or one of the largest, single language communities. Later the proportions gradually changed in favour of the African population who outnumbered the white population in plantation areas considerably. Voorhoeve gives the proportions for Surinam for 1667 and 1702 as $1: 2$ and $1: 11$ respectively. Le Page (General Outlines of Creole English Dialects pp.58-59) presents the numerical proportions of races in now Creole speaking areas and his data seems to support the statement that 
In the first days of the settlement the Europeans were probably the largest single language community. Once a pidgin is established, later change in the numerical proportions does not influence its life-cycle. (see also: Valkhoff 1966: pp 28, 52).

(h) Sex of the speakers involved

Little attention has been given to the role of the different sexes in pidgins and creoles. Nevertheless it may be of great importance. A pldgin which is spoken by men only (and there is evidence that in many pldgin areas men are more likely to learn pidgin than women) will hardly become a creole. The pidgin of women may be a pidginization of the men's pidgin and bring about additional simplifications in the already simple pidgin. Two quotations will serve to illustrate the role of women. Hall (1966: p.132) writes on Ha1tian Creole: "Interestingly enough, women, who, by and large, speak French far less well than men, seem more inclined to make these charges publicly against the native tongue. Possibly this is felt by them to be a compensation for inadequate French." Secondly, Samarin (1955: p.263): "More accurate is the observation that men and boys of any given age group are better acquainted with Sango than are the women. Undoubtedly the reason for this situation is that females are less exposed to Sango than are the males." In both cases, the female part of the population seems to be an exponent of cultural and language conservatism. In the earlier stages of New Guinea Pidgin only men were regular users of the language, whereas women either did not know Pidgin at all or had a passive knowledge only. This development seems to be repeated in the newly developed areas where Pidgin has been introduced only recently. Places where women are competent speakers of Pidgin are those which have been under the influence of the administration and missions for a long period. (Th1s is true for Hiri Motu in Managalas1 area for example.)

It is normally assumed that creoles first develop when speakers of different languages marry and use their only common language-pidgin as means of communication. The children would then be speakers of a creole and the larger the number of first generation speakers and the better their contact with each other the sooner this creole would become stabilized. But this is not a necessary development - it is possible that male and female speakers continue to use their own language and that the use of different languages for different sexes becomes institutionalised. Creolization is, perhaps, favoured in an environment where most of the old traditions have been destroyed or disrupted, such as on plantations which used slave labour. 
The speech of women may be different from men's speech in another way. It may be more conservative, contain more 'Africanisms', etc. Thus, even if the official pidgin spoken between master and slave contains few non-European elements, the language taught to children at home may contain many such elements. The little historical evidence deals with the former kind of pidgin and only some recent investigations have revealed the large African element in some Creoles of the Caribbean (see also Turner 1949; N1da \& Fehderau 1970; Eersel 1971).

(i) Official language policy

It is appropriate to speak of official language policy mainly in the territories that were controlled by European nations (in the form of colonies, protectorates etc.). The main aim of such a language policy must have been the continuation of European supremacy, a discouragement of the ruled peoples to learn the European language, and similar considerations. The attitude of the Europeans is ambivalent: on the one hand one wants to communicate (preferably in one's own language) on the other hand one does not want the colonized people (or the slaves or whosoever) to use the European language as a means of becoming powerful. Therefore the use of a pldgin is the way out: communication becomes possible without lessening the social distance. Only a few selected people (sons of indigenous kings or other important persons) are allowed to learn the European language and are educated in Europe. cf. Richardson (1963a: p.7): "The special attitude of the masters demanded only that their slaves should understand and be understood. For this purpose a variety of French was used. Far from regarding the accurate reproduction of French as an asset in a slave, the tendency was to interpret it as a presumptious attempt to ape the master's speech with his peers."

One must be careful, however, not to make gross generalizations. The language policy varied in time and in space and often the official language policy did not colncide with what was in fact practiced. Brunot (1900: pp.1125-1126) says that "c'éta1t un dogme, du moins parm1 les colons et les administrateurs qu'il ne fallait donner aux noirs aucune instruction." And he quotes the following words of a French governor: "L'instruction est capable de donner aux nègres icy une ouverture qui peut les conduire à d'autres connolssances, à une espèce de raisonnement. La sûreté des Blancs, molns nombreux, entourés sur les habitations par ces gens -là, livrés à eux, exige qu'en les tienne dans la plus profonde 1gnorance." At this stage, one person at least was convinced that the mental capacities of the Negro were such that he could acquire the French language and additional knowledge. Later, 
in a confusion of cause and effect, his not being able to speak standard French were regarded as a proof of the negro's inferiority. For a French Creole this has been said as recent as 1956 (year of publication) by Jourdain (Du Francais aux parlers créoles p. 74): "Il nous semble. donc, pour conclure, que si le noir a très bien compris la nécessité d'exprimer la notion de sexe et qu'il arrive à le falre sans trop de difficulté, la notion abstraite du genre lui échappe totalement."

In the earlier days of colonialism pidgins and creoles often became caste languages - mostly associated with the non-European, uneducated masses, whereas the European languages remained the privilege of the upper classes - the whites. "Unt1l the middle of the last century, natives in the then Dutch East Indies were forbidden by law even to learn Dutch." (Wurm 1968: p. 361). Difference in social caste will reflect difference in linguistic distance. English based creoles could survive in Dutch governed Surinam. Voorhoeve (1962: p. 236) attributes the formation of a pidgin to a less rigid caste system and its creolization to subsequent changes in the soclal structure, and that French based creoles exist in many British islands in the West Indies also suggests that there have been considerable caste differences for several centuries. This is, however, not the whole story. A pidgin or creole can be extremely resistant to all efforts to replace it by a European language. The latecomers of colonlalism, the Germans, found it almost impossible to replace already existing pidgins (e.g. Pidgin English in New Guinea) or lingua francas (Afrikaans in South west Africa) by German, although many efforts were made. A case history of one pidgin (New Guinea Pidgin) is described by Hall (1959: pp. 22-27).

In post-colonial societies new problems arise: in spite of the discrepancy between the official language (say English or French) and the most widely spoken language (English or French-based Creole respectively) the European languages are mostly used in schools, even in primary schools. (Apparently this holds for American Negro English as well.) Adopting the prestige language and 1gnoring the 'inferior' spoken language has very negative effects on school children: "The written compositions of school-children are dull and vapid because the chlldren are so fearful of lapsing into their native creole that they cannot express themselves freely" (De Camp 1968: p.41). Only recently scholars and educationalists began to realize that they are faced not only with a 'dialect problem' but with two different languages. It is outside the scope of this paper to discuss this question in detall. Much of the discussion during the two conferences on pidgin and creole languages held in Jamaica and the Symposium on Multi-lingualism in Brazzaville are devoted to this question. 
It seems to me that the two main purposes of any sound language policy are to remove the social and the linguistic prejudices.

\section{(j) Race relations}

Much of what has already been sald implic1tly dealt with race relations. In general it can be said that in most European based pldgins and creoles racial prejudice and inequality was one of the major causes for pldgins to come into being, be perpetuated, and be creolized. But one gets pidgins and creoles in other areas where no racial tension exists or existed and racial prejudices are certainly not a sine qua non. Valkhoff (1966) wants to explain the phenomenon of pidgins and creoles in terms of 'miscegenation'. "It is in itself understandable that the closer the contact between people of two, or more, different races with different languages, the stronger the influence they exercise upon each other." (p. 215). "This linguistic interpenetration is automatically fostered by intimate social relations."

Valkhoff's arguments are by no means convincing. It is not the 'Intimate social relations' that result in a pidgin and eventually a creole, but the continuous non-intimacy. Whereas in the case of intimacy one language group tends to be absorbed by the other and nothing like a pidgin results, it is true that "real speech mixture does not of ten take place where races $\mathrm{mlx}$, but where a certain intercommunication, especially commercial, is kept up between neighbouring tribes, that do not (emphasis his) mix. Such are the Pidgin-English spoken by the English traders in China, the Chinook jargon or Indian trade language of the north Pacific coast, and the Negro-English of the West African coast." (Hempl 1898: p.31).

Today, in the independence struggle of African and other nations, the former tool of discrimination and exploitation can become an instrument for the national independence, Creole languages and pidgins (especlally New Gulnea Pldgin) as well as American Negro speech are felt to be the languages in which the non-European can express themselves best. "In some areas... a nationalist reaction against the pressures from the standard language results in "hyper-creolization", an aggressive assertion of linguistic discreteness and superior status for creole." (De Camp 1968: p.41).

An attitude of mutual tolerance which is the foundation for any healthy development in soclal and language questions is largely missing. The adoption of one national language as a tool to unite the different people within a new state is a very important factor in the consolidation of a new nation and those nations which have a creole which is used as both vernacular and lingua franca (such as Surinam) stand a better chance 
to become united and racially harmonious.

(k) Group solidarity

This point links in with the two previous points. Group solidarity is of great importance in creolization: speakers of different languages give up their own native language in favour of a new common language which becomes the language of their children. Whereas in pidgins one has much less solidarity with other speakers of pidgins and remains rooted in one's own culture, creoles are the languages of a group which share culture and country. Since officlal language policy often neglected and discriminated against creoles and their speakers the group solidarity tends to become stronger - either in common reaction against everything that is different (hyper-creolization) or in common apathy. Creoles are kept living even when most of 1 ts speakers are bilingual. This happened on Norfolk Is land where the descendants from P1tcairn still cling to their Pitcalrnese language (a situation similar to Wales) although they use English in all official transactions (see Ross 1964).

Group solidarity as a parameter of pidginization and creolization is frequently mentioned. The following quotation reflects the generally accepted point of view: "We must mention one other very important factor which must have helped some degree of stability to develop in fleld slave language; that is the group consciousness of field slaves and those who identified with them. There may have been positive refusals to become totally acculturated to the European way." (Alleyne 1971: p.180).

\section{(1) Isolation and contact}

Isolation and contact have been mentioned on the preceding pages. The isolation can be of two kinds: (1) social isolation in caste societies and (11) political isolation. Although a French-based creole is spoken on Halt 1 and French is the officlal language, the two languages have coexisted for many years without influencing each other considerably due to the large social gap. On the other hand, where soclal mobility becomes more important, (e.g. Jamaica) the creole tends to be strongly influenced by the prestige standard language (Jamaican Creole by English) and a sort of dialect continuum develops (a post-creole continuum). Where the creole is politically isolated from its target language (e.g. Papiamento on the Dutch Antilles) it tends to be unaffected and develop on 1ts own terms. Alternatively - when the creole is not strong enough it becomes lexically more similar to the target language and may end up as a 'relexified language' (this obviously happened to Negerhollands). It seems as if 1solation becomes important only when combined with other factors. 


\subsection{ADDITIONAL PARAMETERS}

The above list is by no means exhaustive. One can easily think of additional factors that may influence the development, maintenance and eventual creolization of a pidgin: the distinction between rural and urban communities, occupation and relative mobllity of pidgin speakers, age distinctions among others. I shall discuss them in a looser way than the previous parameters, mainly because even less is known about these factors that all refer to synchronic rather than diachronic aspects of pidgins.

The rural-urban distinction reflects two different ways of $11 \mathrm{fe}$, the former being assoclated with conservatism, 1solation and a subsistence economy, and the latter with progressive attitudes, mixing of people and trade relations. In. monolingual areas the town often has the effect of dialect-levelling: in multilingual areas urban centres can be compared to catalysts that bring about new languages, in many cases pidgins. In the towns of the Zambian Copperbelt, for example, a new language, Town Bemba, came into being. Often a pidginized form of the vernacular spoken around the most important town of an area becomes the lingua franca (Police Motu, Sranan, Krio, to mention some instances). Moreover, the town does not only account for the origin of the pidgin, but also for its maintenance and development. Hall (1956: p. 93) mentions that "the attitudes and desires of certain groups of Rabaul and other metropolitan centres are reflected in some of the linguistic innovations under discussion." Samarin (1955) tells us that Sango which already existed before the arrival of the Europeans was spread over a large area as a result of their founding urban settlements in remote areas. It is reported (Hall 1955: p.16) that the main centre of New Guinea Pidgin in the territory of Papua is the largest town, Port Moresby. Some pidgins and creoles are restricted in use to single towns, such as Macanese, (Macao, now spoken in Hong Kong as well), Krio (Freetown) and 'ingles des escaladrilla' (Almeria). These towns are seaports of considerable importance.

If towns are the places where the pidgins and creoles come easily into being they are likewise the places where they disappear more rapidly than in other areas. The continuous contact which the town has with the outside world of ten changes as one colonizing power is replaced by another. In some formerly pidgin or creole speaking towns an older European language has taken over or is taking over. Pldgins and creoles that originated in urban areas can eventually be found in some remote rural areas only. This is the case in Surinam where Saramaccan is spoken in the most inaccessible areas, in Trinidad, in 
Jamaica and other creole speaking areas. As in the case of dialectlevelling in towns of monolingual areas, dialectal differences between varleties of the same pidgin tend to be levelled out, and the standards employed in urban centres serve as norm when the pidgin is reduced to writing.

As regards another factor, the occupation of the users of pidgins, very little has been sald, although it may be of considerable importance. It is likely that there is a close correlation between proficiency in pldgin and the speaker's occupation. Although only few observations based on actual data are avallable. (It appears that) missionaries, doctors and members of the police force and administration will be high up on this scale (of proficiency) with (subsistence) farmers, (local) craftsmen and short-term visitors at the bottom of the scale. In between we will get various degrees of intercourse between different groups, such as master and servants and the clients of tallors, shopkeepers and prostitutes, who all need a certain limited vocabulary and language proficlency. Some pldgins are given names such as ChauffeurBalu (P1dgin A 70), Mine Kaffir (Fanagalo), names that reflect the professional status of the group that mainly uses the pidgin.

The relative mobility of the speakers will account for the spread or non-spread rather than for the birth of a pidgin. Again, it is the speakers with a relatively good command of the pidgin that are more likely to be mobile. The distribution of the pidgin can occur in the process of normal relationships such as trade, or under abnormal circumstances, such as in the case of blackblrding (cf. Laycock 1970: p.X): "During the course of the Melanesian labour system in Queensland, and at the end of 1t in 1902, natives were repatriated when their time had expired. If they were lucky, they were taken to their home islands, others were dropped at the ships' captains' nearest guess as to where they had come from. But, wherever they enqed. up, they took pidgin with them, and spread it through countless villages through Island Melanesia and New Guinea."

The same Melanesian Pidgin was spread by the crews of ships - the idea that sallors are one of the main factors in the making of pidgins is an old one and for most creoles and related languages such as Afrikaans a sallors' language hypothesis has been put forward at some point. (cf. Bosman 1962; Goodman 1964).

The insistence on single parameters, however, as in the previous discussion of social parameters, is not justified. In many cases only a combination of the factors outlined and perhaps additional factors can account for a pidgin. It is not enough, for instance, to have intense trade relations. Th1s is discussed by Wurm (1968: p.352): "Cases are 
known from other languages of the world where languages spoken by traders operating outside their sometimes quite small tribal or native regions have spread over wide areas, and have become important lingua francas. Kisuahel1 of East Africa is a good example. However, in all such cases the important factor has been that the traders insisted on using their own language, and speakers of other languages who wanted. to have dealings with them had to learn and speak 1t."

The last point of my preliminary list is controversial. It has often been sald that there is an intense correlation between social change and language change. Jernudd has found evidence in the development of some Australian varieties of Pldgin English "that a period of rapid social change is a period of rapid linguistic change" given two additional factors (Jernudd 1971: p.21).

(1) there is rapidly increasing social mobility within a language community

(11) there is a mixing of speakers of different languages with disruption of old language groups.

This process of detribalization is responsible for the extinction of tribal languages and their replacement by a pidgin that rapidly becomes creolized. Trost (1971: p.124) explains not only change resulting from language contact, but also internal change in terms of the social s1tuation: "In eln1gen Indoeuropä1schen Sprachen begann der Untergang der Flexion offenbar mit lautlichen Änderungen, die in elner gesellschaftlichen Situation elntraten, die für einen radikalen Wandel der grammat1schen Konventionen günst1g war." (cf. also Southworth, 1971: p.261).

It would lead us too far to discuss this problem here. It will suffice to remind that in most cases of social disorder, such as war, subsequent movements of refugees or slavery, more than one language is involved. This means that the main explanation for the rapid change that takes place during these periods is a result of language contacts rather than the situations as such, although factors like discontinuous school education and splitting up of families will contribute to some change in language. The fact that pidgins and creoles normally have a very short history is often explained in these terms. Languages become 'older' in a very short time and will falsify the results of glottochronology for that reason (discussion in Hall 1966); assuming the normal rate of change and assuming that New Guinea Pidgin is derived from the English glottochronology would estimate the time of the splitting about 2 to 3 millenia ago - whereas the age of New Guinea Pidgin is only a few hundred years. 


\subsection{SOME CONCLUSIONS}

Further research will indicate whether the above criteria are relevant or irrelevant to the explanation of the historical development of pidgins and creoles. The multitude of data on the one hand, the contradictory claims of the data and the complicated interrelations that hold between them on the other hand will make this research difficult. Ideally one would like to isolate something, like primes or basic features of social context, and describe their possible groupings under one heading and the arrangement of the groupings very much like a generative phonological feature matrix. One immediately thinks of units such as Pike's 'behavioreme' or 'gusteme'. However, these are no well-defined concepts:

"the units involved are by no means so self-evident, and the classificatory criteria involved are by no means clear." (Crystal 1971: p.168).

In the next chapter more will be sald about the relevance of social parameters for certain linguistic properties of pidgins. Again, this proposal will be of a highly tentative nature. 


\section{CHAPTER 4}

\section{THE CONNECTION BETWEEN LINGUISTIC AND SOCIOLINGUISTIC FACTORS \\ 4.1. INTRODUCTORY REMARKS}

"The structure of Neo-Melanesian derives from the social situation in which the intermediary language was used. Some grammatically important morphemes and some more general detalls of syntactic structure may derive from one or another of the 'terminal' languages, but it is doubtful whether the importance of these is equal to the importance of the social setting in determining Neo-Melanesian structure." We find this statment in Turner (1966: p.208).

The thought that the social situation plays an important role in the 1dea of a pldgin is not a new one. The 'baby-talk' theory posited by several scholars implies this. This theory, however, along with all other key-cause or single-factor theories is not sufficiently sophisticated to explain many properties of pidgin languages. It is, therefore, a logical step from these single-factor theorles to a sociolinguistic theory that aims at explaining the structure of a pidgin in terms of the global social situation. (Turner (1966: p.209) speaks of "a social basis for the semantic structure of a language").

We must, however, not forget that neither the term 'pidgin' nor the term 'social situation' is well defined. In this thesis I have accepted the 4 criteria given by Whinnom (simplification, impoverishment, unintell1gibility, stability) as defining a pidgin. These criteria are scales rather than fixed values. To take the criterion of unintelligibility, for instance, we get total unintelligibility, partial unintellifibility or unidirectional intelligibility. Much less is known about the defining properties of a social context and, given this state of our knowledge, Turner's statement cannot be said to be more than an interesting suggestion or perhaps a working hypothesis. Thus, in addition to asking 
how the social situation influences the structure of pidgins, one needs. to ask how it influences their life-cycle, creolization and de-creolizat1on. Definite answers to these questions are not yet forthcoming and so far many paradoxical cases have been encountered, the same social factor working in two different ways. Thus, in spite of the negative attitude of the Australian administration in Papua, New Guinea Pidgin has spread increasingly whilst, in spite of the positive attitude of the Government, a language such as Fanagalo disappears in another part of the world. Whereas the continuous presence of a related prestige language, together with a creole, normally leads to a restructuring of the creole in the direction of the 'terminal' language, this has not happened with Haltian Creole: "Contrary to Bloomfield's claims, supported by D'Ans (22), the development of Haitian Creole shows not acculturation of Blacks to the speech patterns of the dominant Whites, but the contrary." (review D'Ans p.205).

\subsection{THE CORRELATES OF SIMPLIFICATION}

In the part that now follows I shall look at some linguistic parameters and their sociolinguistic exponents in isolation. Simplification is. perhaps the most important of the four criteria for pidgins and I shall therefore look at simplification first.

It has been sald that wherever forelgners engage in rudimentary linguistic interaction the same kind of rudimentary 'grammarless' language w1ll be the result. Coelho (1881: p.67) is often quoted as the first scholar to make this observation. He says that in order to make oneself understood to forelgners one reduces one's language "to the same typestripped of all grammatical forms - that characterize the creole dialects." ("...au mesmo tipo privado de formas grammaticaes que caracterisam os dialectos creolos."). Reinecke (1964: p.535) says that we get simplified, minimum-approaching languages in "situations where, broadly speaking, it is impossible or impractible for the peoples concerned to learn each other's language well."

Although this view has been advocated by several others ( $D^{\prime A n s}$ 1968; Gáld1 1938; Voorhoeve 1962) 1t has been frequently attacked, especially during the anti-mentalistic period of American structuralism. A recent example is: "He accounts for the striking similarities between the various Caribbean French Creole dialects and these and Indian Ocean varieties by the fact that the 'baby-talk' that the French 'masters' imparted to their slaves could not but reflect abstraction on the part of Frenchmen of principles of simplification inherent in the structure of the language. This is tantamount to claiming that these principles 
could be observed today in French child language and baby talk as well as in speech used to communicate with the numerous forelgn labourers which constitute the French sub-proletariat. While unfortunately few studies of these 'restructured' varieties of French have been undertaken, it is doubtful they would exhib1t such characteristic syntactic features of $\mathrm{HC}$ as post-position of determiners or use of a limited set of aspectual verbs as particles." (review D'Ans: p.204).

I do not believe that this is a fair criticism. It falls to take into account the difference between substantive universals of language simplification (such as loss of grammatical categories without semantic correlates or inflectional irregularities) which may be triggered of $f$ whenever an encounter between speakers of very different languages takes place (cf. Tesnière 1939: p.131) and salient features of certain pidgins which are conditioned by the substrate and superstrate languages. The relative importance of these languages may be different from case to case, and depend on other sociolinguistic factors such as duration of contact, attitude of speakers, and literacy. The similarities and differences of pidgins may be explained in this way more conveniently.

The claim that there is such a thing as a universal intuition about language simplification and that there is a connection to imperfectly learned language by elther children or forelgners is an empirical one (a detalled discussion is found in Vidomec (1963: pp.93-96). Bosman (1962: p.146 ff.) gives a number of examples of correspondences between Dutch baby language, Dutch forelgner talk and Afrlkaans. These correspondences are too striking to be ignored and further investigation may bring to light more support for this hypothesis. The preference for unmarked categories is characteristic of both. I shall discuss the role of unmarked categories in pidgins below. It 1s, however, dangerous to equate child language acquisition with forelgner language learning. Other factors such as the interference from a forelgner's mother tongue may play a relatively important part and the pidgin will appear less simple than expected. That creoles and pidgins owe their characteristics to both universals of simplification and to the terminal languages is by no means a very recent view. We find it already in Schuchardt (1909: p. 443): ". dabe1 kann bis zu elnem gewissen Grade Sprachmischung betelligt sein; wir dürfen aber deshalb nicht das Wesen des Kreolisch in einer Verbindung von Europä1schem Wortstoff mit afrikanischer oder aslatischer Grammatik suchen wollen; aber besonders ungerechtfertigt würde es sein, zu sagen, die Lingua Franca sel Romanisch mit arabischer oder türkischer Grammatik."

There is also another point to be considered here, namely, that 'simple' and 'simplification' are not absolute terms. The simplicity of 
pidgins with a European 'terminal' language may be the same or similar because the European speakers' concept of what is simple is the same in all cases. This need not be the case. The following quotation should give cause for thought: (quoted from Sommerfeldt: p. 137, originally from Junod, Moeurs et Coutumes des Bantous II): "The Western languages seem to tend towards a structural type of the kind which is found, for example, in the metric system. They have reduced redundancy to a considerable degree. Now it is significant, I think, that people belonging to less developed cultures seem to find the metric system more difficult to learn than the English system of welghts and measures which other Europeans find so hard to master" (cf. also Whinnom 1965: p.522). Therefore one could expect that pidgins which do not have any European language as one of their terminal languages are 'simple' in a different way from European influenced pidgins. Nevertheless, the notion of a universal concept of simplification seems to be worth investigating. It is certainly a much stronger claim and therefore easier to falsify. It is methodologically perfectly sound to start from this assumption, and investigation into the structure of more pidgins, indigenous pidgins, will allow either confirmation or disconfirmation of this hypothesis. Again, one must not forget that simplification is seldom total simplification.

Linguistic encounter is not the only parameter that influences the simplicity of the pidgin. In many cases it does not lead to a pidgin or even to a simplified version of a language. The profession of speakers is another variable involved, thus a missionary is certainly interested in learning the indigenous language and is not content with a rudimentary tool for communication, a trader may be only interested in some kind of simple means to establish trade relations and to make bartering possible. More important are the educational facilities, including the official language policy. In the case of many linguistic encounters these educational facilities are either non-existent or insufficient. The educational facilities will improve when the contact is of a longer duration and when the degree of intimacy between the two groups increases. Hall (1966: p.128) regards 'continued non-intimacy' as one of the main reasons for the establishment and continuation of pldgins, and Alleyne (1971: p.180) is of the opinion that "degrees of closeness of contact with Europeans correlated with degrees of acculturation...was clearly the major factor in one kind of linguistic variation."

Most discussions in the literature on pidgins agree on one point. The unfavourable social conditions, this perhaps most outspoken in the case of European-based pidgins, in combination with general principles 
of Imperfect learning by adults are the main reasons for the simple structure of pidgins. I think a discussion of the implications of adult language learning would be useful here.

\subsection{IMPERFECT LEARNING OF A FOREIGN LANGUAGE}

The a1m of generative grammar is to explain the linguistic competence of an (1dealized) native speaker or hearer of a language. In the case of languages that are learned by children as their first language one will eventually be able to correctly describe the output of the grammar of a native speaker, and even explain the 'faculte de langage', but in the case of pidgins the notion of competence is only of limited value. A pidgin is by definition the native language of nobody and the sentences generated by the grammar of a pidgin language cannot therefore be tested against the intuitions of the idealized native speaker. It is doubtful if one can operate with the concept of an 1dealized speaker of pidgin at all, since it is one of the main characteristics of pidgin languages that more than one standard especially regarding their phonetic realization tend to coexist. One could, therefore, elther set up a number of 1dealized speakers, such as European speaker of a pidgin, and in some cases even more restricted groups (such as German speaking missionaries) can be studied. The influence of the German missionaries on some dialects of New Guinea Pidgin and Negro-Dutch are cases in point. Alternatively one could postulate an ideal speaker of pidgin who has internalized various diasystems and embraces the aggregate competences of all speakers of one pidgin. Whatever solution is adopted the norm will be artificial in some way .

A native language can be looked upon as the result of a child's acquisition of a finite set of rules and a finite vocabulary. Generative grammar proposes that a child's grammar tends to coinclde with the most simple grammar which can be constructed for the data to which the child is exposed, this data comprising the conversations with the parents and members of a child's peer group. The following scheme is usually applied in illustrating the child's language-acquisition:

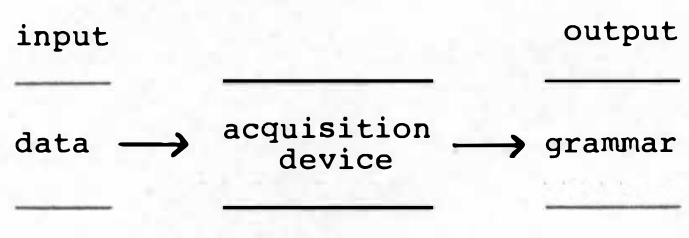


The grammar of the child will be elther identical or only slightly different from that of his parents.

In pidgins the situation is different. Pidgins are learned by adults who have already internalized a grammar of their own. In contrast with a child who is able to learn two different languages at the same time with native or near native proficiency, adults find it extremely difficult to reconstruct even parts of the grammar of a foreign language when they are exposed to the data.

Halle (1962: p.64): "The ab1lity to master a language like a native, which children possess to an extraordinary degree, is almost completely lacking in the adult. I propose to explain this as being due to deterioration or loss in the adult of the ability to construct optimal (simplest) grammar on the basis of a restricted corpus of examples." I want to 1llustrate this with an example from. French creoles: Gáldi (1934: p. 263ff.) "Comme ces parlers reposent exclusivement sur l'impression auditive, c'est-à-dire sur l'imitation acoustique du langage des autres, beaucoup de mots accessoires que accompagnent généralement des noms en francals, se sont soudés aux formes passées en creole. Parmi ces cas de prothèse-une des caracteristiques principales du "pet1t-nègre" - signalons surtout ceux òu l'article a formé avec le nom une unité indissoluble."

This means that the non-native learner of French is no longer able to make cuts at word boundaries in certain cases and that he will construct for himself a grammar that contains such forms as:

lamo from l'amour

so mounonque for son oncle, where the personal pronoun of the model language became an inseparable part of a word in the resulting creole. Similar cases are encountered in Alsatien French as spoken by German speakers where one gets 'vivele l'Empereur' instead of 'vive l'Empereur'.

Sometimes the phonological boundaries of, to mention one case, French-derived creoles do not coincide with those of French. A common example is, that the volced sibilant of the definite plural article becomes the initial consonant of a word that had an initial vowel in French. A detailed discussion can be found in Taylor (1961a).

As far as I can see there is no systematic change from French so that one cannot derive by rules the correct creole forms when the original French forms are given. Apparently there is no way to predict whether the creole will incorporate part of the definite article, possessive pronoun or some other part of speech. On the other hand, one can see certain analogous processes in many words and one does not want 
to say that every single word has its own history. I am not sure how far a diachronic generative grammar such as the model developed by King (1969) could handle these cases. The description of semi-productive diachronic processes may be a challenge for transformational generative grammar.

Another example of this imperfect learning is the treatment of English verbal compounds in New Guinea Pidgin. The pidgin contains a rule that every transitive verb is overtly marked with a marker '-im', which is historically related to the English 'him', e.g.

$\begin{array}{cl}\text { NEW GUINEA PIDGIN } & \text { GLOSS } \\ \text { so - im } & \text { to show } \\ \text { put - im } & \text { to put } \\ \text { luk - im } & \text { to see } \\ \text { mak - im } & \text { to mark }\end{array}$

However, difficulties arise when English verbal compounds with adverbial elements such as -out, -up, or -away appear as transitive verbs in New Guinea Pidgin. In English these elements can appear as either continuous (as in take away the food) or discontinuous (as in take the food away) constituents of the verbal compounds. It is likely that these surface structure variants in the target language were not recognized as such in the imperfect learning situation and that the unity of an English form class was lost during pidginization.

Both Hall (1943) and Mihalic (1971) distinguish two classes of New Guinea Pidgin verbal compounds resulting from this restructuring. One class appears to be related to English forms with continuous adverbial element. These forms have -im added once in final postion. Examples are:

$\begin{array}{ll}\text { NEW GUINEA PIDGIN } & \text { GLOSS } \\ \text { liptapim } & \text { lift up } \\ \text { bagarapim } & \text { to bugger up } \\ \text { kamautim } & \text { to remove } \\ \text { singautim } & \text { to call for }\end{array}$

The second group of forms "when compounded with the adverbial suffixes, ap, aut, ewe make use of the objective suffix -im (or its equivalent -am) twice. One it is infixed between the stem and the adverbial suffix; then it appears again at the end of the resultant compound." (Mihalic 1971: 24). 
Examples are:

NEW GUINEA PIDGIN
bringimapim
eramautim
liptimapim
tekimautim
bloimapim
digimautim

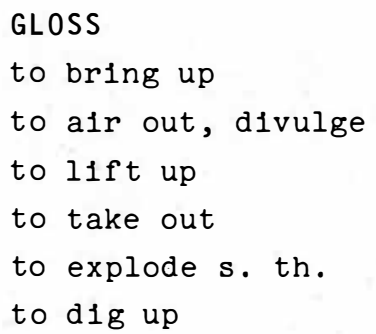

However, this classification is based on purely formal criteria and falls to reveal some important aspects of these 'verbal compounds' in New Guinea Pidgin. The following additional observations reveal that this restructuring is quite far reaching:

1) words that are regarded as compound in English are regarded as simplex in New Guinea Pidgin and vice versa. For example the English go up becomes Pidgin [kuap] which is not considered to be related to go by the average Pidgin speaker. The only correct transitive verb form would be goapim pronounced [kuapim]. Another example would be kirap and kirapim derived from English get up. Kirap is often pronounced [Krap]. On the other hand the English word scrap has become sikerap in Pidgin with the two alternative transitive forms sigerapim and sigerimapim.

(11) It has been suspected by some scholars that the difference between the stem+imtap and the stem+im+aptim forms is one of meaning (cf. Schebesta and Me1sser 1945: p.12). The difference would be one between simple transitivity and double transitivity, the latter implying that the object is affected to a higher degree. Liptapim would then mean to lift up and liptimapim to lift up completely. This may be true in some dialects of Pldgin but I could find no evidence among my informants; many of these forms seem to be in free variation.

(111) In some cases the cholce of one rather than another form reflects a dialectal difference. Bagarapim is the only acceptable form in most lowland dialects of Pidgin, whereas bagarimapim seems to be the form commonly used in the Highlands.

(iv) sometimes the difference between the forms is one of meaning, this being unrelated to double and simple transitivity, however.pulapim has come to mean to fill s.th., whereas pulimapim means to pour s.th. thus, Pulapim kap long $t i=f i l l$ the cup with tea as agalnst pulimapim $t i$ long $k a p=$ pour tea into the cup.

(v) finally it appears that some of these 'verbal compounds' are instances of verbal concatenation. Thus, instead of regarding the elements aut, ewe, etc. as adverbs, they should be regarded as independent verbs. This analysis can be justified in terms of an optional transformation. 


$\begin{array}{cccccccc}\mathrm{v}_{\mathrm{I}}+\mathrm{im} & \mathrm{v}_{2}+\mathrm{im} & \mathrm{N}= & \mathrm{v}_{\mathrm{I}}+\mathrm{im} & \mathrm{v}_{2}+\mathrm{im} & \mathrm{N} & \mathrm{I} & \mathrm{v}_{2} \\ \text { haisim } & \text { apim } & \text { plak } & \text { haisim } & \text { apim } & \text { plak } i & \text { ap } \\ \text { holst } & \text { up } & \text { flag } & \text { holst } & \text { up } & \text { flag } & \text { up }\end{array}$

This would suggest a different classification of 'verbal compounds' in New Guinea Pldgin. On the one hand we would have simple undividable words such as bagarapim 'to ruln' or singautim 'to call for', on the other hand verbal concatenation as is tekimautim 'to remove' and haisimapim 'to hoist up'. This difference is reflected by the acceptab1lity of haisimapim plak i ap 'holst the flag' and the unacceptab1l1ty of *bagarapim kar i ap 'ruin the car'.

I wanted to demonstrate, that the relation between the lexicon of a pidgin and that of 1 ts source language is by no means straightforward, not even on the level of phonology. The data show some consequences of imperfect language-learning by forelgners who seem to be unable to reconstruct certain underlying regularities. Their difficulties seem to increase with the increasing depth of the rules.

Adults must undergo a long process of teaching and intensive learning, explicit memorizing of grammatical rules, and continuous exposure to the target language before they can claim to speak this language with near-native proficiency. It is likely that their 'internalized' grammar will be non-optimal, that certain registers of the target language, nursery language or military jargon for example will almost certainly remain unfamiliar to them, and that interference phenomena from their own language will affect adversely the performance in the second language. In many pidgins the position of the language-learner is even more unfavourable. Harrison (1884: p. 223) observes: "Negro-English is an ear-language altogether bullt up on...otosis, an error of ear, a mishearing...". Authors apparently do not realize that all languages are 'ear-languages' it is not so much the kind of transmission but the time of transmission. It is true that ear-learning will be less effective once the learner has 
reached a certain age. The data to which he is exposed may be distorted by the speaker of the target language who believe they are doing the learner a favour if they resort to baby-talk, or the speakers of the target language may not be a homogenous group but speak various dialects, for example, in the Cape Colony where dialect speakers from many parts of the Netherlands came together.

Another widespread factor is the reluctance on the part of the speakers of the target language to communicate with the learner on an equal level.

One could tentatively set up two modified versions of the standard scheme for language acquisition that take into consideration the special problems of pidgins. These schemes are not mutually exclusive.

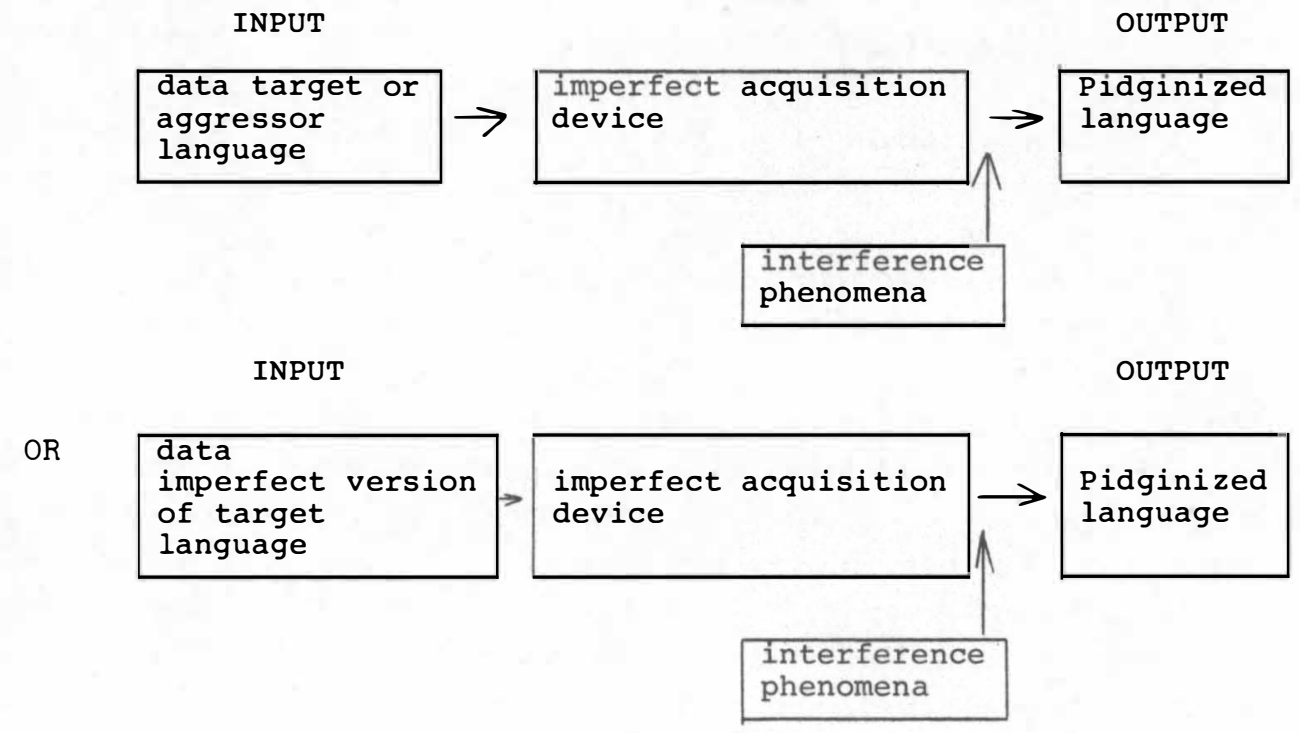

The use of the term 'pidginized language' instead of 'pidgin' in the above scheme is well motivated. Pidginized is used in the sense in which it is used by Samarin (1971) as referring to an imperfectly learned language. A pldginized language has no fixed norms and the inconsistencies in the usage are considerable. It is what Grimshaw calls "a continuously changing unstable collection of 1diolectal variants." (1971: p.431). The explanation by Whinnom of the development of a norm is that this norm is the result of the communication between speakers of different languages who use a pidginized version of the target language in their verbal intercourse. An additional factor is the relative absence of the target language which is kept away from the socially 'inferior' speakers. The pressure for communication may lead to a state where the pidgin becomes 
the native language of a new generation and thereby becomes creolized and extended. If the social pressure is not present, a pidgin can exist in a stable form over a long period of time as is the case in New Guinea or with Fanagalo in Southern Africa.

The relative instability of a pidginized language may be the result of several interference phenomena and they may leave permanent traces in the pidgin once it becomes established. There are two main kinds of interference phenomena, namely intralingual and interlingual phenomena, (cf. Townson 1971). Intralingual mistakes are the over-generalization of a rule of the target language, the non-consideration of the environment of rules and similar 'wrong analogies'. Minor rules are often disposed of. The regular morphology of pidgins and creoles is one of the most likely results of intra-lingual interference (cf. Vidomec 1963: pp.93ff. and Tesnière 1939: pp. 13lff.). Inter-lingual interference, on the other hand, is the transfer of patterns of one's own language into the newly-learned language. The result is observable on all levels of the grammar. It is most evident in the phonological component where the phonemic pattern of the language interferes heavily with that of the target language. In other parts of the grammar one will find such phenomena was syntactic calques, loan-translations and semantic changes where the 'slgnification' of a lexical item of the target language will be assoclated with its 'valeur' in the learner's language. It is concelvable that inter-lingual interference resulted in a certain permanent transfer of African language structures into the Atlantic pidgins and creoles, but it is hardly justified to speak of those languages as African languages with a European vocabulary, as claimed e.g. L. Adam (quoted from Hesseling 1905: p.52): "Le créole est l'adaption de franca1s de l'anglais...au génie, pour ainsi dire, phonétique et grammatical d'une race linguistiquement inférleure." One of the main difficulties is to distinguish between actual carry-over and accidental similarities, in addition "a clear-cut line between analogies within the system of one and the same language and the influence of other languages does not exist." (Vidomec 1963: p.95).

A fact about child language-learning is that the child does not only reproduce the utterances to which it is exposed, but also generates 1ts own simplified version of a grammar. The differences between the child's grammar and an adult grammar for the same language tend to become smaller as the child becomes older. (Examples for simplifications found in children's grammar can be found in Bellugi 1971). One could suspect that a similar process takes place in adult learning, in that the unsophisticated adult learner systematically neglects some 
of the features of his target language. Experimental evidence for this hypothesis would support the claim about universals of pidgins and language simplification. At the moment, our knowledge about the adult language acquisition device is insufficient. There are, however, some points that are normally agreed upon, such as the fact that there is something like a hierarchy of difficulties for learners of foreign languages (cf. Stockwell et al 1965: p.282-291), and that some of these difficulties are language-independent (cf. Lado 1968a). Pidgins seem to come nearest to the type of language that can be learned with a minimum of effort, not because they have no grammar, but for precisely the opposite reason. Grammatical rules are used to simplify and systematize components other than the syntactic, especially the lexicon. I shall demonstrate this in the following chapters. Hall (1954: p.112) writes in his defence of New Guinea Pidgin: "I have been told, by reliable persons with long experience in New Guinea, that a normal native. can in six months learn pidgin quite well, so that he can then begin to recelve instruction as a medical assistant; but that, for him to achieve a comparable command of English in order to learn the same subject-matter, a minimum of five or six years is necessary." Experiments carried out by Voorhoeve led to similar results (cf. Voorhoeve 1962: pp.238-239). Languages that develop in pidgin-situations are more efficient from the point of view of the learner: "Many phenomena of the mutual interference of lanjuages may be reduced to one single rule or law: there is a tendency to save effort." (V1domec 1963: emphasis his).

Although imperfect language-learning will lead to a simpler language, for this language to become a pidgin it needs social approval.

Labov (197la: p.15ff) distinguishes between bilingual idiolects and pidgins. He says about pidgin grammars: "Such grammars are shaped by a very large number of cross-cutting individual transactions. Pidgins are thus social rather than individual solutions to the problem of crosscultural communication." Whinnom (1971) comes to a similar result in his discussion of cocoliche, where he states that the non-acceptance of cocoliche as a means of communication by any society or group disqualifies it as a pidgin.

Thus, to summarize this section on the correlates of simplification, it can be sald that the following sociolinguistic parameters influence the simplification of a pidgin:

(a) nature of contact (social disruption, non-intimacy, pressure for communication),

(b) 1lliteracy and second language learning,

(c) officlal policy which discourages language-learning. 
All these factors can be sald to trigger of some kind of 'simplification process' that seems to work in a simllar way for all languages. Future research should determine the degree of similarity. It is conceivable that typological differences will show up.

\subsection{THE SOCIOLINGUISTIC CORRELATES OF IMPOVERISHMENT}

'Impoverishment' refers to the fact that there are a number of concepts which cannot be expressed in the pidgin language. This does not mean that the speakers of pidgin are unable to deal with these concepts. By definition pidgin speakers are bilingual and therefore able to deal with concepts as they appear in 'natural' languages, in their native languages. The question that is involved is what cannot be said in a pldgin, or at least not equally well. Naturally this differs between pidgins. There will be degrees of fluency in a pidgin, there will be degrees of elaboration of the pldgin and there will be degrees of necessity to deal with relatively complicated concepts. Pidgins develop for a special purpose and they will therefore be adequate for this purpose. Thus, Fanagalo was not made for translating Shakespeare, although this has, in fact, been done in order to illustrate its possibilities of expression. (Bold 1968: p.21). The 1mpoverishment of a pidgin is relative to the need for expression and it is always possible to restructure and expand the pidgin. There are numerous examples that this has indeed been done (e.g. Hall 1956), and is still being done.

The nature of the contact - the social context in which the pidgin is used - will largely determine the relative degree of sophistication of the pidgin. The duration of the contact is less important. Although a relatively long and stable contact will lead to expansion of the pidgin, this is not necessarily so. If the pidgin is only used in a master-slave or domestic situation, as with Tâf Bôy, the pidgin will remain impoverished.

The prestige of the target-language seems to be of more importance. If the target language is in high esteem there will be a switch to the target language as an alternative to an expansion of the pidgin, as is typically the case in diglossic situations. If the number of pidgin speakers is already very high and that of the target-language speakers low, lexical expansion of the pidgin is more likely, even against official pressure. The situation of New Guinea Pidgin is a case in point.

To summarize, it can be said that impoverishment is not an inherent characteristic of pidgin, but is relative to the state of 1 ts development and to the context in which it is used. As with all other languages, the possibilities of expansion through the introduction of new lexical 
1tems and grammatical categories are present. The process of expansion can take place long before a pidgin becomes nativized and creolized. Impoverishment, at some stage, will mean stylistic 1mpoverishment only, meaning the lack of alternative ways of expressing an 1dea. This is one of Labov's (1971a) central claims, although not many descriptions of actual instances are avallable. Field observations as to the adequacy of pidgins in as many situations as possible are the prerequisite for further statements on this point.

\subsection{SOCIOLINGUISTIC PARAMETERS OF UNINTELLIGIBILITY}

Pidgins are not only simplified imperfectly-learned versions of a language, but linguistic systems in themselves. Although in the beginning they serve the purpose of communication between various speakers of different languages and are, therefore, mutually intelligible, they soon became languages of their own with a change in function and their institutionalization in a new environment. By shift of function I mean a change of the parties for whom pidgin is the main means of communication. Thus, whereas a plantation pidgin was originally used to serve as a means of communication between slave and master it developed into the lingua franca used by slaves of different linguistic backgrounds. It subsequently changed, as a result of factors such as language-interference and the desire of the slaves to stress their group identity and delimit themselves against the non-slave group.

Another reason for this unintelligibility is the large-scale semantic change of lexical 1tems. One can mention here the 'wider meaning' of lexical 1tems, (cf. Goodman 1967: p.54), cases of morphological and semantic motivation in the lexicon, categorical change, calques and so on, this change taking place at a much faster rate than in normal language transmission. Phonetic similarity, coupled with semantic dissimilarity is a serious obstacle in the communication between pidgin speakers and speakers from the language from which the pidgin was originally derived (cf. Hall 1955: pp.18-19). Some changes appear to be relatively systematic, others are due to historical accident, willful distortion on the part of the speakers of the dominant languages (interlarding of the lexicon with words that denote obscenities in the related European language is a common feature of European-based pidgins), and misunderstandings. In the process of pidginization, concessions are made by both sides, and, although it cannot normally be sald that the languages involved meet halfway, the pidgin is influenced by both. 
The belief as to what a pidgin must be like may have played a role in its formulation. It seems plausible that many pidgins, although not being relexifications of a Portuguese P1dgin, were created with the model of Portuguese Pidgin in mind. Portuguese Pidgin was known by sallors of other nations at the time it was most widely used .

Unintelligibility is also reported in indigenous pidgins; Wurm (1968: p.353) mentions Police Motu as a case in point: "Speakers of Motu proper of the Port Moresby area cannot readily understand Police Motu if they have not been previously exposed to 1t, though they can learn to understand and speak it in a very short time." The study of these little described languages may provide explanations for many features of pidgins, such as non-intelligibility, which are not very well understood at present.

Certainly the 1lliteracy of pidgin speakers, the fact that most pldgins are not reduced to writing and the fact that there is more than one norm, especially in the phonological component, will all contribute to rapid change and subsequent unintelligibility. The continuous presence of the model language will influence the direction of this change. As in other languages, there are dialects in pidgins (cf. Fischer 1966 and Mafen1 1971), but very little is known about the differences and distribution of these dialects. Possibly the levelling out of dialect differences in pidgins can lead a further step away from the original language.

The unintelligibility of the pidgins is continued in the creoles that may develop out of them. Whereas, however, French-derived creoles are sald to be mutually intelligible and non-intelligible to speakers of French, we get a different picture for pidgins; neither the various English pidgins nor the French pidgins are mutually intelligible. Most English-based creoles are not mutually intelligible, and the same holds for creoles that presumably developed from Portuguese and later came under the influence of Spanish, 1.e. the contact vernaculars of the Philippine islands and Papiamento. The reason for the intelligibility on the one hand, and the unintelligibility on the other, is, however, unclear.

Our knowledge in this field is unsatisfactory. But by pointing out this, a possible field for further research is shown.

\subsection{THE SOCIOLINGUISTIC PARAMETERS OF STABILITY}

More is known about the factors that contribute to the relative stability of a pidgin. Labov (197lb: p.15) ascribes the relative stablilty of pidgins to a pressure for communication. The "pressure for 
a stable grammar is even greater when speakers of many subordinate languages arrive at the scene." Thus, the number of speakers involved, and the relative multitude of languages they speak, as well. as their common destiny, are the main factors contributing to the development of a stable pidgin. This can be related to Whinnom's (1971) proposal that stable pidgins develop only in situations where speakers of more than two languages are involved and where the pidginized superordinate language becomes the sole means of communication for the speakers of the subordinate languages. It is perhaps too absolute to say this, considering that relatively stable forms of pidgin have developed in bilingual (in the strict sense of the word) situations, but it is certainly an important factor and one that may also contribute to subsequent creolization.

Pressure for communication seems to counteract the initial instability of 'early' pidgins, pidgins "which show such a fluctuating and unsystematic character that one can question whether or not they are systems in the sense given above." (Labov 1971: p.447). However, for a pidgin to survive, it must become institutionalized, this being helped by the presence of influences such as permanent settlements, markets, and garrisons. The result in all cases is a language which, however simple, must be learned. There is a misconception among Europeans that pidgins are not languages in their own right, but just debased forms of their own language (cf. Murphy 1966: Apologia). The result is that they use an ad hoc simplification of their language, which is instable and not socially accepted. As soon, however, as the European language is no longer a target language for the speakers of the pidgin, this continuous interference from the model is ruled out and the pidgin will become more stable. Most pidgins have stabilized in an environment where this is the case.

The stability of a pidgin is also determined by other factors. If the official policy favours the use of Pidgin (for New Guinea c.f. Hall 1954 and 1956), if the pidgin is used by missionaries or if it is reduced to writing and used in educational programs in broadcasts, it will become more stable. In short, the more soclal domains and the more technically-advanced domains are dealt with in pldgin the better is its chance of stabilization.

\subsection{SUMMARY OF CHAPTER 4}

The results of this part of my paper are rather speculative. The discussion does not mention the numerous cases where simplified stable varleties of a language are used in quite different clrcumstances; for 
example, there is ample evidence of languages of hunters, priests, and other soclal groups which bear many structural similarities to pidgins (cf. Bausani 1970). The soclal parameters described above may only be one instance that triggers off 'simplified', pldgin-like languages. Simplification of language is a human activity which has not been given enough attention. It is by no means clear what relation holds between the sociolinguistic and linguistic features developed above. Against the hypothesis of 'stimulus diffusion', the belief that similar social conditions determine simllar language structures, there is the historical argument, that most pidgins and creoles are somehow historically related. If one was to adopt the latter thesis, many apparent universals of pldgins and pidginization would be reduced to results of historical processes. The indication is that both factors play a role.

It is, however, beyond the scope of this thesis to discuss all this and in addition the data do not warrant further statements. 



\section{CHAPTER 5}

\section{SIMPLIFICATION OF LANGUAGE}

\subsection{INTRODUCTION}

One of the aims of this thesis is to isolate some of the linguistic parameters of pidgins and in particular simplicity. One must however, bear in mind that this is not the only parameter, and that the importance of this parameter for pidgins is not totally clear, as the discussion of some views held on this topic will show. The definition of this term as a concept that can be integrated in a grammatical theory is, however, absolutely essential: "part of the challenge of pidgins to linguistic theory is to show the need for much measures (1.e. complexity, simplicity and functional load) if the defining criteria of reduction in form and use are to have any power." (Hymes 1971: p.69).

\subsection{DIFFERENT USES OF THE NOTION OF 'SIMPLICITY'}

The notions of "simplicity", "simplification", "simple", etc. are used in more than one sense in linguistics. We must distinguish between the loose pretheoretical use of these terms, 1mplying that a language or some language is simple in some poorly defined way, and the use of these terms as theoretical constructs. Additional confusion may be caused by the recent use of the simplicity criterion as a metatheoretical term in transformational generative grammar. It is not impossible that all these terms are somehow related but, if that is the case, this relationship should be made explicit: "The notion of simplicity in language and language description has been a perennial issue in linguistics as in other disciplines, and there is little agreement on what constitutes simplicity. Some recent work in linguistics has been concerned with a 'simplicity metric' in evaluating alternative grammars or partial grammars. The notion of simplicity in language itself, however, is only indirectly 
related to this." (Ferguson 1971: pp.114-145). The notion of simplicity as part of a general theory of language was originally developed by Chomsky (1957: pp.53-56) and elaborated subsequently (e.g. Halle. 1964a: pp.335ff., Bach 1968, Chomsky 1965: p.37 ff, 1966: p.22, Botha 1968: p.24 and many others). However, it is a controversial and not very well understood part of transformational generative theory. By relating markedness and descriptive simplicity, moreover, the boundary between descriptIve simplicity and simplification of language becomes unclear. I propose to use two different terms to keep the two meanings apart: simplicity for the metatheoretical metric; and simplification for the kind of simplicity found in pidgins or language in general. This term may appear inappropriate since it seems to imply that simplicity is dynamic. In fact, this is what happens in reality: pidgins are not just simplest languages but vary in their degree of simplification from speaker to speaker and from pidgin to pidgin. The tendencles of simplification and complication are continuously present and the pressure of communication may trigger of simpliciation of varying degrees. In a recent article (Babcock 1972) the term simplicity is used in still another meaning. "Simplicity of paraphrastic causatives" ( $p .31$ ) means that the underlying sentence is a simple sentence, 1.e. "one in which each of the categorial relationships occurs just once." (p.32).

It is only in terms of rules that simplification of grammars and metatheoretical simplicity can be measured. There is no unsystematic simplicity. It has been suggested that all simplification may eventually yield the same results, namely that one will arrive at some universal deep structure that is the same for all languages "by universal reductions in surface specializations" (S1lverstein 1971: p.191). At present this suggestion is no more than an interesting hypothesis and nothing is known about substantive universals of a deep structure.

One of Voorhoeve's (1961) main arguments against early transformational generative grammar is based on a misunderstanding of the term 'simplicity'. Voorhoeve (1961: p.40) formulates the following objections against generative grammar: "Chomsky's starting point is that the natural order in the language, given by the language 1tself, colncides with the most simple order. Therefore he concludes that we can measure the value of a language description through simplicity of presentation." "Chomsky therefore with his criterion of simplicity of presentation, is moving in a dangerous direction. Those linguists who have used their structural intuition in syntactic analysis with a bad conscience are encouraged by Chomsky; he gives them, in his criterion of simplicity of presentation, a means of control which is theoretically plausible although in practice 
we cannot do very much with 1t." (1bidem: p.46). I do not think that this criticism is justified, even by looking at what is sald about the simplicity criterion in Syntactic structures alone. Chomsky (1957: p.53) uses the word simplicity "to refer to the set of formal properties of grammars that we shall consider in choosing among them." Further, Chomsky does not say that there are sentences, kernel sentences that are simpler per se than other sentences but merely asks (p.55) "whether the whole grammar is simplified if we consider a certain class of sentences to be kernel sentences or if we consider them to be derived by transformation."

Later (Chomsky 1965: p.6) Chomsky explic1telydismisses the 1dea that there is some natural order of thought that coincides with the most simple order: "Another reason for the fallure of traditional grammar, particular or universal, to attempt a precise statement of regular processes of sentence formation and sentence interpretation lay in the widely held belief that there is a 'natural order of thoughts' that is mirrored by the order of words."

What is sald is that for the description of sentences of a language there is a most convenient order that may or may not coincide with the order in simple declarative sentences. For English, the grammar will be simpler if one starts with declarative sentences, whilst for German, the descriptions by Bach (1962) and Blerwisch (1971) take the order of subordinate sentences as basis and it is demonstrated that, in adopting this order, one needs fewer rules for the generation of German sentences. "Diese Freihe1t, zunachst eine fiktive Stellung zu erzeugen und dann die Elnhelten zur tatsächlichen Anordnung in Sätzen umzustellen, ist besonders zweckmâssig für die Handbagung diskontinulerlicher Satzglieder." (Bach 1962: p.110).

So far, no transformational grammar has claimed that the 'ordre naturel' coincides with either the order of the elements in the deep or the sequence in the surface structure. I do not say that Chomsky is right in his rejection of an 'ordre naturel', but it is certainly the case that Voorhoeve is wrong in attacking Chomsky for that reason.

\subsection{THE DISCUSSION OF SIMPLIFICATION IN THE LITERATURE}

Most observers of pidgins feel that these languages are somehow 'simple', 'defective' or less complex than the natural languages they are used to dealing with, but there is not much agreement as to what exactly constitutes 'simplicity' in pidgins. Before I try to answer this question I shall briefly review a number of instances in the avallable literature on pidgins, where simplification is mentioned. 
A view that was held at one stage (and of which a relatively recent UN report on New Guinea Pidgin is an example) is that simplicity of pidgins is a result of their lack of grammar: (French 1953: p.58): "If the attempt to simplify vocabulary is fraught with difficulties, the attempt to simplify grammar is simply disastrous. The standard grammar has, in fact, been jettisoned, and a new, crude, and incredibly tortuous form of grammar has been bullt up in 1 ts place.... So, far from being an independent language, pidgin takes over a whole ready-made phonetic and morphological system, crudely distorted by false ideas of simplification."

The following quotations come from Bos 1880; his article on Mauritian Creole does not only reflect the whole gamut of linguistic prejudices of the time when it was written, but racial arrogance as well. p. 574: "Nous verrons...cette tendence à la simplification détruire pour ains1 dire laconjugaison." p.576: "S1 la conjugaison est d'une simplic1té qui n'égale que son vague, la syntaxe présente encore à un plus haut dégré le même caractère. Les differents mots qui servent a marquer les rapports des phrases entre elles sont plus que simples, ils n'existent pas." p.577: "Nous n'avons plus 1c1 du francais simplifié, ma1s bien du francals détraqué.

The fact that pidgins often do not show a highly developed morphological system was wrongly taken as an indication that these languages lack grammar. The fallacy of this argumentation is an old one. It has been applied to most European languages that did not follow the patterns of Greek or Latin. (For a discussion c.f. Palmer 1971: p.l2 ff and also Whinnom 1965: p.526). Most recent treatments of pidgins concede that there are rules and that simplification is systematic rather than random. For example, J.S. Goodman 1967: p.52: "The expected broad generalization about simplification of grammar is no more suggestive of adequate description. What Jespersen ( $p .233)$ calls the 'total disregard of grammar' in pidgins is better expanded to include minimum morphological signalling through what Sapir called relational affirmes, great dependence on parataxis and looseness of form classes."

One has to differentiate between at least three approaches to the problem of simplification:

(a) pidgins are not simple at all

(b) pidgins are the result of simplification of their European model languages, but there is no such thing as language independent simplification

(c) there is universal principle underlying all kinds of simplificat1on.

The three assumptions underlying these three approaches differ in strength, assumption (c) being the strongest one. For the rest of this 
thesis I shall adopt this assumption and try to find possible evidence for 1t. Thus I shall argue that it is possible to define a pidgin on intralinguistic evidence alone. This means that the question of the origin of pldgins will not be discussed, since, more specifically, the conditions which trigger of a pidgin are separate from the language 1tself. Since most of the rest of this thesis deals with (c) I shall not anticipate the argumentation here.

(a) The following quotation (De Camp 1971: p.15) may be taken as representative for view (a): "1t (pidgin) is characterized by a limited vocabulary, an elimination of many grammatical devices such as number and gender, and a drastic reduction of redundant features. This reduction has often been called simplification but it is now considered debatable whether the less redundant pidgin is simpler or more complex than the standard language." Certainly, this is not a question of debate but an empirical question. One can devise empirical tests such as tests of learnabllity. Voorhoeve (1962) reports on such a test, the results of which point in the direction of greater simplicity in pidgins and creoles and one can define degrees of complexity within an empirically justified model of language. Similarly Bold (1968: p.4) writes about Fanagalo: "It is more easily and speedily learned than any other language in the world." Such a statement, however, must be taken with a pinch of salt. It has often been argued that what seemed to be simplification of language is in reality simplification of one of the components of a grammar and that this simplification takes place at the cost of greater complexity in another component. Thus Burling (1970: p. 161) in his discussion of pidgins states that: "Linguists tend to belleve that all languages have roughly the same degree of complexity; complexity is difficult to define or measure, but we suppose that the average complexity controlled by each individual is roughly the same, whatever the language." I do not think that is necessarily so. If one assumes that simplification is systematic and rule governed it is concelvable that one natural language is more simple than another - the criterion being the scope of the rules; greater generality of rules and fewer exceptions that are not otherwise motivated can be taken as indication of greater simplicity. Simplification will certainly play an important role in the establishment of a language typology. Historical linguistics shows that rule simplification occurs as part of the historical change in a language; in pidgins the principles of rulesimplification may be exploited to a greater degree than in other languages. The reason may be the mode of transmission: I have mentioned above the relationship between imperfect language learning and language 
simplification. I think a reasonable approach is to recognize a scale of complexity and look for linguistic parameters: "simplication may be not an isolated phenomenon, but one pole of a continuum applicable to outer form in all languages." (Hymes 1971: p.73).

A longer discussion of complexity that seems to support hypothesis (a) is found in Crystal (1971: pp.71-72). An interesting suggestion 1s made by Heine (1970: p.27). He suggests that the degree of simplification is directly related to certain extra-linguistic factors, especially to the numerical relation between the speakers of the base language and the speakers that use this language as a lingua franca: "The smaller the value of the lingua franca form, the larger the influence of the basis form tends to be... In the case of a small influence of the basic form...an increasing tendency towards pidginization frequently asserts 1tself in the case of the lingua franca form."

(b) One of the main arguments that is used in supporting the socalled relexification theory is that the simplicity found in Europeanbased pidgins and creoles is a typically European phenomenon, that Indigenous pldgins are much more complex etc. This view is incompatible with view (a). Voorhoeve (1962: p.238) writes: "Pidgins are characterized by a maximum reduction in the vocabulary and grammar of the language model. This reduction, however general, as a tendency to simplification In all pidgins, is dependent upon the accidental structure of the language model, and therefore cannot be held responsible for universal grammatical similarities." A clearer statement by the same author can be found in Hymes (1971: p.189): "All (speclalists) seem to agree that pldgins are characterized by a process of reduction or simplification. This does not mean that pidgins are simpler languages than non-pidgins, but they seem simplified in comparison to their model." A detalled discussion of a presumably European simplicity that originated in Sabir and found 1ts way into most pidgins and creoles via a Pidgin Portuguese can be found in Whinnom (1965: pp.519-522).

Nevertheless one has to recognize that similar phenomena of simplification occur in pidgins other than the European-based ones. It is possible that some of the European pidgins have reached a maximum of simplification (this has been denied by several workers, e.g. Hjelmslev (1.938)) but that some of the better known pidgins are higher up on the scale of complexity but still lower than, say, an average natural language as spoken by native speakers.

Thus, having briefly discussed the first two approaches outlined above I shall now continue this discussion (based on assumption (c)), and attempt a distinction between the parameters of simplification and impoverishment. 


\subsection{SIMPLIFICATION AND IMPOVERISHMENT}

The criteria for this distinction are not always obvious and there is often uncertainty in the relevant literature. Only recently Alleyne (1971: p.173) wrote: "It has not been clarified, to my knowledge, which features of the syntax of 'creoles' represent simplifications or reductions." (c.f. also Tonkin 1971: p.129).

If we understand by impoverishment the loss of certain means of expression we can delimit it against simplification, if the latter term is taken to imply an increase in regularity. The most obvious place in grammar for impoverishment to take place is the lexical component: impoverishment is reflected by the loss of lexical items. According to Hall (1954: p.23) the number of lexical 1tems every ordinary speaker of a language has is between 25,000 and 30,000, "and this figure will hold for virtually all languages (including those of "primitive tribes") thathave been fully studied. I have counted about 1,500 words in Pidgin, which, however, can be combined into phrases so as to say anything that can be said in English." The most likely place for simplification is the morphophonemic component (or readjustment component in a generative model). It would, however, be wrong to restrict impoverishment to the lexical subcomponent and simplification to the readjustment component. I w1ll attempt to demonstrate that there are a number of other, perhaps less obvious areas of the grammar where both impoverishment and simplification can occur.

The terms simplification and impoverishment, it should be noted, have no implications for non-segmental means of communication, in fact most treatments of pidgins have not even attempted an account of para-linguistic parameters of communication. Information cannot only be carried by purely linguistic means but may be given in terms of other means of expression. Non-vocal signs will often make up for the inadequacies of the vocal message and presumably impoverished and inadequate languages can be compensated for by means of this. This is equally the case in the socalled 'restricted code' of language where concepts that were said to be missing in comparison with 'elaborated code' were found to be expressed by non-vocal means and paralinguistic means. Any account of 1mpoverishment that does not take this into consideration must be unsatisfactory. The lack of data, however, forces one to adopt an artificial approach.

The question that must be asked 1s: 'What can a pidgin not express as a result of Impoverishment?' Labov (1971a), for instance, has given several answers, especially in connection with grammatical categories such as tense time and gender. These categories are not obligatory in most pidgins, whereas many other languages must express them obligatorily in the surface structure, and even redundantly so. One of the consequences 
is that the grammatical categorles that are obligatorily introduced become phonologically part of a bracketed category such as noun or verb. (Paul 1970, in the Chapter "psychologische und grammatische Kategorle." p.263 ff gives some interesting examples of the historical development as does Labov 1971: p.57 ff: Phonological condensation of the tense system). The fact that a pldgin does not need to express time but can do so by using adverbs seems to be an instance of simplification rather than impoverishment. If one takes into consideration, however, that the obligatory category is normally phonologically reduced and unstressed, we get a different picture: a pidgin has no way of making a difference in stress between lexical 1tems that are central to the meaning of a message and grammatical categorles that are peripheral, This is basically the line of argumentation taken by Labov. The result is some kind of stylistic impoverishment. Ferguson (1959: p.333) argues that the optionality of 'categorles marked by morphemes or concord' makes a language simpler than one that marks these categorles obligatorily. In Ferguson (1971) he treats the absence of copula in pidgins as an instance of such a simplification. (p.14l-150). There is something missing in his argument, namely the function that the copula fulfils: "The copula is not a lexical 1tem...but a purely grammatical 'dummy' serving as the 'locus' for the indication of tense, mood and aspect; (Lyons 1968: p.246; I am aware of other treatments such as Ross (1969: pp. 352-260)). It is therefore not quite appropriate to compare e.g. Mary is beautiful with something like Mary beautiful. The semant1c information given by the latter sequence is less, 1.e. the indication of tense is missing. One might thus say with some justification that the loss of the copula is some kind of 1mpoverishment. The obvious counter-argument is that this loss can be compensated for by the introduction of a time-adverbial in the copula-less construction. This time adverbial would presumably be stressed; on the other hand the language that includes a copula can add an optional stressed time adverbial as well (in assuming for this argumentation that absence of copula is not a carrier of a meaning equivalent to a time adverbial, but an indication of a construction that is unmarked for time).

In considering what all the possible indications for an impoverishment are we have to look at certain surface structure phenomena such as topicalization. The placement of stress in the surface structure contributes (or at least can contribute) to the overall meaning of a grammatical construction. And if we follow Chomsky (1971) in believing that semantic information is partly carried by the surface structure, the Inadequacy of the surface structure of pidgins to accommodate these features of meaning would be an indication of 1mpoverishment. Th1s 
assumption would explain the fact that when pidgins become creoles they regularly develop a system of unstressed tense or aspect markers. As too little data are avallable I shall leave the discussion of impoverishment at this point.

Simplification, as it is normally understood in current generative literature (cf. King (1969: pp. 64-104) Chapter on 'Simplification of grammar'), involves the optimalization of grammatical rules, 1.e. the possibility of applying rules to large classes of 1tems that belong to such a class on independent grounds. The technical term for such rules is major rules, and regularity in grammar is negatively characterlzed by the absence of minor rules. (cf. Lakoff 1965, and Isenberg 1968: pp. 15 ff for discussion).

Whether one assumes with Chomsky that the lexicon is the place where the full set of 1rregularities is found (1965: p. 142) or whether one allows for 1rregularity to be found in other places (e.g. Botha 1968: p. $152 \mathrm{ff}$ ) the fact remains that greater regularity of the lexicon is one of the main factors of language simplification, in other words the existence of lexical redundancy rules may be taken as an indication of the degree of difficulty of a language. The regularity of the lexicon has in essence two main aspects:

1) morphophonemic regularity

2) regular correspondences between content and expression.

The fact that most descriptions of pldgins have been made in purely 'formal' terms (for example Hall's descriptions of New Guinea Pidgin and Chinese Pldgin English) explains why the main stress in the characterization of simplification is put on morphophonemic regularity. Ferguson (1959: pp. 333-334), for example, attempts the following characterization of simplification: "There is probably falrly wide agreement among linguists that the grammatical structure of language $A$ is simpler than that of $B$ if, other things being equal,

1) The morphophonemics of $A$ is simpler...

2) there are fewer obligatory categorles marked by morphemes of concord....

3) paradigms are more symmetrical

4) concord and rection are stricter (e.g. prepositions take the same case rather than different cases)..."

Practically all four criterla can be reduced to morphophonemic simplicity. Only very little has been sald about the second aspect (e.g. Hjelmslev 1938 and Voorhoeve 1962). 


\subsection{MARKED CATEGORIES AND THEIR LOSS IN PIDGINIZATION}

Before I deal with these two points I want to mention a third much less understood - aspect of simplification, namely the relation between simplification and markedness. As this topic is still rather controversial I shall not give any systematic account of replacement of marked by unmarked categories in pidgins but shall merely enumerate a few examples that may serve as a point of departure for further research and that can be partly found in the literature on pidgins. Unmarked features are those that are more widespread among the languages of the world, that are acquired earlier in the language development of a child, and lost later under pathological conditions according to Jacobson and his followers. Instances are the following:

(a) predilection for a syllable structure CVCV

(b) the absence of highly marked sounds, such as rounded front vowels, clicks, the replacement of volced sibilants by volceless ones, etc.

(c) the loss of tonal distinctions

(d) loss of the passive

(e) Infinitive present form for verbs

(f) preference for continuous constituents

(g) use of masculine for all genders when languages with a gender system become simplified

(h) use of singular in all cases

(1) relational words.

This list is by no means exhaustive, but may be regarded as representat1ve. Nothing is sald about markedness of sequence of lexical items in the surface structure, although this may be an important factor in the overall simplification. At present, too little is known about unmarked ordering of elements.

(a) Syllable Structure

One of the salient features of most pidgins and many creoles is the predilection for the syllable structure CVCV, either as the only possible structure or as non-significant alternant of syllables that involve consonant clusters. Clusters of consonants are more marked than CVCV. Cairns (1969: p.872) writes in this connexion: "The first universal of interest here states that all languages have sequence type A (+CV...); furthermore, no other type is universal. Therefore sequence-type $A$ is the least marked." Instances of descriptions of cluster simplification are frequent in the avallable literature and whilst not giving any examples of cluster simplification, I shall refer 
to a few treatments: Burling (1970: p.126); Hall (1948: p. 97); LePage (1957: p. 384); Samarin (1958: p. 70); Taylor (1947: p. 178); Valkhoff (1966: p. 89). The observations made by Mafeni (1971: p. 108) suggest that the alternation between consonant clusters and anaptyxis correlates with certain sociolinguistic parameters: the use of clusters indicates that the speaker alms at linguistic and social intimacy with English language and culture. A more detalled discussion of this point with examples from a number of languages can be found in Voorhoeve (1962: pp. 240-241).

(b) The absence of highly marked sounds

The Prague School notion of phonological markedness and the extension of this idea in recent generative theory aims at explaining certain facts such as the very rare occurrences of certain sounds and the ease with which children and presumably adults learn certain sounds. If it is true that some sounds (the marked ones) are less likely to occur in natural languages this is even more so the case in pidgins: this may be the result of several partly independent factors:

(1) In as much as the phonological system of a pidgin can be seen partly as a common denominator of various sound systems of the speakers' mother-languages, highly-marked sounds are more likely to be 'filtered out' since it is unlikely that they will appear in all languages that are natively spoken by the users of a pidgin. This tendency is more pronounced when the speakers have very different language backgrounds, and I shall use Fanakalo as an illustration. If Fanagalo is used as a means of communication between speakers of the various languages belonging to the local South African 'Sprachbund', then highly marked sounds such as clicks are preserved. In a use by Europeans, however, these clicks often tend to be replaced by the corresponding less marked stops (cf. Bold 1968: p.7): "If you find you can't manage the clicks, even after coaching, you can at a pinch use the letter $k$ instead."

(11) There may be some intuition related to a principle of universal simplification that makes speakers of the target language avold certain 'difficult' sounds, or at least that enables them to identify the less marked sound correctly when it is uttered in imperfect imitation.

Instances of shift from marked to unmarked category characterize practically all pidgins. The most obvious cases which I shall shortly mention are the replacement of volced sibilants by their volceless counterparts, fricatives by homorganic plosives, rounded front vowels by corresponding unrounded vowels, etc. and so on. 
(c) The loss of tonal distinctions

In his survey of African pldgins and creoles, Berry (1971) writes (p. 527): "Peculiar to the African pidgins would appear to be the simplification of tonal systems. The extreme of simplification in this respect (which only occurs perhaps when large numbers of non-Africans have had a significant role in the formation of the pidgins) is the replacement of tone systems by one of stress." The 1nstances that are adduced are P1dgin Sango (p. 521), and K1tuba (p. 525) and 1t would not be difficult to find further examples.

Markedness theory is closely assoclated with phonology and this is the only part of grammar where the notion of markedness is falrly well established. Less is known about syntactic markedness and only very few attempts have been made to propose a theory in this fleld. A recent discussion in a transformational-generative framework can be found in Lakoff (1965: C 4: Markedness in Syntax). One of the few cases that have come under the attention of a large group of investigators is the loss of the passive. The following quotation may be representative: "E1nen ersten Hinwels gewinnt man, wenn man fragt, was als "markierte Form" und was als "demgegenüber neutrale, unmarkierte Form" betrachtet werden soll. Offensichtlich ist es sinnvoll, die belden Passive als "markierte Formern" zu betrachten, durch deren Gebrauch etwas Besonderes slgnalislert wird, während das Akt1v demgegenüber als "unmarkiert" zu betrachten 1st". (Glinz 1971: p. 19).

Passive is considered here as a grammatical category and not a semant1c one. The languages under discussion are marked by an absence of a formally distinctive category of the verb, such that it is not possible for most pldgins and creoles to express the same sentence (subject-verb-object) by a synonymous or near-synonymous passive sentence. This does not mean that the semantic content of the agentless construction, expressed by many passive constructions, cannot be expressed.

Hesseling (1905) writes: "In their tendency toward simplification and levelling that is characteristic of creole languages, the abolition of the passive construction - this 'Luxus der Sprache' as it is called by Von der Gabelentz - Is only too obvious an example; many languages do not have a passive construction." ( $p$. 102 translated from Dutch). Similar cases to the above which refers to Negro-Dutch are mentioned by Thomas (1969: p. 63), Balley (1966: p. 146) for other Caribbean Creoles and by Hooley (1962: p. 118) for New Gulnea Pldgin also in the discussion of Hooley by Turner (1966: p. 207). 
The passive transformation that cannot be found is the optional transformation of the 1957 model of generative grammar. The decision to treat the passive as the marked category is supported by the fact that even in those languages that do have a morphologically and syntactically marked passive, the distinction between active and passive is neutralized in many cases, for example in the nominalizations of verbs ("The shooting of the hunters") cf. Greenberg (1970: p. 74): "The category which does not appear in the position of neutralization, may be called a marked category".

In pidgins and creoles we find numerous examples where not only some forms of the verb are neutral between active and passive but all forms. Clyne (1968: p. 135) gives some interesting instances in Pidgin German. Thus, we have to do with a generalization of a rule. The generalization is greater, and the grammar consequently simpler, if this rule applies to a maximal number op lexical items classified as verbs.

Although we do not get passive constructions with specification of the agent (a 'Luxus der Sprache') we do get constructions without agents that correspond to agentless passives in European languages. Hooley (1962: pp. 118-119) enumerates a subset of transitive verbs in New Guinea Pidgin that undergo what he calls a passive transformation:

$$
\mathrm{N}_{1} \mathrm{tV} \mathrm{N} \mathrm{N}_{2} \longrightarrow \mathrm{N}_{2} \mathrm{tV}
$$

(The symbol $t$ stands for tense, Hooley's notation is a pre-Chomskian notation and his transformations may be meaning-changing).

Examples :

New Guinea Pidgin

Gloss

em i-brukim glas he breaks the thermometer

glas i-bruk the thermometer is broken

ol i-kapsaitim bensin they spllled the petrol

bensin i-kapsait the petrol is spilled

The following examples illustrate the same transformation for a Caribbean Creole (data from Winford 1972 and DeCamp 1971):

di bota sel aaf the tree cut up the ground can plant etc. the butter has been sold the tree has been cut up can be planted 
The evidence given by DeCamp suggests that originally in a pidginized form of English all verbs could undergo this transformation (the only possible restriction being collocational), but that later, and under the Influence of English as target language, some verbs became, exceptions to this rule. "In standard English, including standard Jamaican, only a small number of verbs can appear in such inchoative constructions. As we approach the creole end of the spectrum, however, we find that almost every transitive verb is so privileged... In fact, beyond a certain point on the continuum, the passive transformation is blocked and this is the only means of translating the standard English passive." (DeCamp 1971: p. 363). This is certainly not true for New Guinea Pidgin, but I expect that the set of verbs that can undergo the "passive transformation" is not fully lexicalized. An analysis of a large set of examples would perhaps yield a system of verb classes similar to the one found by R. Lagan in French. Lagane refers to this phenomenon as "économie morpho-syntaxique".

I do not want to discuss this further, since what I wanted to show is how marked categories of standard languages can be expressed by means of unmarked categories. The passive transformation in the above examples is replaced by a lexical redundancy rule that disambiguates verbs that are neutral between active and passive and must be associated with one or the other according to the functional position in which they appear.

(e) Infinitive present as the favoured form for verbs

The hypothesis is that some forms of the verb are less marked than other forms. In pidgins, inflectional categories of the verb are not expressed obligatorlly and one base form is chosen for all occurrences of a verb. Very often this base form is identical with the infinitive of the target language. However, this may be accidental in many cases, in that the phonological reduction of verb forms may lead to a form that happens to resemble the infinitive. Again, it may be a salient feature for a number of European-based pldgins and creoles only. For Police Motu, for instance, Nida and Fehderau (1970: p. 149) write: "This has meant that only one form of the verb, the third person singular, is selected as the base for all the analytic phrases." To say that the use of the infinitive is part of a 'fuller definition of "Creole language"' (Valkhoff 1966: p. 26) is dangerous. Some instances of the use of the infinitive are the following: Gáld1 (1934: p. 271): .."thème verbal". Cette forme infléchissable... dérivée, dans la plupart des cas, d'un infinitif et plus rarement d'un participe francais."; Clyne (p. 132): "Eine sehr einheitliche Erschelnung bel den Testpersonen war das 
Auftreten des Infinitivs anstelle einer konjugierten Form des Verbs. Bel manchen Gastarbeltern ist dieses Phänomen auf einzelne Zeitwörter beschränkt, bel anderen hingegen auf ein gewisses Tempus." Whinnom (1965: p. 511): "The Spanish contact-vernacular verb in the Philippines has three forms. The basic verbal notion is conveyed by the Spanish infinitive minus its final R.", in the case of Sabir Whinnom (ibidem: p. 532) says that "about half the verbs are used in the infinitive" in a form of "inconsistently pidginized Italian" whereas in the actual spoken lingua franca it is likely that "the verb is normally used simply in the form of the Romance infinitive." ( $p$. 524). I myself found that the infinitive is the most common form of the verb in a kind of German Pldgin, still known by some of the old people of All Island in the West Sepik Distict of Papua New Guinea. A look at one of the few sources for a non-European pidgin (Fanagalo), however, shows that the situation there is completely different; past tense and present passive are morphologically signalled and the verb form used there is different from the infinitive (source: Bold 1968).

(f) Preference for continuous constituents

Discontinuity is not only a source of difficulty for grammatical analysis but apparently for the learning of forelgn languages as well. It is therefore not surprising that discontinuous elements tend to disappear or to be joined with their corresponding 'partner' in pidgins and creoles. Some instances of the disappearance of discontinuity in verbal compounds in New Guinea Pidgin have already been mentioned in the discussion of imperfect language learning. In this language the positionally conditioned discontinuity of verbal compounds such as to hang up, and to bugger up, has become an inseparable unit: hangimapim, bagerapim, etc. The same phenomenon is found, for instance, in Negro Dutch: Dutch oppassen past...op becomes pasop in Virgin Island Negro Dutch, and similar cases are found in 'advanced Afrikaans'. Again, Clyne's data for Pidgin-German do lead to the same conclusion: dann ist mitnehmen for dann nehme ich es mit ( $p$. 133). The need for more data is great; the available data do not suggest any exception to this rule.

(g) The use of masculine gender

When a language with gender-distinctions becomes simplified these genders are lost. In languages where gender partly reflects a semantic feature 'masculine' or 'feminine' the masculine is considered to be the unmarked category: "masculine is the unmarked state of a human noun" (Chafe 1971: p. 11l). This form of neutralization will only become apparent in those pidgins and creoles that are related to languages with grammatical gender; mainly French, Spanish and Portuguese. The only 
data for a pldgin that I could obtain concerned Vletnamese French P1dgin (Relnecke 1971: p. 51: "Adjectives are almost always masculine."). For French Creoles the plcture is less clear. The predominant use of the masculine form is a statistical tendency rather than an exact rule. For example Jourdain (1956: p. 78) states: "La raison qu1 a falt prévalo1r tantôt le masculin, tantôt le feminin nous a paru 1mpossible à déterminer, c'est probablement la fréquence d'emplo1." Similar information is given In Thomas (1969: p. 30): "The French masculine form seems to be preferred in the case of adjectives terminating in $n t$, $1 \mathrm{~s}, t$, which two last are mostly participial. In French an e mute is added to these endings to form the feminine." On the same page and on the following, Thomas gives examples of invariable adjectives that can be traced back to either French masculine or feminine forms and it is hard to see any principle behind this. In any case this distinction is of purely historical interest and does not say anything about the system of the creole. It is interesting only insofar as it reflects some former pidginized French.

For an example of a Portuguese Creole we may select the Creole of Bissau/Guiné (W1lson 1962: p. 15). "Adjective - these are Invariable, belng derlved from the masculine form in Ptg."

And speaking on the Spanish 'contact vernaculars' of the Philippines Whinnom (1965) writes (p. 510): "...like almost all creoles and pidgins, they discard such 'superfluous' European features as number and gender. The articles and adjectives are invariable, normally in the Spanish masculine singular form, though certain adjectives, such as guapa, (-nice,) have become fixed in the Spanish feminine form." (A very plausible reason for guapa to appear in the feminine form is that this adjective is almost exclusively used with feminine nouns in Spanish).

Another creole with a Spanish lexicon is Paplamento and here the same predominance of the masculine forms of the adjective is observable (Go110: p. $46 \mathrm{ff.}$ ).

Whinnom (1965: p. 524) mentions that this tendency was also present In the first known pidgin, the Sab1r of the Mediterranean: "Adjectives are Invarlable; usually in their Romance masculine singular forms." Whinnom wants to take this as supporting evidence for his relexification theory. However, the fact that the French creoles do not follow this pattern in a neat way and that replacement of more marked gender by less marked is not only restricted to European-derived pldgins, does make a theory of simplification in terms of reduction of markedness equally plausible. The present state of our knowledge makes any decision 1mpossible. 
(h) The use of the singular

It seems to be a universal that all languages having a category plural automatically have a singular as well. The reverse is not necessarily true. Assuming that the singular is less marked than the plural, the data that are available for pidgins and creoles seem to support the suggestion that the tendency of these languages is to become less marked. The sources cited above contain some references to the singular. Others may be found in the following; Richardson (1963: p. 8); Wilson (1962: p. 15); Eersel (1971: pp. 321, 322). Eersel mentions the case of Sranan where the morphological distinction was introduced by a young Surinamese poet who "wanted to start a discussion on the need for a plural in Sranan".

The plural category of the noun is also becoming more common in New Guinea Pidgin. However, the nominal plural that is developing here is quite different from the English grammatical category. If plurality is expressed openly it is expressed for all nouns that are semantically plural. The distinction between English mass and count nouns is not maintained and mass nouns are generally plural in Pidgin:

$\begin{array}{cl}\text { New Guinea Pidgin } & \text { English gloss } \\ \text { ol misin } & \text { they mission }= \\ & \text { the mission } \\ \text { ol tabak } & \text { tobacco } \\ \text { ol rais } & \text { rice } \\ \text { ol ami } & \text { the army }\end{array}$

There is an almost complete agreement between grammatical and psychological categories.

(i) Relational words

The small number of prepositions or their total absence is a characteristic trait of most pidgins and creoles. Clyne (1968: pp. $136 \mathrm{ff}$. ) mentions that the distinction between prepositions is a difficult one, not only for forelgn learners but even for native speakers: "Die Wahl des Verhältriswortes z.B. verursacht sowohl Zwelsprachigen wie auch Deutschlernenden erhebliche Schwierigkeiten; auch bei einsprachigen Deutschen entstehen tellweise wegen dieses Problems Bedeutungserwelterungen mancher Präpositionen und zusammengesetzte Substantive, die dem Gebrauch des Verhältniswortes auswelchen (z.B. Schütz-Memorandum); Die wenigen Gastarbeiter, die Präpositionen gebrauchten, wählten meistens die falschen. Das alles führt zur Frage: "Wle notwendig ist die Präposition überhaupt Im Deutschen?" Voorhoeve (1962: pp. 238-239) discusses the 'wider meaning' of prepositions in Sranan as regards linguistic efficlency: "In the European languages the preposition must be specific, 
so that a whole series of prepositions is needed... Specification is also possible in creole languages, and is indicated where necessary by means of a special specifying word...but the non-compulsory character of the specification means that one can suffice with the general preposition. Moreover, one saves not merely a single preposition, but half the total number of prepositions in European languages." (p. 239). Further examples of these 'all purpose prepositions' are given by Taylor (1960: p. 156) and Laycock (1970: p. XXVIII). (cf. also Tsuzak1 1971: p. 331; Gáld1 1934: p. 267). A look at the examples in Chomsky (1970: p. 196) will give an indication of the 1diosyncratic behaviour of many prepositions in English. I am not quite sure if general prepositions can be equated with less marked prepositions, but further research into the role of prepositions may well lead to such a conclusion.

I end this discussion of markedness by quoting Chafe (1971: p. 346): "The factors which are relevant, and the formalism most appropriate to their formalization, are by no means understood at the present time, even within phonology. The situation with semantics is even more problematic."

\subsection{SIMPLIFICATION OF THE MORPHOPHONEMIC COMPONENT}

"One feature, which is virtually universal to these languages generally classified as pidgins and creoles is the drastic reduction of morphological complexity and 1rregularity." (Goodman 1971: p. 253).

The claim of universality of this phenomenon is supported by evidence from many often unrelated pldgins. According to Tesnière (1939: p. 131) morphological simplification can be found in all instances where languages are in contact: "Une langue mêlée est normalement une langue sans morphologie." A few quotations will lllustrate how widespread the phenomenon is.

Portuguese Pidgins and Creoles:

Whinnom (1965: p. 513): "all (Portuguese oriental creoles) shared certain basic characteristics. Articles, adjectives and nouns are invariable in form.... Most distinctly of all, all Portuguese verbal inflections are lost..."

The same can be said of the African Portuguese creoles (Wilson 1962: Valkhoff 1966: especially pp. 26 ff.).

French Based Pidgins and Creoles:

Reinecke (1971: p. 51) on Vietnamese Pidgin French: "Except for a few isolated forms standard French inflection has been dropped and has not been replaced by new formations as in many creole dialects." Gáldi (1934: p. 257) on French Créoles: "Le mot creole est toujours invariable: $11 \mathrm{n}$ 'a qu'une seule forme infléchissable dont le caractère, comme partie 
du discours, dépend de la place qu'1l occupe dans la phrase." More details can be found in Richardson (1963a: pp. 7-9).

Spanish-Based Creoles:

Bickerton and Escalante (1970: p. 262) on Palanquero of Columbia: "1ts features, in particular the heavy functional load of the syntactic as opposed to the morphological resources, ought to qualify it as a creole by the most stringent criteria."

Whinnom (1965: pp. 510-511) on the Spanish contact vernaculars of the Phillppine 1slands: "First of all, of course, like almost all creoles and pldgins, they discard such "superfluous" European features as number and gender." And on the following pages he discusses the loss of morphology in other parts of speech.

Lenz (1928: p. 735) on Papiamento ( $I$ do not want to discuss here the affiliation of Paplamento with Portuguese rather than Spanish): "Lo caracteristico de la gramatica del papiamento, y probablemente tamblén de las demás lenguas criollas perfectas de las cucles no he visto gramaticas, completas, ..., es que ella es casi absolutamente logica 1 no conoce, salvo pocae escepclones heredadas del espanol, formaciones irregulares como las que abundan sobre todo en las lenguas flexivas."

The tendency for unitary symbolization of lexical units can be found in the better-known indigenous pidgins as well:

Berry (1971a: p. 527): "That inflection is the commonest casuality in the contact situation seems true of both European and African pidgins. The massive reduction of the Bantu nominal prefix system in Fanagalo and other indigenous African pidgins parallels the less striking losses of gender, case and number distinctions in European pidgins." (1bidem: p. 521) on P1dgin Sango of the Central African Republic: "P1dgin Sango can best be described as a dialect of vernacular Sango, simplified by the loss of most of 1ts morphology."

N1da and Fehderau (1970: p. 148) on K1tuba, spoken in the lower Congo area: "Kituba reflects the modifications characteristic of all pidgins..." The following features of this simplification process are significant:

(1) The prefixal aspect-tense forms are drastically reduced.

(2) The subject prefixes to the verb are replaced by independent pronouns.

Wurm (1971: p. 1016) on Police Motu (H1r1 Motu) of Papua-New Guinea: "Motu is a morphologically complex language using a large number of suffixes and prefixes, whereas Police Motu has only very few affixes, and the grammatical features expressed in Motu by affixes are indicated 
with the help of auxiliary words and clitics which give the language a different typological appearance."

I shall illustrate the simplification brought about by the loss of morphological categories using examples from Fanagalo. The prefixes of the noun classes of one of the Nguni languages (Xhosa) are the following:

Class number
1
1 a
2
3
4
5
6
7
8

$\begin{array}{rr}\text { Singular } & \text { Plural } \\ \text { umu- } & \text { aba- } \\ \text { umu- } & \text { o- } \\ \text { ili- } & \text { imi- } \\ \text { isi- } & \text { ama- } \\ \text { in- } & \text { izi- } \\ \text { ulu- } & \text { izin- } \\ \text { ubu- } & \text { izin- } \\ \text { uku- } & \end{array}$

There are additional phonetically conditioned variants of these prefixes. One can see that it is necessary to know to which class each noun belongs in order to be able to assign the correct plural. Thus each noun has to be marked in the lexicon as belonging to one class. In all cases, with the exception of a class which is predictable from the semantic feature ( + human), the gender class is not predictable given all semantic information. In learning Xhosa as a new language they have to be memorized, and for the non-native speaker of Xhosa they remain a source of mistakes - especially for a speaker of a non-Bantu (or non-Ngun1) language.

Fanagalo has abandoned this system, except for some idiosyncratic plurals in a few frequently used words, and replaced the different plural prefixes by a single prefix ma-. This tool is very useful for loan-words from Afrikaans and English which otherwise would have been given a grammatical gender which is not related to their semantic or any other properties.

The loss of gender in Fanagalo is certainly a simplification of the overall system, since no other component of the grammar has to make up for this simplification of the morphophonemic component. This simplification, moreover, involves more than the singular-plural distinction. It means that one no longer needs to take into account the obligatory and facultative categories of subjectival and objectival concord in the verb, the adjective and a predicative construction. Take for example the following sentence: 
uThemba wakutanda ukuhamba - Themba enjoyed traveling

the analysis would be something like:

$\mathrm{u}$ - classmarker of noun class la; Themba - Proper name; wa = $u$ subjectival concord marker + a denoting remote past; ku - objectival concord referring to ukuhamba; thanda - to like; uku - marker of class 8 , sort of deverbalizer; hamba - to go.

In Fanagalo the same information can be expressed by:

Themba thanda hamba - Themba liked travelling

This means that one does not have to know the gender of the subject and the object in order to produce the correct verb form.

From another point of view, however, this simplification is an indication of some terrible corruption: "Of the fascinating system of concords, which puts music and poetry into every Bantu sentence, nothing at all remains in Fanagalo." (Cole 1964: p. 557).

Recent discussions of pidgins have tended to cast doubt on the belief that morphophonemic simplification is as important in the characterization of pidgins as it was believed to be. Two lines of argumentation can be distinguished. One is that adopted by Hymes (1971: p. 70): "While the use of word order rather than inflection, of syntax rather than morphology, is a kind of simplification in outer form common to pidgins, to treat it as diagnostic of pidginization (or previous pidginization) would make Chinese a creole and former pidgin. Such mistaking of part for whole does in fact continue to occur."

The second kind of objections are reflected in Samarin (1971: p. 125): "Of much more interest is the concept of reduction. We are generally led to believe that what is involved in reduction is primarily a decrease in the number of linguistic elements, whether phonological, morphological or lexical." And Le Page, agreeing with Hall in principle, further restricts the concept of reduction by adding that "since the inflectional structures of two languages in contact situation rarely coincides inflection is the commonest casualty in a contact situation." (1967: p. 86). Such a narrow view of simplification is unfortunate although it is understandable. Both Le Page and Hall are thinking too much about pidgins they are most familiar with, the ones that are closely linked to European languages. This view ignores the possibility that pidginization could occur without the drastic reduction of an inflectional system. Moreover, pidginization can certainly occur when the source language has very little inflection." 
Hymes seems to be concerned with the question of overall simplicity as opposed to simplicity of one of the components of a language. This reflects the fact that the morphophonemic component is relatively simple and does not exclude complexity in other components of the grammar, especially the lexicon and syntax. Any further investigation of simplification of the morphophonemic component must therefore deal exclusively with those simplifications that are not paired with cost elsewhere. For example, surface case-markers allow freedom of lexical 1tems in the surface structure, but the additional possibility that surface case marking is different for a number of semantically unpredictable gender classes of nouns is a complication that is not paralleled by any simplification in another component of the grammar. Its abolition would therefore contribute to overall simplification.

The answer to Samarin's objections is partly implicit in the answer to Hymes. In addition, it can be said that simplification must be taken to be a continuum rather than the extreme end of a continuum, but Samarin is right in rejecting any suggestion that simplification takes place exclusively in the morphophonemic component.

It would be wrong to classify all simplification that takes place in the morphophonemic component under one heading. In fact there are at least two completely different kinds that can occur. One is simplification by means of introducing greater regularity, through the abolition of exceptions to the rules of this component. An example would be to have a unitary representation of past tense, for instance, all past tense forms ending in /D/ In English, with the variants predictably conditioned by the phonological enviroment. All suppletive forms would be replaced by the new regular pattern. Whereas in normal language transmission,1.e. child language learning, this kind of simplification is extremely widespread, its importance for pidgins is marginal; since they tend to do away completely with what Lyons (1968: p. 272 for discussion) has called the accidental categories of grammatical theory' like gender, number, case and tense. A detalled discussion of these grammatical categories can be found in Palmer (1971: pp. 82-106).

The question that must be asked first is: "Are we dealing with impoverishment or with genuine simplification?" The main function of the grammatical categories is to indicate syntactical relations. The semantic information they carry is much less than generally assumed and "may vary from tolerable closeness to extreme indeterminacy" (Robins 1964: p. 279). One could add that languages where obligatory grammatical categories are found, will be simpler if these categories are predicted by semantic properties in a one to one way. Apparently the historical development of the grammatical categories had 1ts origin in such a 
one-to-one correspondence. "Jede grammatische Kategorie erzeugt sich auf Grundlage einer psychologischen. Die erstere ist ursprünglich nichts als das Eintreten der letzteren in die äussere Erscheinung." (Paul 1970: p. 263). This can be demonstrated with the recent developments that took place in the initial creolization of certain pidgins such as New Guinea Pidgin (Labov 197la: pp. $29 \mathrm{ff.}$ ). It would be extremely interesting to observe if the second development, mentioned by Paul: "Dadurch kann die anfänglich zwischen belden bestehende Harmonie im Laufe der Zeit zerstört werden." (1bidem) and "Dazu kommt, dass der Bedeutungswandel vielfach darauf wirkt, dass die grammatische Kategorie der psychologischen nicht adäquat bleibt." (1bidem) will happen in New Guinea Pidgin, 1.e. the development of a discrepancy between semantic and grammatical category. The more straightforward relation between expression and content in pidgins must be called simplification. Grammatical categories that are obligatory easily become part (phonologically) of certain parts of speech, 1.e. they become inflectional categories. One result of this is that the information that was carried by word order will be partly carried by inflectional differences. Whether this can be related to simplification or not will be discussed later.

It lies in the nature of inflections that they force the user of an inflectional language to 'add' certain information to his message, even if this additional information is not relevant to the message or is already expressed elsewhere. What makes languages different in the surface structure is what they must express obligatorily. The more obligatory categories a language will have the more redundant they will be (see Labov 197la for discussion). It seems likely that there is a correlation between the number of obligatory grammatical categories and the complexity of a language, a complexity that becomes greater the less the grammatical categories are semantically motivated. I shall now look at some grammatical categories in more detail:

\section{(i) Gender}

Pidgins do not have a sub-classification of nouns in terms of gender. This seems to be true of both European-based and indigenous pidgins. Insofar as gender in European languages only vaguely corresponds with the semantic concept of 'sex', its abolition will not be a conceptual loss but a substantial simplification. The examples will show that it is perfectly possible for a pidgin to express optionally the concept of sex. The place where gender is assoclated with lexical items is in the lexicon. In most languages there will be only a small number of lexical items where gender can be specified by means of lexical redundancy rules. It therefore makes no sense to say: "Il nous semble donc, pour conclure, que si le noir a très bien compris la nécessité d'exprimer la 
notion de sexe et qu'il arrive à le falre sans trop de difficulté, la notion abstraite du genre lu1 échappe totalement." (Jourdain 1956: p. 74). It will be the case that 'le noir' will be able to make sex distinctions without any difficulty and not "sans trop de difficulté". He will, however, only do this where it is necessary. Thus, a semantic feature ( \pm masculine) will be needed only in connection with animates, and often only with some lexical items from the total set of animates. The knowledge of the sex of the being concerned is more important with human beings, domesticated and large animals than with leeches, worms or ants. Sex can be expressed in two ways and use of both is made in pidgins and creoles. Elther the difference in sex of two animates that share all other semantic features is lexicalized or it is expressed by an optional element such as a prenominal adjective.

Lexicalization would be given in the following examples (data from Jourdain 1956).

\begin{tabular}{llll} 
Martinique French Creole & \multicolumn{3}{c}{ Gloss } \\
nhome & $=$ femme & man - woman \\
gacon & fi & boy - girl \\
taureau & vache & $=$ & bull - cow
\end{tabular}

Lexicalization implies 1rregularity while the second method of expressing sex saves half the unmotivated forms by relating content and expression in a systematic way: the unmarked male form is taken as the base form and is expanded into the corresponding female form by adding one invariable morpheme. This mechanism is used in many animal names in Martinique Creole: "Quand 11 est nécessaire de préciser le sexe, on fa1t précéder le nom de l'animal du mot mâle ou femelle, ou encore du mot 'papa' ou 'mama'." (Jourdain 1956: p. 73).

For example:

$$
\begin{aligned}
& \text { Martinique Creole } \\
& \text { an maman coden } \\
& \text { an maman sepent } \\
& \text { an maman cana }
\end{aligned}
$$

Gloss

$$
\text { turkey-hen }
$$

female snake

female duck

The following examples from New Guinea Pidgin show the same tendency towards uniform representation of the same units of content:

New Guinea Pidgin
man
meri
bulmakau
bulmakau man
bulmakau meri

\author{
Gloss \\ man, male \\ woman, female \\ cattle \\ bull \\ cow
}




$\begin{array}{ll}\text { New Guinea Pidgin } & \text { Gloss } \\ \text { hos man } & \text { stallion } \\ \text { hos meri } & \text { mare } \\ \text { pikinini } & \text { chlld } \\ \text { pikinini man bilong.. } & \text { son of } \\ \text { pikinini meri bilong.. } & \text { daughter of }\end{array}$

Although one may find exceptions to this principle in pidgins they will be much less frequent than in fully-fledged languages where suppletion is extremely common. The difference in other words, is one of degree rather than kind. Furthermore, pldgins do not have additional gender distinctions that may be quite different from sex distinctions. In languages that do have masculine and feminine gender this is only indirectly related to sex, whilst the classification of inanimate objects into masculines and feminines is completely arbitrary.

\section{(ii) Number}

The relation between semantic number and grammatical singular, plural and so on 1s by no means stralghtforward. There are a large number of collective nouns which are grammatically singular and semantically plural; in Latin, for example, one finds many instances where the agreement of the adjective with the noun is made in terms of grammatical number, whereas the accompanying verb is inflected in terms of the semantic number. The obligatory grammatical category of number forces one to classify lexical 1tems that are semantically nelther one or more than one, as either singular or plural. As in the case of sex differences, every language is able to refer to plurality as opposed to singularity, but there is no more need for this to involve a specific grammatical formation in words or concordial relations in sentences than there is for duality to be referred to in this way." (Robins 1964: p. 280).

Pidgins do not have obligatory grammatical categories of number for nouns. However, number is normally expressed by pronouns, where grammat1cal and semantic number colncide.

I do not want here to say more about specific grammatical categories and how they are expressed in languages, but what emerges from the short discussion of gender and number is that these grammatical categories have little exact meaning, and that in most cases they must be introduced as part of lexical information. Where government and agreement are obligatory there must be additional grammatical rules; the more inflectlonal categorles a language has the more difficult the rules for agreement tend to become. In many cases the information carried by features of agreement is small or non-existent. The intultive feeling that languages without grammatical categories and agreement are simpler seems 
to be supported by the above analysis. "What information do they provide? One answer is that they often provide little or no information and are almost completely redundant. "French would be no less intelligible, and would certainly be easier to learn, if we did not have to bother with the gender and the number of adjectives, if in fact its adjectives followed the same pattern as those of English.... Thus, in languages where there is a falrly fixed order of words, and where that order indicates the grammatical relations between the words, concord and government would appear to be unnecessary luxuries (or difficulties)." (Palmer 1971: p. 105). My own experlence taught me that, although I am a native speaker of a highly inflectional Germanic language (German), to learn another highly inflectional Germanic language (Icelandic) was very much more difficult then to learn a Germanic language with hardly any inflections (Afrikaans). This fact must be explained by the absolute degree of complexity rather than by the degree of structural similarity. Languages become more complex the larger the number of semantic categories that are obligatorily expressed by grammatical categories and the greater the degree of divergence between grammatical and semantic categories. Another indication of the complexity of a language, which is closely related to the obligatory categories, is the expression of optional categories. It has been mentioned above that there are considerable differences in the degree of lexicalization of semantically-related 1tems. The marking of sex in the surface structure was a case in point. Whereas the above discussion dealt with grammatical categorles that are not directly related to semantics the rest of the thesis will deal mainly with the simplification of the lexical component, where semantics is much more closely involved.

Before this is done, some suggestions will be made about word order as an alternative way of expressing relations that can be expressed by grammatical categories.

\subsection{STRICT ORDER OF SURFACE STRUCTURE ELEMENTS AND SIMPLIFICATION}

One of the consequences of the flexional poverty of pidgins and creoles is that the meanings that would otherwise be expressed by inflectional categories are mainly carried by what is commonly known as word-order, some of the remaining information being carried by nonsegmental features as well. Bloomfield (1969: p. 198) introduces the two notions of 'taxems of selection' (morphologically marked classes and subclasses) and 'taxeme of selection', as two alternative ways of fulfilling the same function. Bloomfield sees the relationship between the two as follows: "In languages which use highly complex taxemes of 
selection, order is largely non-distributive and connotative." and "from the standpoint of economy taxemes of order are a gain, since the forms are bound to be spoken in some succession." (p. 198). Palmer (1964: p. 125) also mentions this principle: "If our linguistic symbols are written in order, it is convenient to make order significant and the simplest use is to indicate sequence." Although it is not the case that all inflectional languages have a free word order, the reverse is true. The historical development of Latin into Spanish, French etc. 1llustrates this change from a falrly complex morphological system with free word order into a system with a simpler morphology and meaningful word order. The same happened in the case of pidgins: the word order that was already falrly rigid in many target languages became even more rigid in the derived pidgin. The use of surface order of elements as a means of expressing parts of the meaning of a sentence is not only a salient feature but most probably a universal of pidgins. Again, the mere fact that word order is important, will not make a language a pidgin or former pidgin. One must look at it as a necessary, but not a sufficient, condition. Before I discuss some implications of this feature of pidgins I shall look at some quotations in the relevant literature:

Gáld1 (1934: p. 258): "Grâce à l'invariabilité des mots, le créole falt toujours l'impression de mote juxtaposés et déterminés, du point de vue de la fonction, par la place gúits. occupent dans la phrase. Comme la morphologie est rédulte au minimum, l'ordre des mots devient naturellement invariable."

Jacobs (1963: p. 43): "All expression of relations between concepts or words is supplied by means of precise word order pattern." (for Chinook jargon).

Hjemslev (1938: p. 373): "L'expression des formes grammaticales est dans les langues créoles à l'optimum.....l'ordre des mots pourvu d'une valeur grammaticale."

Turner (1966: p. 206): "The important and interesting part of the grammar of an uninflected language concerns its phrase and clause structure, and when the use of a few bound morphemes has been described, and a few closed sets of words have been enumerated, the study of Neomelanesian grammar concerns the order of elements and their coherence in structures."

Richardson (1963: p.7/8): "This flexional 'neutrality' is so typical of all types of creole and pidgin that it has led to many comments on the common grammatical structure of these languages. In the grammatical fleld, if this common feature is subtracted there remains only word 
order as a potential differential between creole speeches... When the word order of the slave languages is similar to that of the dominant language there is no conflict. Where there is conflict, as was the case in Mauritius, the word order of the dominant language prevalis in the new language. Since the dominant languages are generally members of the same linguistic family, they too have similar word orders, hence a further reason for the basic structural similarity of creole languages."

These quotations illustrate the importance of word order. I shall from henceforth refer to it as sequence to distinguish it from deep structure order. (cf. Palmer 1964) in these languages. Normally all we come to know is that there is one fixed sequence for all sentences: statement, question and subordinate sentence. However, not very much is known about the detalls; a falrly extensive account of some sequential arrangements of lexical items in various pidgins and creoles can be found in Hall (1966: pp. 68-88). I know of no contrastive analysis of a pldgin and 1ts source language that is anywhere near complete and statements such as: "The syntax of Sabir, however simplified, is beyond question Romance: the word-order is a Romance word order." (Whinnom 1965: p. 524) or "Neomelanesian is much more closely related to English structurally than is generally conceded." (Hooley 1963: p. 127) that 1mply that the word order is more or less colned on the image of another better known language (generally a European language) are dangerous at the present stage of our knowledge. A look at a recent treatment of possible surface arrangements and their semantic implication for one of the better described languages (e.g. van der Lubbe 1965 for Dutch) reveals the lack of knowledge in this field. The importance of the sequence of adjectives as qualifiers of nouns, the possible positions of postdeterminers and predeterminers of nouns, the admissable combinatlons of verbal qualifiers, in short, all questions of sequence in sentences other than the most basic ones, are topics that still have to be dealt with in the description of pidgins. One must ask as well: How much meaning can surface sequence carry? If the place in which a lexical item is found contributes to its semantic interpretation, the number of possible places in the surface must be relatively small and be generated by a recursive mechanism.

Voorhoeve has tried to escape this by looking at the possible positions of lexical 1tems within any given intonation unit. "We have accustomed ourselves to define the sentence as an intonation unit." (p. 49). Although 1t may be true that intonation units are the exponents of some sentences there will be grammatical units with meaningful surface positions that are either longer or shorter than an intonation unit. A generative grammar would generate surface structures by means of 
recursive rule mechanisms, thus providing descriptions for structures of any length.

I am not certain how a generative grammar of a pldgin would be different from that of a normal language spoken by a native speaker. I want to make a guess, however, as to what one is likely to find.

(1) Since the sequence of surface structure elements is meaningful, this sequence may be directly related to some meaningful deep structure order, if the assumption that grammatical functions are defined in the deep structure holds.

(11) The kind of transformations that operate between deep and surface structure will be severely restricted. Permutation and deletion transformations will be much less common and perhaps non-existent in cases of pure pldgins. The sequence of elements is the same for questions and subordinate clauses as for simple declarative sentences, 1.e. no permutation is allowed. The fact that even imperative sentences are structurally 1dentical with declarative sentences indicates that no deletion of the 'recoverable' second person has taken place: "Imperative clauses have, normally, the same structure as that of an ordinary clause, and may have elther ordinary or exclamatory intonation." (Hall 1944: p. 101) and "In Melaneslan P1dgin we use the usual second person singular or.plural in most such cases (1mperative), with a few small differences from their regular usage." (Mihalic 1971: p. 30). And in Police Motu, unlike in English, word order is never used to distinguish sentence types like these. By means of such changes of intonation we can convert all the Police Motu sentences Into questions; some may also have the function of commands or exhortations. The sentence oi lao can mean either you go away (oi = you lao = go away) or go away depending on the intonation used. In some pldgins (e.g. Fanagalo and optionally New Guinea Pldgin) the person can be deleted in the imperative. Perhaps one must distinguish between deletions that take place at the periphery of sentences and those that take place somewhere else, since deletions may affect the intelligib111ty and transparency of the surface structure more than others.

(111) For very much the same reasons as in (11) one can expect less embedding, especially self-embedding, since this kind of transformation destroys the surface sequence of lexical 1tems. Conjolining of simple sentences will be very frequent, and a superficlal look at some discourses in varlous pidgins shows a definite predilection for short 'kernel' -like sentences. One should test this hypothes is, however, using a large corpus of data.

Bloomfleld and others (e.g. Martinet) seem to agree that the use of sequence rather than inflection for the expression of certain grammatical functions is the more economical method. This does not mean that 1 is 
the simpler method from the point of view of a learner of a second language and... "there are obvious advantages for the speaker if he enjoys some measure of freedom in the order of the monemes or the more complex signs, since it enables him to analyse the experience to be communicated in an order adapted to the special circumstances in which he is placed." (Martinet 1960: p. 101). A method of indicating grammatical relations in the surface structure other than order, would be by means of a small set of items such as subject marker, predicate marker, transitivity marker etc. This is found, for example, in New Guinea Pidgin:

ologeta manmeri i go kisim pis

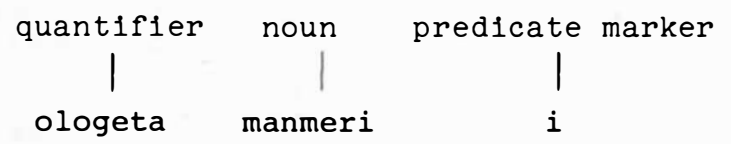

all men and women go and get fish

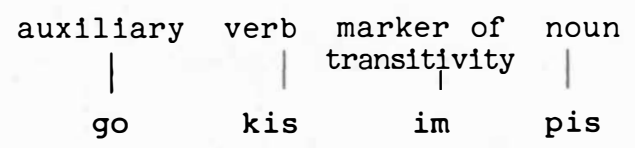

Instead of special particles, reduplication may also be used as a means of indicating certain grammatical relations, for example, to mark the predicate, or any other part of a sentence. I have not, in fact, investigated the role of reduplication as a means of indicating grammatical relationships in surface structure, but one case with which I am familiar is reduplication in Afrikaans.

Sy het sing-sing in die tuin geloop - she walked into the garden and was singing at the same time.

I found a similar example for New Guinea Pidgin. However, the use of this grammatical pattern seems to be very restricted in this language.

olgeta samting $i$ pundaun everything fell down brukbruk nabaut and was shattered to pieces.

From what has been said just now it does not emerge that the use of word order per se is simple - rather it is a slight complication of a language. However, since it is motivated by simplifications in the morphophonemic component of the grammar and since it can contribute to a substantial simplification of the lexicon, strict order of surface elements is a necessary precondition for simplification of other components.

I have avoided the question of whether the surface structure in pidgins corresponds in any way to some universal deep-order, or perhaps to the least marked sequence of surface structure elements. Some of the problems of word-order are discussed by Staal (1967). For pidgins 
Cassidy (1971: p. 216) writes: "Structures that grow up in pidgins may reflect the underlying structure of related base-languages, but they may also testify the still deeper universals of human communication." However, at present the evidence for claims about the properties of a universal deep structure is insufficient and any statements made at this point would not be based on empirical findings.

\subsection{SIMPLIFICATION IN THE LEXICON I}

"La Limitation de l'arbitraire...(est)...une correction partielle d'un système naturellement chaot1que." (Saussure, p. 182) Saussure, as Chomsky later, 1dentifies lexicon and arbitrariness on the one hand, grammar and motivation on the other. Not all languages have the same amount of motivation in their lexicon: "It was one of Saussure's most important discoveries that the proportion of transparent and opaque words varies characteristically from one language to another... He even foresaw the possibility that languages might one day be classified on this ground, and outlined in a rudimentary 'typology' based on morphological motivation. He distinguishes between lexical languages, which have a preference for the conventional word, and 'grammatical' languages, which favour the transparent type. English, in his view, is less motivated than German; Chinese represents the extreme of opaqueness." (Ullmann 1964: p. 105). This morphological motivation is discussed in detall in Halliday (1966: p. 157). He uses the term 'equivalence between series and set' to refer to the same phenomenon and uses this criterion as a means of establishing a lexical typology: "One would predict that in Chinese, for example, practically all such series do form sets..., whereas in Malay and English they very often do not." The difference between equivalence and non-equivalence between series and sets can be shown with the following serles: 'oaktree-ashtree-beechtree-planetree' and 'Inkstand-bandstand-hallstand-grandstand' .

The kind of motivation that will be discussed is what Ullmann calls 'morphological motivation', 1.e. the morphological structure suggests the 1dea of a whole 1tem. Typical exponents are derivation and compounding, and paraphrase would presumably fall into the same group. (I am thinking in particular of phrasal words in pidgins such as 'him fellow bik boks, yu fight him, he cry' for plano - the authenticity of this expression is not up for discussion). When Saussure introduced the notion of motivation he referred to the motivation of the significant only, 1.e. he does not deal with a possible motivation of the signifié at the same time (discussion: Gauger 1970: pp. 90ff.) This only takes into consideration cases where the word is motivated by its meaning, where the 
same set of semantic features is consistently expressed by one phonetic shape.

I do not have enough data to prove conclusively that pidgins are generally more motivated than any other languages, but it seems safe to say that they are more motivated than the languages from which they derive. Above I have given some examples of uniform representation of sex in a pidgin and a creole and a superficlal look at the lexicon of a pldgin will show that many antonyms are related morphologically, for example, in New Guinea Pidgin:

$\begin{array}{lll}\text { New Guinea Pidgin } & \text { Gloss } & \text { From English } \\ \text { no kamap } & \text { be absent } & \text { come up } \\ \text { nogut } & \text { bad } & \text { good } \\ \text { no inap } & \text { deficlent } & \text { enough } \\ \text { no hatwok } & \text { easy } & \text { hard work } \\ \text { no planti } & \text { few } & \text { plenty } \\ \text { no sitrong } & \text { frail } & \text { strong } \\ \text { no sitret } & \text { incorrect } & \text { straight } \\ \text { no gat } & \text { lack } & \text { got }\end{array}$

Th1s is not only found in European-based pidgins. Very similar examples can be drawn from Fanagalo:

$\begin{array}{lll}\text { Fanaglo } & \text { Gloss } & \text { Literal translation } \\ \text { hayi figile } & \text { absent } & \text { has not some } \\ \text { hayi muhle } & \text { bad } & \text { not good } \\ \text { hayi bona } & \text { blind } & \text { not see } \\ \text { hayi saba } & \text { brave } & \text { not fear } \\ \text { hayi vuma } & \text { refuse } & \text { not agree } \\ \text { hayi fundile } & \text { 1gnorant } & \text { has not learnt } \\ \text { hayi dagiwe } & \text { sober } & \text { not drunk }\end{array}$

Both lists could be extended conslderably. Most (perhaps all) languages make use of this kind of morphological motivation and the consequence of this is that the number of unmotivated forms in the lexicon can be reduced. It seems to me a fair assumption to expect more motivation of the above kind when the lexicon of the users of a language is small, as in the case of an imperfectly acquired second language and a pidgin. 
Many of these neat patterns are destroyed, however, when the lexicon is supplemented with new words from a target language. One salient feature of certain pidgins, and one that has often been emphasized, is that certain concepts, rendered by a single lexical 1tem in a European language, are expressed by a long phrase in the corresponding pidgin. This kind of paraphrase may be called an extreme example of motivation. Consider the following:

From Beach-la-Mer: (Churchill 1911)

suppose me kitch him grass he die coconut belong him grass not stop

big fellow master too much

he all bone got no meat

pickanninny stop along him fellow
Gloss or translation

to pick flowers (kitch from catch)

he is bald; there is no grass on his coconut

governor

he is thin

egg (little is inside)

New Guinea Pidgin (Schuchardt 1898):

fellow belong make open bottle

corkscrew

Pidgin English (Rogge 1957 - unfortunately Rogge falls to distinguish between the different languages called Pldgin English):

sit-down go ahead chair bicycle

big fellow ga-ga makee go water duck inside

These paraphrases are interesting in various ways.

Obviously they characterize only a rather early, and most probably unstable, phase of the pidgin. For example, in New Guinea Pidgin as It is spoken today, the paraphrases that are found in Beach-la-Mer from which it developed are replaced by single lexical items:

$\begin{array}{lll}\text { Kela } & = & \text { bald } \\ \text { kiau } & = & \text { egg } \\ \text { etc. } & \end{array}$

Th1s has also been observed by Reed (1943: p. 280): "Many have remarked on the paucity of the pidgin vocabulary and the necessity of extensive circumlocution in order to express relatively simple 1deas. Nevermann, for instance, c1tes three examples: 


$$
\text { English }
$$

half-moon

bed

to write
Melanesian Pidgin Equivalent

small fela mun

ples bilong slip

putim mark long pepa

Whatever has been the interval of time since these expressions were recorded, we find today that a closer approximation to English has been achleved in the pldgin terms hap mun, bet and raitim, all of which were heard in common use during 1936-37 by the author.

Circumlocutions are still necessary, but cases like those above show that the native is quick to adopt simpler modes of expression whenever he can borrow or invent them." There may be several reasons for this. One, which is mentioned by Hall (1956: p. 93): "The desire of some groups among the more soph1sticated non-Europeans to avold previously existent Neomelanesian words or expressions which they consider to carry a connotation of inferiority.......and which they replace by the corresponding English terms." This would be a soc1olinguistic explanation. There is a second possible explanation in terms of psycholinguistic factors. It is concelvable that there is something like an optimum for motivation. The price that has to be pald when a concept is fully lexicalized (opaque) is that 1 t has to be learned as a totally new 1tem; overt morphological motivation, on the other hand, leads to a drastic increase in length of paraphrases that stand for a single concept. This may not only affect the length of time that is needed for a single utterance, but it may affect intelligibility as well. When more than a certain number of features of a concept are overlty reallzed, the users of the language will at some point perhaps become unable to grasp the concept as a unit. The span of the short term memory (Lado 1968a) comprises at most twelve isolated units "a length which is beyond the memory span of most subjects." (p. 124). These paraphrases are no longer totally morphologically motivated but 'semantically motivated' (to use Ullmann's term) at the same time. This means that there is not only uniform representation of meaning but also something like semantic motivation,malnly flgurative use of words. Semantic motivation means that, for example, in phrasal words like suppose me kitch him he die the phrase is not an exact paraphrase orlginally. However, as in the case idiomatic expressions, the phrase becomes equivalent to a single lexical item by means of a semantic process. One can only speculate about the relative 'complexity' of semantic and morphological motivation, but, certainly, semantic motivation tends to be much more 1diosyncratic. 
It is not 1mmediately obvious how paraphrases could be sald to be simplifications. By defining one term by another, one will have a large amount of clrcularity in definitions. The same be sald of a componential analys1s, an example being the large number of distingulshers that are needed In Fodor and Katz's semant1c component. Dixon (1971) has devised a mechanism that combines both componential and definitial methods of semant1c analysis and that can be related to the facts found in registers of certain languages (his examples come from a taboo register of Dy1rbal a mother-1n-law language) and in pldgins. For the analysis of verbal forms, D1xon (1971) proposes two sets of verbs, a nuclear set that can be described most conveniently in componential terms and a non-nuclear set wh1ch "can be defined in terms of semant1c descriptions of neculear verbs (or previously defined non-nuclear words), and the syntactic apparatus of the language." (p. 436). The division of verbs into these two groups is justified by their being composed of a falrly small number of general semantic features. Nuclear verbs can in addition not be defined in terms of other nuclear verbs. A language that wants to have the absolute minimum of verbs (this tendency is very strong in pidgins) "need not contain any non-nuclear verb. In place of a putative nonnuclear verb it could simply use a 'definition', thus instead of stare It could have look hard. The language would, however, have to contain a full set of nuclear verbs." (1b1dem: p. 442). It seems to me that along these lines one could justify a distinction between semant1c markers and semant1c distinguishers (see Fodor and Katz 1964: p. 496).

One may put forward as a hypothesis that the distinction between nuclear and non-nuclear lexical 1tems (rather than verbs) is universal and that these princlples of simplification of the lexicon will be of great importance in the first stages of the development of a pidgin. Before more definite statements can be made a large corpus of data has to be analysed, preferably data from pldgins that are not historically related. I want to list here some 1tems from New Guinea Pidgin that were felt to support this hypothesis:

New Guinea Pidgin

bikpela man tumas

lait strong tumas

kunai i drai pinis

singsing taim maus $i$ pas
Gloss

b1g $\operatorname{man}$ very $=$ glant

light strong very $=$ glare

grass dry past = hay

sing when mouth shut $=$ hum 
To study how pidgins exploit the semantic possibilities of language seems to be a very promising fleld of research.

Paraphrases and, to a lesser degree, compounding and derivation. in pldgins, may provide important counter-examples to the relexification theory. Relexification means that a "a wholesale shift in the lexicon of a pldgin, whlle preserving not just the grammar but certain lexical 1tems assoclated with the grammar" (Whinnom 1965: p. 518) can account for the basic similarities of most pidgins and creoles. The instances that have been adduced to support this theory have almost exclusively dealt with single words or morphs. Although single morphs do often function as words in pldgins, this means as units of sentence-composition, this does not mean that one should equate word and morph in these languages. In practice this has often been done and higher size-level units of the lexicon have been neglected.

This is, however, a much too simplistic view of the lexicon, although a very widespread one: It does not consider the possibility that the lexicon is not just an inventory of words but may consist of units of various sizes, such as morphs, words, phrases, 1doms and 1diomatic expressions. A comparison of units above the level of the word may show that there are considerable differences in the ways in which the lexicons of different pldgins are organised. What is a single word in one pidgin may be a phrasal word in the next one, or, to mention another possibility, phrasal words may have a different composition in two pidgins. An example is the way in which the concept to greet is expressed in Chinese Pidgin English (mojki haensom fés fó = make a handsome face) and New Guinea Pidgin (givim gude long = give good day). Practically nothing is known about this, though the small corpus of evidence that can be found in Todd (1971) seems to give support for such a suspicion. One of the next steps in research into pldgins should therefore be a comparison of the organisation rather than the inventory, of lexicons. This could at the same time yield information about the relative degree of motivation in the lexicons of these languages.

Ullman (1964: p. 113): "One could not say in general that transparent 1dioms are easier to acquire than opaque ones, for the advantages and disadvantages are neatly balanced." One of the main reasons for this is that many of the opaque words are international technical words that need not be learned for that reason. The situation will be very different, however, when a language is learnt by members of a totally different culture and when two socleties had no previous experience with one another's thinking. In this case regular patterns of compounding and derivation can be called a genuine simplification. 
Simplification of the lexicon must be seen as only one of the possible simplifications that can occur. For a language to qualify as a pidgin, lexical motivation on 1 ts own will not suffice. The same has always been sald of simplification of the morphophonemic component, and Hymes (1971: p. 70) has also objected to a vlew that consldered the loss of inflection as symptomatic of pidgins and creoles (a view that would classify Chinese as a former pidgin). The criterion of simplification of the lexicon gives us linguistic grounds for rejecting this view of Chinese (as well as suggesting that we need to take all these different types of simplification into consideration when deciding whether a language should qualify as a pidgin or not).

Simplification of the lexicon implies that lexical items can be partly predicted by grammatical rules; the rules that have been treated so far deal with the relationship between form and content. There is another form of simplification that is found in most pidgins, namely that involving rules that determine the relation between content, form and grammatical function: these are rules that concern meaning on one hand, and 1 ts dependence on function on the other. Cases of lexical 1tems that are used in more than one function, and the problems for grammatical theory that are created by this phenomenon will be discussed presently.

\subsection{SIMPLIFICATION IN THE LEXICON II}

One of the main mechanisms of simplification in the lexicon is the use of the same lexical 1tem in more than one grammatical function in the surface structure. Only a few scholars (Hjelmslev 1938, Voorhoeve 1962, Jones 1971) seem to have reallzed the value of this mechanism; in many cases it is referred to by derogatory terms such as 'confusion of parts of speech' or 'mixing of word classes'. Since pidgins and creoles were mostly described in terms of the grammar of their target language, such statements are understandable. The theoretical implications of this 'multifunctionality' w1ll be discussed later. First I shall quote some instances in the literature which 1llustrate 1ts widespread use in pldgins and creoles: Jacobs (1932: p. 40): "It should be remembered that in (Chinook) Jargon elements are indiscriminately verbs, nouns, adjectives, or adverbs depending on their meaning and the ability an element of a given meaning has to serve as another form of word." Gáld1 (1934: p. 258): "La plupart des mots créoles renferment une pluralité de sens, dont l'un est actualisé selon le role de sujet ou de prédicat que le mot joue dans une phrase donnée." 
(1bidem: p. 269): "Ce seul example que nous venons d'analyser dans ses déta1ls suffit à prouver combien les catégories grammaticales sont instables en créole. Par l'interchangeabilité des fonctions avec un minimum de changement des signes...."

Hall (1943: p. 23): "Change of function, from that of one part of speech to that of another, is even more common than in English...." (for New Guinea Pidgin).

Goodman (1967: p.53): "Another key process in the syntax of EnglishJapanese Pidgin is the use of many words in a varlety of grammatical functions. This process is closely related to and probably inseparable from the semantic tendency towards abstraction."

Voorhoeve (1962: p.242): "In creole languages a word-form is seldom limited to one grammatical category, but can in principle be used in three different functions. This makes for a great saving in vocabulary and a slight complication in syntax. From the point of view of the learner of the language this system of organization of linguistic elements offers great advantages."

Clyne (1968: p. 135): "In diesen Belegen erweist sich die Neigung, Verb und Substantiv durch Weglassen gebundener Morpheme gle1chzumachen. Diese Tendenz wird durch Abkürzung der Substantive erwe1tert."

(1b1dem: p. 137): "Was Unentbehrlichke1t betrifft, lautet be1 unseren Versuchspersonen die Rangordnung der dre1 Haupt-Wortarten: 1. Substant1v, 2. Adjekt1v, 3. Verb. Die schon erwähnte Tendenz zum Gebrauch des freien Morphems...führte häufig zum Ausgle1ch zwischen diesen Wortarten." Cassidy (1971: p. 214): "The relationship of modification would soon demand expression, not necessarily in terms of adjectival or adverbial words: formal marking of the parts of speech as in full languages should not be expected - on the contrary, functional shift without change of form."

Taylor (review Whinnom: p. 498): "The fact that many pidgins and creoles have but little morphology may make it particularly hard to find criteria by which their several word-classes (be these the same as the parent language or not) may be recognized; but 1t does not excuse a statement as the following (which seems to be all that is sald on this subject in this work). 'Parts of speech belong to the Indo-European languages, and In Beach-La-Mar and Pidgin (with Polynesian and Chinese substrata in place of Malay) we find that same readiness to confuse different parts of speech.' What this means, or rather what Whinnom means by this, I do not quite know."

Wurm (197la: p. 8): "A characteristic feature of Pidgin is the presence of many universal bases, 1.e. words which can function as nouns, noun and verb adjuncts, intransitive verbs and transitive verbs.... The 
functional possibilities of pidgin bases are fundamental to the grammar of Pidgin." Wurm and Harris (1963: p. 3): "The predicates of such simple sentences often consist of words which we have called bases, and which can be translated by English verbs, adjectives or nouns." (on Police Motu).

Jones (1971: p. 78): "Also, since Krio borrows concepts rather than just words from English, so that the normal and verbal forms of the same concept are usually identical, the language relies very heavily on syntactical structure. When signals other than word order are needed to indicate function or meaning, these are usually free-standing units." (1b1dem: p. 79): " a go sing
a lek dis sing
dis sing biznes I will sing I like this song this singing business

Th1s 1llustration shows some more of the devices by which Krio extends the range of 1 ts borrowings, making what would appear perhaps a limited lexicon go a long way." (emphasis mine).

That the same lexical 1tem is used in more than one grammatical function is by no means a feature that is only to be found in pidgins; it is a very widespread phenomenon and is dependent on a number of conditions.

Dixon (1971: p. 438) mentions that the lexically simplified mother-inlaw register of Dyirbal makes extensive use of this mechanism, by having, for instance, a single word that acts as adjective as well as adverb, where the standard language has both an adjective and a noncognate adverbal. The most important condition is the loss of morphological categories: "Naturally, languages with less morphological word form variation admit of multiple class-membership more readily than languages wherein several of the distinct word classes are characterized by separate morphological paradigms." (Robins 1964: 229-230).

In English, for example, we find many instances of 1tems that are nouns and verbs at the same time (work, scream, scratch...) or verbs and adjectives (clean, dry...) and the notorious item round to belong to no less than five different classes. It is not so much the phonological shape but the semantic similarity that is of interest, the fact that there are regular correspondences between class-membership and meaning being important for description and grammatical theory. Some of the implications of this will be discussed below.

A second condition is that surface sequence is used to indicate grammatical functions. This means that sequence alone will ideally indicate the grammatical function of any given lexical item and that the same phonetic form used in different surface structure positions will 
fulfill the same function that is fulfilled by morphologically or lexically distinguished parts of speech in other languages.

A third condition is the absence of obligatory semantic information carried by certain parts of speech (e.g. tense and aspect in the English verb).

Pidgins seem to meet all these three conditions and probably to a higher degree than other languages: classes of words are neither morphologically marked nor semantically determined. Only the position in the surface structure gives an indication of their grammatical function. Yet this is not the whole story. Obviously pidgins do not make use of all possibilities of lexical simplification that were outlined above. The three conditions are necessary but not sufficient. Voorhoeve (1961: pp. 241-262) however, seems to assume that they are sufficient and that "there exists a certain relationship between the size of the vocabulary and the complexity of the grammar..." which is optimal in pidgins and creoles: "Now, if we introduce two grammatical rules into our hypothetical language, to distinguish, for example, between verbs and non-verbal words, then this means that the number of words can be reduced by a half."

Further on ( $p .242$ ) Voorhoeve claims that "compared with a model language containing $X$ words and $X$ rules, creole languages have $X / p$ ( $X$ divided by $p$ ) words and $Y+p$ ( $Y$ plus $p)$ rules. The reduction in the number of words is far greater than the increase in the number of rules." It can, however, easily be shown that this is not so, and that creoles and pidgins are minimum - approaching rather than minimum-attaining. Hjelmslev (1938) has made a case for this view. Thus, there are a number of exceptions to this lexical simplification, especially cases where different lexical 1tems used for semantically closely related forms in different grammatical functions, examples being:

law - legal
church - ecclesiastical
bishop - eplscopal
town - urban
mouth - oral

Suppletive 1tems are exceptions in as much as they cannot be predicted by any inherent property and thus restrict the application of certain general rules. The relative importance of suppletive patterns in the lexicon would give an indication of the degree of simplification found in languages. One can expect that pidgins will be simple in terms of such a typology. 
However, indiscriminate borrowing from the target language can increase the number of suppletive patterns considerably. In New Guinea Pidgin, for instance, words such as nesinol (national) urban, lokal and human have been introduced, thereby destroying some of the regular patterns of Pidgin word formation.

Another important application more directly usefull than the establishment of a language typology would be a comparison between creoles, pidgins and their lexically related target languages. The degree to which suppletion, and lexical rules colncide may allow statements about their genetic relationship.

I am thinking here of one case that has been a point of debate for almost a century, namely the origin of Afrikaans. Since the appearance of Hesseling's book on Afrikaans, the 'random confusion of parts of speech' (w1llekeurige deureenhaspeling van woordsoorte) has been regarded as a central argument for the claim that Afrikaans is a creole. However, a comparison of the system of suppletion and lexical rules of Dutch and Afrikaans will show that in Afrikaans:

(1) In almost hundred percent of the instances Dutch models are followed

(11) the loss of inflection did not lead to any change in the function. (Kempen 1964: p. 486). Contrary to Valkhoff's imputations (Valkhoff 1966: p. 193) it is perfectly justified to summarize Kempen's findings as follows: "It is shown here that the use of words in different functions mostly happens according to a clear system of notions (begripsoortelike sisteem) and not arbitrarily as Hesseling and others thought. This book proves that Afrikaaners have remained infinitely more Dutch than people have realized hitherto." (quoted from Valkhoff 1966: p. 193).

A comparison between English and New Guinea Pidgin on the other hand reveals a different picture. The system of notions, lexical rules and suppletion in New Guinea Pidgin is clearly distinct from English. The differences in the distribution of the functions of English and Pidgin bases are far-reaching. Unfortunately, the descriptions that are available for most pidgins and creoles are insufficient at present. One would like to see similar accounts of their lexical systems as exist for Afrikaans. Again, the simplistic conception of the lexicon that is still predominant in most descriptions has prevented progress in this very important field.

Suppletion is one of the reasons why Voorhoeve's formula does not work for creoles. Another reason is that the occurrence of elements is restricted by "their meanings and the ability an element of a given meaning 
has to serve as another form of word." The restrictions are either collocational restrictions or restrictions of a more general kind. An example of the latter category is the traditional distinction between particular and universal terms. (Jacobs 1932: p. 40) "Whereas universal terms are found in both subject and predicate position in well-formed propositions, particular terms are restricted to subject position." (Lyons 1968: p. 338). Another instance is the exclusion of inanimate nominals from subject position. (1bidem: pp. $355 \mathrm{ff.}$ ) Insofar as these semantic restrictions are universals they need not be part of any particular grammar of a pidgin. Restrictions of this kind seem to be very important but relatively little is known about them.

The third reason for not accepting Voorhoeve's formula is his use of the symbol ' $p$ ' for the number of grammatical rules. Obviously $p$ cannot stand for any number. To say that an introduction of 100 , or 50 or even 10 grammatical rules would reduce the number of lexical items to $1 / 100,1 / 50$ or $1 / 10$ respectively is absurd. There are good reasons why $p$ must be relatively small, possibly 3 or even less. Although the number of surface structure functional slots may be larger, it is unlikely that a lexical 1tem can fill all slots at once. In any case, as a result of the recursiveness of grammar, the number of functional slots remains small. A look at some tagmemic analyses of units at clause level will give some indication of what once can expect to find.

Surface function does not determine the meaning of a lexical item. in a straightforward way. There are a number of regularities relating to the semantic content of an item appearing in a certain surface function. Recent discussions in transformational theory have of ten dealt with such phenomena; case grammar in particular has pointed out instances such as:

(1) John broke the window

(11) a hammer broke the window.

Fillmore and his followers take these examples as an indication of the existence of a deep grammar that contains deep cases. Chomsky has pointed out an alternative way of explaining these sentences: the properties of the lexical items inserted in a grammatical function account for the different interpretations.

Another well known case is the 'ambiguity' of lexical items such as thesis refering in one case to the content and in the other to the physical object, (reification in Lakof's terms). McCawley (1970: pp. 130ff.) holds the view that "probably all languages have implicational relationships among their lexical 1tems.", and c1tes further examples. Implicational relationships are still another means of reducing the number of lexical items with separate phonological shape and one may expect such 
phenomena to be widespread in pidgins, not only in nouns, but in all parts of speech. Some examples are the use of the same verb form for active or passive, or that a pidgin that is lexically related to English would not be expected to differentiate between mutton and sheep or pork and pig, this being true for New Guinea Pidgin. There is a very strong tendency in pidgins to subsume under one signe with a falrly wide valeur what in the target languages were two or more signes the sum of whose significations equals the valeur of the pidgin signe.

All these aspects of simplification of the lexicon are neglected by the above formula, yet any language typology that aims at a linguistic definition of pidgin must take them into consideration.

\section{SUMMARY}

At the beginning of this chapter the question was put as to how simplification in language could be defined and measured. I hope that the suggestions put forward above have helped to clarify some of the 1ssues. The central point of my argument is that any simplification is aimed at introducing more regularity into the language. All components of the grammar can be made more regular, but the importance of the various components in simplification differs. The most likely components for simplification to take place in are the morphophonemic component and the lexicon. Whereas most recent discussions of pidgins stress the loss of inflectional irregularities, I have tried to stress the importance of simplification that takes place in the lexicon.

One of the reasons why simplification in the lexicon has been overlooked is the inadequacy of most models of language with regard to their treatment of the lexicon. The notion of an inventory has to be replaced by a lexicon that is highly structured and consists of several size levels. Recent developments in grammatical theory, such as the introduction of lexical redundancy rules in transformational grammar, reflect this need. The next chapter will concentrate on some of the problems that have to be solved by grammatical theory.

One of the most important findings of our investigation so far is that the simplification that takes place in pidgins and creoles is not different in kind from the simplificatory processes that can be found in all other languages and that characterize development of speech in a child as well as the historical development of languages. The difference is one of degree, and further typological research may perhaps provide exact measure for relative degrees of simplification. 
The second finding is that simplification must be overall simplificat1on. There is a certain interaction between the various components of a language, and simplification of one component may result in complicatIon of another. However, there are certain general princlples such as, for example, the fact that the introduction of lexical redundancy rules instead of lexical items is more economical. It is these principles that were often overlooked in studies that concentrated on the simplificatIon of an 1solated component. Many of my proposals are not supported by sufficient data and must be taken as hypotheses about simplification in language rather than established facts. One hopes, however, that the facts, when obtained, will support some of these hypotheses. 


\section{CHAPTER 6}

\section{THE DETERMINATION OF FORM CLASSES IN PIDGINS}

In the previous chapter we dealt with various kinds of simplifications that are found in pidgins. Among these the use of lexical items in more than one function was felt to be of major importance. The fact that multifunctionality is the rule rather than the exception in pidgins has caused a falr amount of uncertainty. The problems that were encountered were of two kinds: problems of description and pretheoretical classiflcation and problems in connection with grammatical theory.

\subsection{PROBLEMS IN PRETHEORETICAL CLASSIFICATION}

Classification is one of the main activities at this stage of investigation. The investigator feels that there is some kind of regular1ty in his data and he wants to account for this in some way. One obvious thing to do is to group together items that behave similarly. At this stage the criteria that serve as the basis of the classification are often unclear or at least not justified independently. They lack theoretical as well as empirical import, and the classification at this stage may undergo drastic changes once they are incorporated into an independently motivated theory. Th1s means that questions as to the 'god's truth' or 'hocus-pocus' nature of the classification are pseudo-questions.

A clear picture of what pretheoretical classification can say about the use of 1tems in more than one function emerges from Bazell (1958: pp. 6-7): "If each of these four linguists took his system seriously from the standpoint of typology, the first would say that English has a large measure of overlapping in 1ts categories; the second that not the categories, but rather their ranges, overlap; the third that English is characterized by a large number of homonyms; and finally the fourth, that 1t is characterized by a large number of defective paradigms." 
For reasons outlined earlier the probability of class-overlap is very high in pldgins if any of the conventional criteria for establishing form classes are applied. These problems in the subcategorization of main classes are encountered in probably all languages (e.g. Bierwisch 1971) and some of the proposed remedies w1ll be discussed later.

When the first scientific descriptions of pidgins were made, the 1deas of American structuralism were generally accepted. This meant that the criteria for establishing classes had to be purely formal, and that any classification had to "begin where lingulstic analysis should begin, with morphological characteristics: first inflection, then wordformation." (Hall 1962: p. 172). Since pidgins have very little or no inflection,morphological criterla will yleld very few classes and syntactic criterla must be applied to establish further classes. Some objections against the definition of form classes by applying certain syntactic frames, as is done by Hall (1962), Voorhoeve (1961), and several other structuralist scholars, have been pointed out by Crystal (1966) and this criticlsm will not be repeated here.

One advantage of a purely formal approach to the classification of lexical items is that morphological and syntactical criteria are normally supplementary. As soon, however, as additional criteria, in particular criterla that involve meaning, are taken into consideration, much of the symmetry disappears. There is a fair amount of discrepancy between the classes ylelded by the various criteria, and problems such as classoverlap are frequent; some 1tems belong to the same class according to semantic criterlabut different classes on the basis of syntactic criteria. A solution that is in agreement with the structuralist principles of classification is to establish new classes such as NV for noun and verb. Th1s suggestion has been made by Hockett (1968: pp. 226ff.) The mer1ts, or rather drawbacks, of this solution are discussed by Palmer (1971: p. 69). An equally possible solution is the one proposed, for instance, by Householder (1971: p.222): "If one says that when a noun and a verb are homophonous and very close in meaning, elther the noun must be a zero nominalization of the verb or the verb consists of some verb-making zero affix, then many difficulties are avolded." Again, there is no principled way of deciding which of the analyses is correct or the best.

Householder and other analysts who support an IP view want to introduce directionality into thelr analysis, that 1s, the 1dea that one 1tem is basic and another one derived. Th1s same 1dea can be found in most treatments of derivational processes. One reason for this is that in many cases derived forms are phonologically distinct; there are certain prefixes or suffixes that are added to a basic form which apparently is pre-existent. In some cases there will be zero differences, the solutions 
that have been put forward in morphological analysis belng well known.

Independent of American structuralism, two French grammarians developed grammatical frameworks to deal with the phenomenon of multifunctionallty, namely Bally and Tesnlère. Both treatments attempt to account for transformational relationships, not so much between sentences, but between signs of smaller size-levels, malnly words. I shall give a summary of their main 1deas. A more detalled analysis of their grammat1cal theorles can be found in Grunig (1965).

The central notion in Bally's book is 'la transposition'. The need for this 'transposition' 1s motivated by the now well known change of function of lexical 1tems: "Un signe linguistique peut, tout en conservant sa valeur sémantique, changer de valeur grammaticale en prenant la fonction d'une catégorie lexicale (substantive, adverbe, verbe, adjectif) à laquelle 11 n'appartient pas." (p. 116, emphasis mine).

Both Bally and Tesnière assume that there are four basic parts of speech: noun, verb, adjective and adverb. For French this distinction can be justified in terms of their morphological properties and in terms of their appearance in some sort of basic (kernel?) sentence. Each of these parts of speech has, in addition to its categorial value, a basic functional value. The relation between category and function, however, is not clear in all cases. Apart from these four categorles we have a number of 'transpositeurs' - words, derivational and inflectional morphemes - that serve as a means of changing the categorlal value of any glven lexical 1tem. "Alnsi les substantives planète et campagne, sans changer de signification, deviennent (fonctionellement) adjectives dans (système) planètaire et (maison) de campagne." ( $p .116)$.

Bally uses the terms 'transponend', 'transpositeur', and 'transpośe' in the sense that is lllustrated by the following scheme:

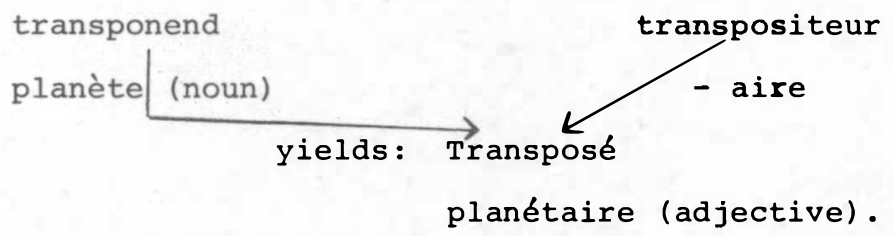

We have seen that the 'transpositeur' can have many different shapes, most of which are falrly unpredictable and therefore have to be specified separately for small numbers of 'transponends'. In the case of pidgins and creoles it is very often the case that the 'transpositeur' is phonemically not realized, $1 . e$. appears as $\varnothing$. This means that no specification of any phonological idiosyncrasies is necessary. Bally 
recognized only one basic function of the noun, that of the subject in a simple declarative sentence. In all other cases it is a 'transposé', thus, for example, in 'conquérir une ville', 'une ville' is a 'transposé'. The 'transpositeur' is a zero which, however, appears under nominalizatIon as in 'la conquète d'une ville: Bally allows for a 'transposition' that changes a sentence into a noun (embedding) but since he lacks a recursive mechanism he is unable to formalize this 1dea within his theory. Whatever the deficiencies of this approach may be (for a discussion see Grunig 1965, or Ruwet 1967), it is obvious that Bally brought up some very important issues, namely the relationship between parts of speech, and the relationship between category and function. The mechanism he developed is able to express the relationship between any word or sentence in one grammatical function and the corresponding 'transpose' in another function. However, as long as we do not know the number of possible functions (this question comes up again in the discussion of a case grammar), and since there are no rules that state all possible relationsh1ps between 'transponends' and 'transposés', we do not have a generative grammar but merely a descriptive tool for analysing surface structure phenomena. It is the restrictions on generative rules that transform a 'transponend' Into a 'transpose' which are of interest to us and which generative grammar should specify. One would like to see what exactly the role of the transpositeur is; is it merely a tool for recategorizing, has it semantic implications and are these implications predictable?

Partly as a reaction against Bally a much more explicit theory of relationships between parts of speech was developed by L. Tesnière. He proposed a category-changing mechanism called 'la translation' which supplemented his categorial grammar. He distinguished between 'translatIon du second degré' (embedding) and 'translation du premier degré - I shall only look at the latter - the mechanism that changes the categorlal value of parts of speech.

Tesniere uses the terms 'translation', 'transféré', 'translatif', and 'transférande' which correspond roughly with Bally's 'transposition', 'transpose', 'transpositeur' and 'transponends' respectively. (Discussion of the differences in Tesniere: pp. $381 \mathrm{ff.})$. Schematically this is rendered by means of a schematised ' $T$ ' standing for 'translation'. (In his notation 0 stands for noun, I for verb, A for adjective, and $E$ for adverb).

An example is the analysis of 'le livre de Pierre' - Pierre's book: 
transféré

A

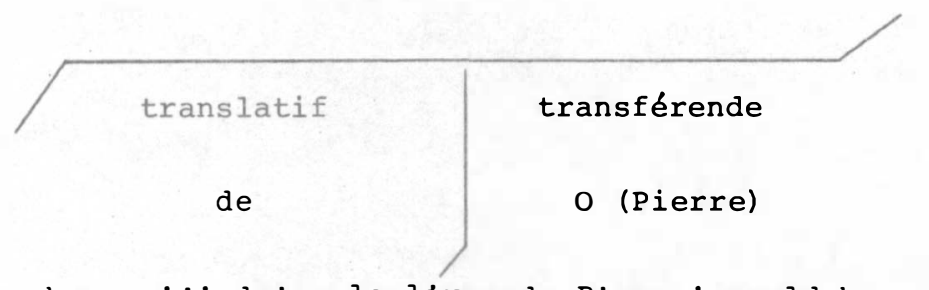

A sentence such as ' $\mathrm{g}$ 'admire le livre de Plerre' would be rendered as:
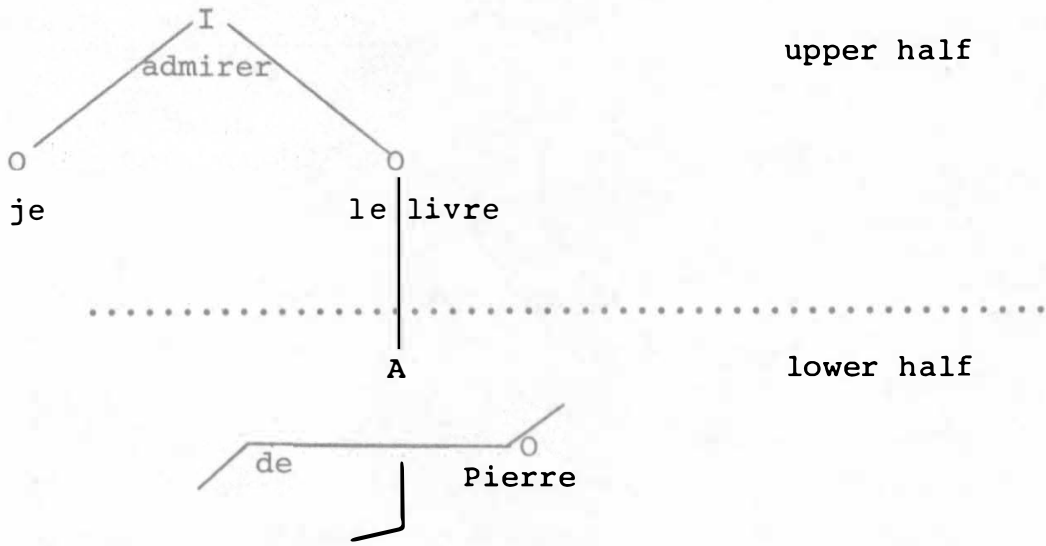

lower half

This 1llustration may help one to understand two kinds of categorial change: that which can take place in the upper half of the tree (1tems change the depth of dependency) and that which occurs in the lower half (1tems change their categorial status without any change in the dependency relations). For the functions of the word hebi in Sranan (discussed by Voorhoeve 1961: p.47) one could find two different solutions. Thus it is possible to say that in simple declarative sentences 'hebi' ${ }_{1}$, (verb) would be in top position, 'hebi'2, (noun) in the second and 'hebi' 3 ', (adjective) in the third.

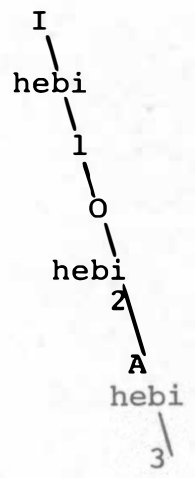


On the other hand, one has to ask several questions in connection with this solution. What is the justification for calling a lexical 1tem Inherently e1ther a noun or a verb? Are 'hebi'1,2,3, inherently nouns, verbs and adjectives respectively or are they 'transférés' by means of a zero 'transférende' as lllustrated by the following diagram?

transféré

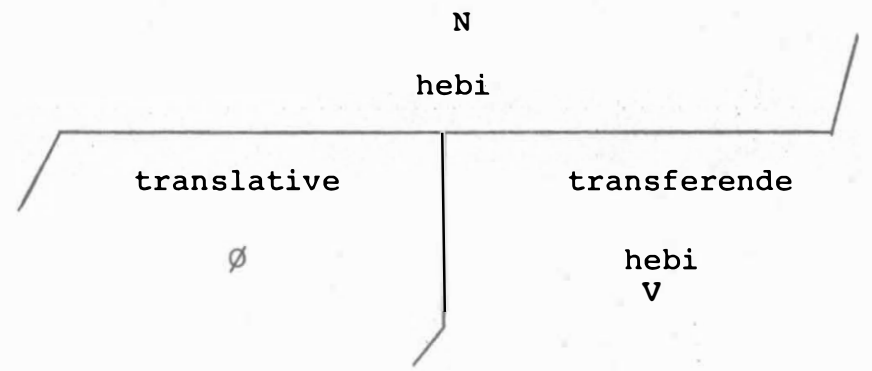

In other words, is 'hebi' one lexical 1tem that appears in three different functions, or is it three 1tems that happen to have the same phonological shape? The reason for the confusion is the same that appears in Nida (Identification of morphemes (1969), especially princlples 8 and 9), namely the fallure to distingulsh between change in category without semantic consequences and that with semantic consequences. It is certainly not enough to say that the forms are phonologically 1dentical, since one must then specify the semantic implications. The role of the translatif can be seen as a mechanism that adds certain semantic features (e.g. causative, state) and certain phonological features (both sets of features may be zero), and which may result in another part of speech, that is, change the grammatical features, but not necessarlly. These changes (semantic, grammatical and phonological) are independent of each other in princlple although the existence of regular correspondences between them will simplify the grammar considerably; this simplification will mean an increase in major grammatical rules and a resultant drastic decrease in lexical 1tems. Tesnière does not specify these rules; he falls to formalize the relation between grammatical and semant1c change. For the same reason that was given in the discussion of Bally, his grammar is not generative.

Overlapping word-classes were a problem that was widely discussed, not only in American structuralism. The discussion came to an end at the beginning of the transformation-generative 'age'. Earlier transformational accounts treat the lexicon as basically a list of 1tems that are hierarchically subclassifled. Concepts, such as 'noun' and 'verb' are 
Introduced as some kind of 'primitives', their place in a grammatical theory being taken for granted. However, when we ask how the categorles of this grammar are related to reality, especlally regarding the properties which are common to all 1tems subsumed under a category, we do not get satisfactory answers: "If we ask what a SENTENCE 1s, the grammar points out to the constituents NOUN PHRASE and VERB PHRASE; we ask about the category VERB phrase, and the grammar points out to the VERB and NOUN phrase; and so on. It is only in terms of the grammar as whole, if at all, that we are able to gain some information about the properties which characterize members of categories, and this information can be gained only indirectly and by inference. In fact, whatever structural information is gleaned from the grammar could almost as easily have been gained through inspection of grammatical sentences themselves. The grammar 1tself is neutral concerning the properties of members of categories; that 1s, members are not assigned to the same category because of shared properties (although some members of the same category may accidentally have properties in common); rather, categorles are set up for the sole purpose of getting from initial symbol to terminal symbol as simply as possible. To be sure, some restrictions are imposed upon the way in which the symbols and rules may be employed, but these restrictions do not influence the essential arbitrary manner in which elements with the most diverse characteristics are lumped together in the same category." (Hawkey 1970: pp.206-207). One of the reasons why the problem of overlapping classes was of no importance in the initial stage of generative grammar was that the classes that functioned in the grammar were purely formally determined. One of the critics of the first model of transformationalgenerative grammar, Voorhoeve, objects to the large amount of multiple listing and points out the unsatisfactory character of a theory that cannot handle the relationship between certain semantically related lexical items that appear as different parts of speech in the surface structure. He discusses in detall one example from a creole language, Sranan. The form hebi (related with English heavy) can function as noun, verb, and adjective. Voorhoeve (1961: p. 48): "The least we may expect is that 1t (=transformational analysis) will be able to describe the transformations of the word hebi in the three examples above and also, if Chomsky's promises hold good, explain them. We find, however, that it is powerless to help unless we work with symbols representing the possibilities of combination with other words....Transformational analysis can only give a solution for those transformations which are in some way recognized by the word-form (w1th the ald of bound morphemes)."

It was belleved that elements such as $\mathrm{N}$ and $\mathrm{V}$ could be justified in terms of their transformational properties. The incorporation of a 
semantic component into the later model drew the attention to overlapping classes and semantically related 1tems in different classes. It was felt that a mere listing in the lexicon would treat regular properties of language as irregularities; only when the semantics of these 1tems is taken into consideration will they be treated as different from mere homophones. The importance of multifunctionality is that it is a means of simplifying language, a means of replacing lexicalization by rules. To list 1tems, in the description of a pidgin, without pointing out their regular connections would be tantamount to overlooking one of the main sources of the simplification of language: "The functional possibilities of Pldgin bases are fundamental to the grammar of Pidgin." (Wurm 1971a: p. 8). It is for this reason that the two most read1ly avallable transformational generative accounts of pldgins and creoles, Ba1ley (1966) and Hooley (1962), are totally inadequate as descriptions of these languages. Balley (1966) certainly does not provide "a badly needed '1deal-type' description of creole" (De Camp 1971a: p. 32); by neglecting the problem of word-classes, she excludes one of the most interesting problems of creoles and pidgins from her description: "The setting up of the word classes has been motivated purely by consideration of expediency, that is to make the description possible. It is therefore not necessary to make lengthy definitions of word class problems."

(Ba1ley 1966: p. 20).

\subsection{FORM CLASSES IN GENERATIVE THEORY}

In the pre-theoretical stage, much of the classification was justified by appealing to such principles as neatness and simplicity. A grammat1cal theory, however, has an additional alm, namely to make important generalizations about language. The simplicity of some pretheoretical classifications - especially those that excluded semantic criteria - is mostly due to the small number of criterla that served as the basis of the classification. We have seen, that, although the pattern that emerges can be very neat, Important generalizations about language, generalizations that not only refer to the synchronic system of language

but also to diachronic developments, cannot be made, in change in grammatical function, expansion and narrowing of the functional ranges of lexical 1tems are common processes in historical change. Diachronic generative treatments such as that of King (1969) have not considered this possibility, although there are extensive discussions in earlier standard textbooks such as Paul's Prinzipien der Sprachgeschichte. I would suggest that multifunctionality is a process that is common to all languages both diachronically and synchronically and that this 
tendency is perhaps further developed in pidgins than in other languages. An adequate treatment of this phenomenon is one of the tasks now facing grammatical theory. How recent discussion in generative theory has approached this problem will be dealt with in the next paragraph.

Even a superficlal look at the development of transformational grammar is enough to show that there has been a falr amount of uncertainty and contradiction concerning the status of symbols such as N, V, Adj, Adv. These categorles were taken over almost wholesale from earlier grammatical work and are the main components of the rules of early transformational grammar. In Chomsky's 1957 model it was not questioned that these categorles are parts of the grammar and that all transformations operate on strings containing such elements. Some other elements such as to, do, have were introduced transformationally and they were apparently not related to the above categories; their status in the model is not very clear.

Although there were no restrictions of the kind that would exclude rules such as:

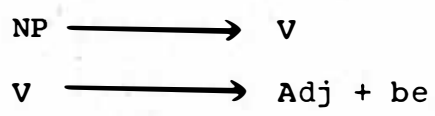

no use is made of them. The reason is probably that there was no necessity for such rules since considerations of meaning played a very subordinate role. The main justification for the symbols in a 1957 grammar is that transformational rules apply most readily to structures that contain these elements and that they enable the grammarian to make important generalizations about the relatedness of grammatical construct1ons, In particular the active-passive, statement-question and statementcommand relationship. Given a structural description and a set of transformational rules the grammar will generate an infinite number of grammatical sentences.

Chomsky (1957) rejected the 1dea that there is a symstematic semantic relationship between underlying phrase marker, kernel and transform: "Not even the weakest semantic relation (factual equivalence) holds in general between active and passive." (1b1dem: pp. 100-101). By defining the grammatical categorles and their relationships in purely formal terms, the model avolds many problems. The criterla for the establishment of categorial symbols are formal and syntactic transformations that operate with them are of great generality.

The weak point of this early model was the lexical component. It was concelved of as a list of 1tems that could be inserted into the lowest point of derivation. It was further assumed that the lexicon was 
characterized by hierarchical subclassification and that a category symbol such as $\mathrm{N}$ or $\mathrm{V}$ was the starting point of this subclassification.

The main reason for subclassification was syntactic: the transformational potential of lexical 1tems served as the basis for establishing subclasses. Th1s hypothesis was tested in deta1l for the German language by writers such as Motsch (1971), Blerw1sch (1971) and Steinitz (1971).

Blerw1sch (1971: p. 47) sees as the alm of such a subclassification "um alle syntakt1schen Bezlehungen $z w 1 s c h e n$ Verben und 1hren verschiedenen Objekten und Ergänzungen zu beschrelben." A look at some results of Blerwisch's attempt shows the inadequacy of hierarchical subclassification (in particular his proposed subclasses on pp. 82-85). There is a considerable overlap among the members of the subclasses. Many verbs have to be listed twice or more and the important intultion that, for Instance, fühl $\left(c l a s s V_{l c}\right)$ and fühl $\left(V_{r c}\right)$ are closely related cannot be expressed. The Importance of Blerwisch (1971) lies in the fact that he has pushed a proposal as far as possible and has thus la1d bare 1ts deficlencles.

The same objections just made against a syntactic hierarchical subclassification can also be made against a semantic hierarchical subclassification; such a classification, in fact, being developed not long after Blerwisch's proposals were first published. Thus, Katz and Fodor (1964: p. 494) propose hierarchic trees for the subclassification of lexical 1tems. Again, this means that the same semantic marker (for example (male) in bachelor) w1ll appear at different points of their hierarchical trees (p. 496) and the relation between 1tems becomes unclear in many cases.

Both the syntactic and the semantic subclassifications were made under the assumption that primary categories such as $\mathrm{V}$ and $\mathrm{N}$ should be the starting point of any classification. This is surprising since the categorles were not motivated by any properties common to all members in the first place. Nelther Blerwisch nor Katz and Fodor consider the implications of the multiple class membership (categorial value) of many lexical 1tems. Katz and Fodor would show at least that the phonet1c shape can be identical (for example in play, p. 494) but it is difficult to see how any hierarchical subclassification can account for the close semantic similarities.

It is for this reason that transformational-generative accounts after the appearance of Chomsky (1965) favoured a feature notation. By isolating syntactically and semantically relevant features and accommodating combinations of features under a cover symbol (complex symbol) one could eas1ly avold multiple class membership conditioned by crossclassifying features and one could, at the same time, show semantic 
similarities and dissimilarities in terms of feature combinations. In addition, the metatheoretical criteria of simplicity and generality were satisfied to a larger degree than in the earlier model.

The most important notion of Chomsky (1965) is that of 'deep structure' as a level of analysis. We are concerned with the following aspects of this level: that it is the place where all lexical insertion takes place, where at the same time all categorial information is given and where all other information that is relevant to semantic interpretation is found. The categories $\mathrm{V}, \mathrm{N}$ and Adj. are some of those appearing in the 1965 deep structure.

Again, as in the case of the argument against hierarchical subclassification, one can object to the Chomskyan notion of a deep structure on the grounds that important generalizations cannot be made. At the basis of most grammatical discussions that followed lay the fact that the classes yielded by syntactic criteria do not necessarily coincide with the classes established on the basis of semantic criteria. If the categories found at the level of deep structure could express important correspondences between syntactically related sentences, they often falled to indicate the relationship between semantically related (synonymous) constructions. A typical example of the arguments against deep structure is that of Lakoff (1968). Lakoff's main point is that, in order to relate certain synonymous constructions (for the discussion of synonymy in general and that of Lakoff (1968) in particular see Coseriu: pp. $34 \mathrm{ff.}$ ) by independently motivated rules, one has to postulate a deep structure without a category 'instrumental adverb'. This category, Lakoff 'claims', can be derived from a verb 'to use' in an even deeper structure. Although Lakoff's deep structures are far more removed from the surface structure than Chomsky's he still makes use of categorial information. It is not at all clear why there should be such a thing as a deep structure verb, why instrumental adverbs should be derived from these deep structure verbs and not vice versa, what the status of deep structure verbs in grammatical theory is, or whether such universals must be formulated for languages which may not have a surface structure verb use but only instrumental adverbs. Since Lakoff does not provide any rules to govern how deep and surface structures could be related under his assumptions, the proposals cannot be regarded as empirical claims. Even the theoretical justification - more generality - does not seem conclusive: it is conceivable that a number of generalisations about grammatical structures are lost. Moreover, what is the use of introducing deep structure elements that are deleted before they appear in the surface structure and furnishing them with categorial status? If it is true that grammatical categories are justified by the 
role they play in transformations, any prior decision as to the categorial status of 'very deep' elements is arbitrary. It is by no means obvious that the path from a surface structure category to the meaning should go via deep structure categorles at all. What is the empirical justification for postulating the following deep structure verbs: declare, happen, cause, do and come about in the sentence Floyd broke the glass? (Example from Bach \& Harme 1970: p. v111). It seems to be more adequate to say "that the distinctions between such parts of speech as nouns, adjectives, and verbs have no direct representation as such in the base, but are the results of transformational developments in one or another language." (Bach 1970: p. 121).

However, if the restrictions on transformations are such that it is possible to change or introduce categorles at some level between semantics and surface structure, there is no way of preferring Bach's view to any other view concerning the categorlal status of deep elements. It is equally possible to adopt Chafe's view that there are two categorles in the semant1c structure, namely nouns and verbs: "My assumption w1ll be that the total human conceptual universe is dichotomized initially Into two major areas. One, the area of the verb, embraces states (conditions, qualities and events) the other, the area of the noun, embraces 'things' (both physical objects and reifled abstractions)." (Chafe 1970: p. 96). Chafe assumes that these semant1c nouns and verbs are typically reflected as surface nouns and verbs, although sometimes in a 'distorted way'. H1s powerful post-semantic rules can easily account for eventual distortions.

Chafe seems to suggest that our knowledge of the categorlal status of elements in the semantic structure can be recovered by introspection. The same introspection would suggest in his opinion the knowledge..."as to which 1tems in his language are derived and which not. The independence of this knowledge from surface considerations (such as the presence of a suffix) is suggested by the fact that we know the process open to be derlved from the state..., even though no suffix is present, but even more by the fact that we evidently know that tired (as in Michael is tired) is basic and (tires as in Michael tires easily) derived from 1t, even though the surface evidence - the fact that it 1s tired which has a suffix - perversely suggests the opposite." (Chafe 1971: p. 122). I am not at all convinced that intuition alone is a criterion that can declde on such 1ssues (cf. Rob1ns 1959: p. 118): "Noone would seriously support the view today that linguistic analysis should be based on categorles taken from sentiment linguistique or the native speaker's intultions." This is, however, precisely what is often done in recent transformational-generative work. "Judgements about the membership of 
words in part-of-speech categories.... represent the simplest kind of judgement that can be eliclted from fluent speakers of the language." (Langendoen 1971: p. 12 ). There are many cases where the dec1sion as to what is derived from what is by no means as easy as in Chafe's sample.

The following discussion is still concelved in terms of such categorles as $\mathrm{N}$ and $\mathrm{V}$; later thelr status w1ll be attacked on other grounds.

I shall use an example to demonstrate the difficulties involved in the use of grammatical categories; the different ways in which the concept 'I am hungry' can be expressed in the surface structure. In this case it is impossible to decide whether the concept expressed by 'hungry' is inherently a verb, noun, or an adjective. It is, however, exactly this information that is needed if we operate with such terms as 'derivation', 'transposition' and 'translation' (Tesnière). In the Aspects model of generative grammar, as well as in Chafe's model, this information is needed. It is assumed that in some deeper structure the categories are attributed to lexical 1tems, but the discussions do not make this very clear. In Chomsky (1965: p. 65), for Instance, 'sincerity' Is introduced as a deep structure element ' $N$ '. Later (1b1dem: p. 186), 1t is sald that $1 \mathrm{t}$ is the result of a transformational development, $1 . e$. that 'sincerity' is derlved from a deeper structure 'someone is sincere'. It seems that much of this decision is due to the existence of an actual adjective 'sincere' In the English language, and not to any 'semantic' considerations, yet if that is the only reason that sincerity is sald to be derived from an adjective, or rather to be a sentence containing an adjective in the deep structure, it is not very convincing. One could carry the argument further and claim that there is a still deeper structure where the adjective 'sincere' is derlved from a verb, and so forth. The example on the following page will 1llustrate this. 


\begin{tabular}{|c|c|c|}
\hline Compare: & English & I am hungry \\
\hline & & $\mathrm{N}$ cop Adj \\
\hline & Afrikaans & Ek is honger \\
\hline & & $\mathrm{N}$ cop N? \\
\hline & New Guinea Pidgin & M1 hangre \\
\hline & & $\mathrm{N} \quad \mathrm{N} ?$ \\
\hline & Latin & esurio \\
\hline & & $\mathrm{V}$ \\
\hline & German & Ich habe Hunger \\
\hline & & $\mathrm{N} \quad \mathrm{V} ? \quad \mathrm{~N}$ \\
\hline & & Ich bin hungrig \\
\hline & & $\mathrm{N} \quad \mathrm{cop} \quad$ Adj \\
\hline & & Mich hungert (es) \\
\hline & & $\mathrm{N} \quad \mathrm{V} \quad$ pro-element? \\
\hline & $\begin{array}{l}\text { French Creole } \\
\text { (Mauritian) }\end{array}$ & Mo fa1m \\
\hline & & $\mathrm{N} \quad \mathrm{N}$ \\
\hline
\end{tabular}

To simplify the following point I am assuming that there are only three elements in the deep structure: one corresponding to the 1dea of 'first person', one to the concept of 'hungry' and one to 'present'. I am thus assuming, for the time being, that at one stage the deep structure for all the above sentences are 1dentical; the difference in the surface structure is due to different groupings of the three basic concepts and to differences in the association of these groupings with parts of speech.

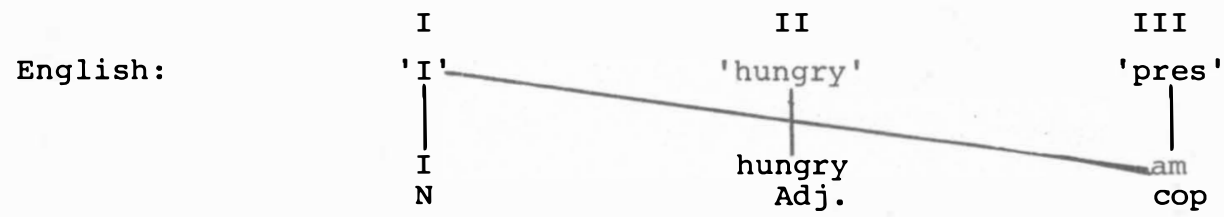

which becomes, after permutation transformation, 'I am hungry'. 
Afrikaans :
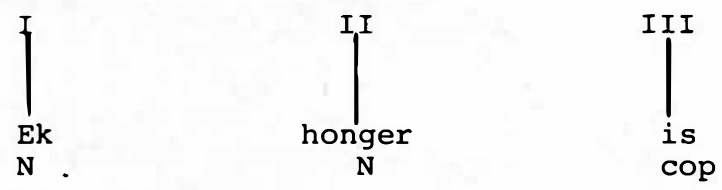

.

It is very difficult to speak of 'honger' as a noun, the justifications being its morphological properties and the existence of an adjective 'hongerig' in Afrikaans; there is, however, a second construction in which 'honger' is more definitely a noun:
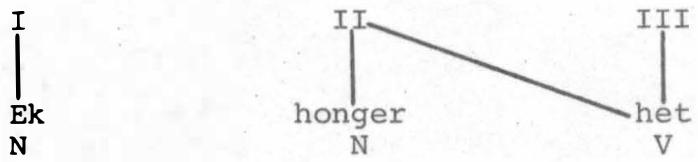

The permutation transformation will give: 'Ek is honger' or Ek het honger'. (A similar example is the German 'Ich habe Schuld' vs. 'Ich bin schuld' = 'I am guilty, I am to blame')

New Guinea Pidgin
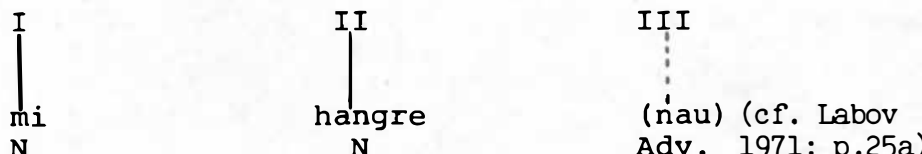

(I justify my calling 'hangre' a noun in the same way as I did with the Afrikaans construction. I suppose it would make more sense to leave it unspecified; the categorial information seems to be irrelevant to subsequent transformations)

Latin:

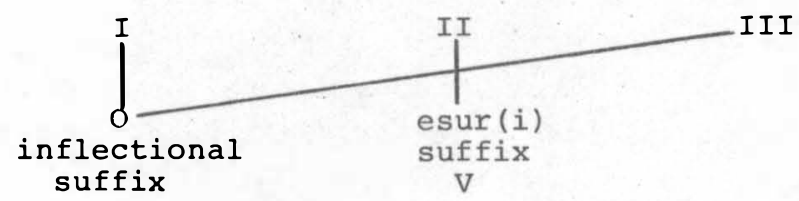

4

German :

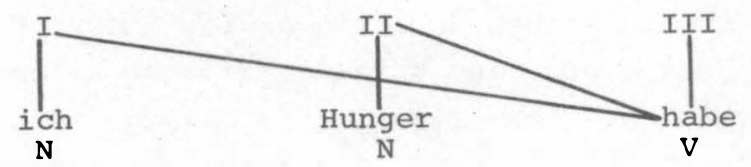


German :

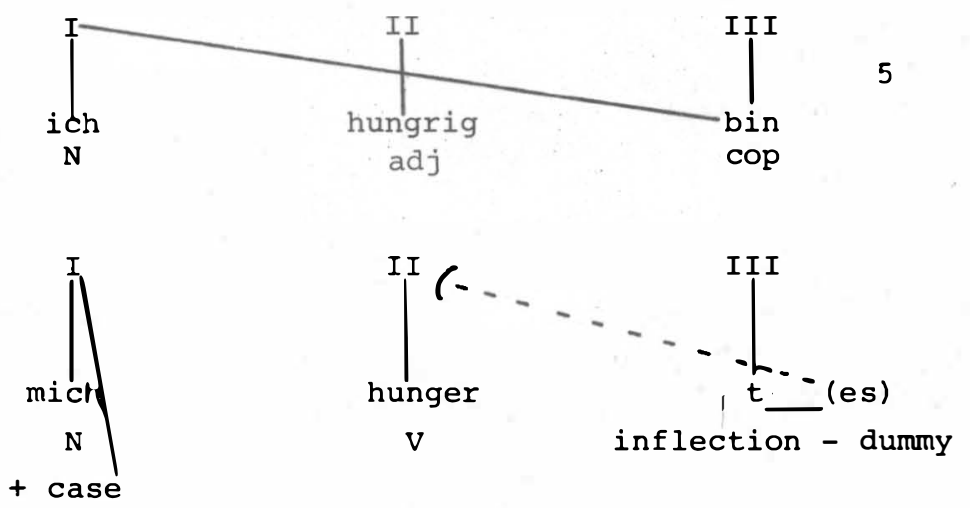

The German example 1llustrates how the same meaning can be realized in very different forms in the surface structure, involving different parts of speech in each case. A completely different question from that concerning grammatical categories suggests itself when one looks at the analyses of the sentence 'I am hungry', namely, which of the possibilities is the simplest? Why is 1t necessary for some languages to realize the same meaning in several different surface structures?

One possible answer is that it is more economical to have only one possible surface realization. This means that, if we assume that pidgins are simpler than other languages, we expect them to have only one. Th1s seems to be the case for many pldgins, but the data are not sufficient to make any general statement.

One hypothesis about the degree of simplification is that languages are simpler when the same semantic information is not carried by more than one surface-structure phonological form as, for example, when 'first person' is expressed by a pronoun only. The schemes drawn on the previous pages reflect this type of simplification. Thus, if I give a value to each line, 1 to the vertical lines and 2 to the diagonal ones, whilst Ignoring the optional lines - we get the lowest total value for New Guinea Pldgin (a pldgin) and the highest value for German ( 2 and 7 respect1vely). One may suggest analyses such as this as a further line of investigation. As 1t stands it is a very shaky proposal and the variables Involved are not controlled to a degree that allows any cla1ms. It seems at first sight that simplification in pidgins means the loss of diagonal lines, that is, loss of cross reference between parts of speech.

The above analysis may help to clarify my earlier point that semantic elements can be assoclated with any part of speech. I do not think there is any justification for having parts of speech in the semantic structure. 
Categorial information is needed in other components of the grammar, especially the transformational component; this will be discussed later. In any case, we have seen so far that the surface categorization is almost completely independent of semantic classification. On the other hand, once a certain surface class is established it can predictably receive additional semantic information. In German, for instance, the concept of 'first person' is carried by a part of speech that may be called 'noun' (or pronoun) whilst in Latin this information is carried by an inflectional suffix. This casts doubt on the claim that 'noun', 'verb' or 'adjective' are substantive universals of a grammatical theory. One may rather assume a formal universal to the effect that the parts of speech which are used in syntactic transformations in any language result from the way in which semantic information can be realized in 'chunks' in the surface structure of that language. cf. Blerwisch (1970: p. 182): "What is learned during the process of language acquisition is not semantic components, but rather their particular combination in special concepts, and the assignment of phonemic forms of morphological properties to these concepts."

Much of the insistence on the universal status of 'noun', 'verb' and other parts of speech may be the result of a tradition in grammatical thinking rather than a reflection of actual facts: Dixon (1966: p. 177): "It is interesting to speculate whether anything resembling 'noun' would have been set up if we had had no continuity of grammatical descriptIon since Thrax's time, or if a genetic relationship between Greek, Latin and English had not been recognized. This question is even more relevant for some of the other traditional categories that are used to describe English". I do not propose to discuss this question in much more detall. I wanted primarily to show that it is necessary for a grammatical theory to define its theoretical terms in a way that is not exclusively dependent on the intuitions of the investigator but that makes provision for empirical checks. It is for that reason that $I$ am not convinced that elther Chafe or Bach have made any helpful suggestion towards the solution of the problem of parts of speech. As long as the restrictions on transformational and postsemantic rules are not specified, the empirical content of their proposals is very low. This applies to any theory that assumes some kind of universal base with universal categories. (cf. Matthews1970: p. 186). Both the 1dea of a universal base, and the related 1dea of substantive universals, have occupled an important place in the discussion of the transformational-generative model. That the structures underlying kernel sentences may be universal was first suggested by Lees in his review of Syntactic structures. (p. 405). 
Whereas Bach (1962: p. 50 footnote) leaves the question open: "I am 1gnoring here the 1mportant question that at least some of the designations for syntactic classes will be supplied by general linguistic theory, 1.e. by a set of universal categorles like 'noun', 'verb', and so forth," Blerwisch (1966: p. 119) supports the 1dea of such universals: "Das führt zu der Annahme, dass die syntakt1schen Grundelnhelten wie Subjekt, Prädikat, Objekt, Verb, Adverb, Nomen usw. substantielle Universalien sind. Dem Grundinventar der phonologischen und semantischen Merkmale entsprechend gibt es dann auch elne Menge syntaktischer Kategorien, aus der jede Sprache elne charakteristische Auswahl trifft." (cf. also Chomsky 1965: p. 28).

Although it is possible to postulate such universals and derive the surface structures of different languages by different transformations, this is not a very helpful approach, especially since the justification of these universal categories is by no means evident. The alternative is to look first for empirical evidence of the conditions underlying the establishment of surface-structure parts of speech and subsequently for possible universal conditions. Syntactic categories would then be defined by the grammar 1tself rather than belng preexistent (cf. Crystal 1966). "Da alle syntakt1schen Kategorlen s1ch 1m Regelsystem definieren und fur alle Sprachen andere Regelsysteme bestehen, kann es streng genommen kelne sprachlichen Unlversalien der Art 'Substantiv', 'Adjekt1v' usw. geben. Alle solchen Klassen sind definiert durch das syntaktische System elner Sprache. Dle hler verwendeten Abkürzungen sind nur lt1lfsm1ttelzum ungefähren Verständn1s. W1ll man die Klasse der deutschen Adjektive mit Adjektiven elner anderen Sprache vergleichen, so kann das nur helssen, dass man die Plereme der anderen Sprache danach klassiflziert, ob sie deutsche Adjektive übersetzen oder nicht. Nur so wird die Rede von Adjekt1ven in elner anderen Sprache überhaupt sinnvoll. Die Stellung von Positionen in verschiedenen Sprachsystemen Kann nur ähnlich nicht gleich sein." (Heringer 1970: p. 77).

The criteria for the establishment of classes are not yet known and their discussion is still a central theme in grammatical theory (cf. Lingua 17, the volume on word classes). It seems, however, clear that any criterion, to be of any empirical value, must be justified in syntactic rather than semantic terms. Surface-structure function and transformatIonal potential of 1 tems seem to be two promising criteria and both have been widely applied in tagmemic and transformational-generative analysis respectively. The two criteria are not mutually exclusive. Most transformations can be expressed in terms of processes that operate on functional notions such as subject or object rather than on categories such as noun and verb. In fact, the principal transformations that involve nouns and verbs are agreement transformations. 
I suggest that lexical 1tems should not be treated as belonging to more than one class; but rather as having different degrees of functIonal and transformational possibilities; one might call them syntactically expanded and syntactically restricted classes. A scale could besigned on which the degrees of expansion for each individual language can be inserted. This would reflect the intultively important fact that suppletion is not only found in inflectional paradigms but to varying degrees in the organization of derivational paradigms as well. My hypothesis would be that pldgins are very high up this scale. A recent proposal by Chomsky (1970: p. 190) w1ll serve as a basis for further discussion of functional possibilities of lexical items.

\subsection{DERIVATION VERSUS CROSS-CLASSIFICATION}

One of the problems in the classification of lexical items was their classification in terms of grammatical categories since it has become obvious that important generalizations about semantically and phonologically related 1tems are lost by dolng this. There are two kinds of approach to this problem; the first derives an 1tem belonging to one category from another more basic 1tem from another category. Th1s is what happens in those cases where related 1tems are explained by derivational processes. The second approach would say that the 1tems are 1dentical at one level and different at another; the 1dentity would concern their lexical properties, the differences their functional ranges In grammatical constructions. Cf. Halliday (1966: p. 151): "strong, strongly, strength and strengthened can all be regarded for this present purpose as the same 1tem; and a strong argument, he argued strongly, the strength of his argument and his argument was strengthened all as instances of one and the same syntagmatic relation. What is abstracted is an 1tem strong, having the scatter strong, strongly, strength, strengthened, which collocates with 1tems argue (argument) and tea...."

I shall argue agalnst both these approaches. One of the 'residual problems' in Chomsky (1965) was the treatment of 'derivational processes' In language. "Derivational processes create much more of a problem for any sort of generative (that is, explicit) grammar than do inflectional systems. This results from the fact that they are typically sporadic and only quas1-productive." (Chomsky 1965: p. 184). The relation between a derlved 1tem and 1 ts source is 1diosyncratic and quasi-productive in two ways. First, they are different phonologically in a way that is often not rule-determined; given the source one cannot predict automatically the derived word. In languages such as English there are 
numerous examples:

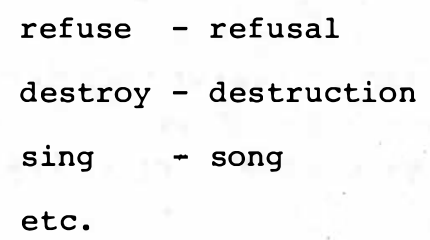

This kind of idiosyncracy, which is one of the main arguments for a lexicalist view of nominalization, is virtually non-existent in pidgins and most creoles. In these languages two or more derivationally related 1tems are either phonologically identical or related by general phonological rules. The descriptive mechanism for the phonological part of the derivation can be much simpler, this being a direct reflection of the degree of simplification found in these languages.

The second kind of 1diosyncracy has its source in the semantic properties of related 1tems. This is at least partly predicatable in as much as membership of a category verb in English, for instance, will associate tense and time information with a lexical 1tem. On the other hand, at least some of these semantic properties cannot be predicted and have to be specifled in the lexicon.

One hypothesis about the predictability of semantic features which is frequently encountered is the assumption that grammatical categories have some kind of inherent meaning, a distinguishing semantic feature such as substantiality for a noun, and quality for an adjective. This proposal was put forward by Weinreich (1966), among others, and rejected by Katz (1967: p. 192). Although 'nounness' often has certain semantic correlates, they are not general and predictable and therefore unsultable as lexical redundancy rules. There is another, more sophisticated, version of this 1dea presented by Chomsky (1970: p. 190): "Let us propose, then, as a tentative hypothesis, that a great many items appear in the lexicon with fixed selectional and strict subcategorization features, but with a cholce as to the features associated with the lexical categories noun, verb, adjective. The lexical entry may specify that semantic features are in part dependent on the choice of one or another of these categorial features." (emphasis mine).

I believe that this hypothesis is basically correct except for its unnecessary stress on lexical categories. It is not so much the lexical category that determines the meaning but the surface function - along with collocational restrictions. Let me illustrate this with an example of multifunctionality in Afrikaans: 


$\begin{array}{ll}\text { Afrikaans } & \text { Gloss } \\ \text { kês } & \text { curd } \\ \text { die melk is kês } & \text { the milk is curd }\end{array}$

Structure of the sentence:

$\begin{array}{ccc}\text { subject } & \text { copula } & \text { predicate attribute } \\ \text { die melk } & \text { is } & \text { kês }\end{array}$

In the lexicon kês would be specifled as (+ predicate attribute) rather than (+ adjective), the main reason being that kês does not share many of the properties of what are normally considered to be adjectives (being able to appear in attributive position, allowing for degrees of comparison). Kês would get other additional features such as (- subject) and (- count). Again, a feature (t noun) would not be very useful, since kês does not have some of the features that are assoclated with other 1tems that are generally regarded as nouns.

The rules of interpretation that interpret kês as quality rather than state would be l1ke the rules that Chomsky (1971: p. 191) proposed for semantic interpretation, e.g.: "Thus one rule (probably universal) w1ll stipulate that for verbs of action, the animate subject is interpreted as the agent, etc." I shall give some more examples to lllustrate this; further assessment of thelr correctness and theoretical consistency is necessary and the descriptions are rather tentative.

The lexical 1tem anka in New Guinea Pldgin is related to English anchor. It can appear in a number of functions (these are 1talized in the following functional frames):

$$
\begin{array}{ll}
\text { subject } & \text { predicate attribute } \\
\text { subject } & \text { predicate object } \\
\text { subject } & \text { predicate } \\
\text { subject } & \text { predicate object }
\end{array}
$$

and possibly others.

The four frames represent the strict subcategorlzation in terms of surface functions. In addition to this information we need statements about the collocational restrictions and their influence on the semantic interpretation. Some of the rules would be: 


For (1) the predicate attributes must relate to the shape,
material and so forth of the anchor
For (11) the subject must be animate
For (11i) the subject must be a ship or human
For (1v) the subject must be animate and human; the object
must be animate.

Further rules would be of the kind 'if anka appears in frame (1) it must refer to the physical properties of an anchor, if it appears in (111) or (iv) it will refer to the function of an anchor, 1.e. to cause to stay in a place.

Another example from the same language can be described in the same way. Tambu (English taboo, forbidden) can appear in the following frames: subject predicate object subject predicate object

The additional restrictions on collocation would specify that the subject in (1) is human and the object a non-physical object; in (11) the subject is human and the object is concrete and optionally human; for (111) that the restrictions for object in (11) are identical to the restrictions for subject in (111); for (1v) that subject is human and that predicate attribute refers to human qualities.

If some of these rules for interpretation are - as Chomsky expects universal rules of interpretation, they could appear as redundancy rules at the beginning of the lexicon and need not be specified for every individual lexical item.

The evidence from the few examples just given seems to support a view that considers grammatical function as central. Grammatical function is independent of lexical category, and the relation between the two is not necessarily one of determination, as is generally assumed in transformational-generative grammar. The bridge between grammar and lexicon is not constructed out of either traditional parts of speech or those introduced by the base rules, but from the set of basic functions into which lexical items can be inserted. These basic functions are subject, predicate, complement, and adjunct, and possibly others. They are all surface functions and dependent on individual languages. There will be recursive transformations that operate in terms of these surface functions. 
The functions cannot fully predict the class of 1 tems that can be inserted into a functional slot. The functional potential of items must be lexicalized and varies from language to language. It is partly dependent on semantic properties in a way which is not yet well understood. In the 1deal case, given the semantic properties of an 1tem, 1ts functional range should be predictable. The large degree of suppletive patterns in both inflection and derivation (in the traditional sense) destroys the regularities that apparently are much more marked in pidgins and that reappear when a language is imperfectly learned. It is not clear to me what the function of suppletive patterns in grammar is, but they are present in at least the majority of languages. A language typology based on the criterion of suppletion would most probably reveal that pldgins have less than other languages. Extending the conclusions of Voorhoeve (1961) about the interrelationship between grammar and lexicon, one can suggest that the most likely result of the use of suppletive forms is a reduction in the number of grammatical rules, greater positional freedom and more stylistic transformations.

Both inflectional and derivational properties of lexical items can be described as paradigm (cf. Robins 1959: p. 125). The task of the grammar would be to describe how the functional position of a lexical 1tem affects 1 ts semantic and phonological properties. Both derivation and inflection are not so much processes as phenomena that have to be explained in terms of the discrepancles between grammar and lexis. Derivation, in particular, should be seen as an account of the functional possibilities of lexical 1tems. It is not so that 'verbs' are derived from'nouns' by means of grammatical (transformational) rules, as recent treatments of languages in generative terms have attempted to maintain; rather they are only indirectly related via shared lexical properties. The lexicon enumerates and organizes a set of lexical 1tems which are inserted into functions generated by the grammar.

Again, these are mere proposals that need to be formalized and tested rigorously before any clalm about their validity can be made. They are the result of the considerations that led to the rejection of the parts of speech and relatedness in earlier transformational-generative grammar. Chomsky's (1970) suggestions about a treatment of related lexical 1tems is certainly one of the major improvements on earlier models. However, as I have tried to point out, they create difficulties in relating the lexicon to the grammatical base component.

Most of the discussion in the last two chapters has been concerned with the lexicon. Its internal organization and 1ts relation to grammar 
have not yet been unravelled yet. Before a grammar can be said to be both generative and adequate to describe natural language in the most simple way, these two problems must be solved.

Incidently, the way in which the lexicon and grammar are related in a language, such that arbitrariness is reduced and a greater degree of simplification attained seems to be indirectly related to descriptive simplicity. It is likely that a description of language becomes simpler when one abandons a criterion of simplicity that is only concerned with grammar, in favour of one which also takes into account the relation between grammar and lexicon. 


\section{CHAPTER 7}

\section{CONCLUSIONS}

The principal conclusion of this thesis is that pidgins are languages that are different in degree and not in kind from languages that have, or have had, native speakers.

In the first part of my investigation I looked at some extra-linguistic causes for the development of pidgins. Although many detalls are yet unknown it is certain that most of the extralinguistic factors can be reduced to one common denominator: they create abnormal conditions of language transmission by destroying, temporarlly or permanently language communities. The same phenomenon is present in normal language change and transmission, although the rate of change is considerably slower.

Imperfect learning seems to be the main reason for language change of this sort. It is not yet known to what degree imperfect learning by children is different from that of foreigners. The ability to construct optimal grammars from language data is considerably more limited in adults than in children. The role that the interference phenomena of adult language learning play in pidgin languages is not well understood. Opinions about substratum influences differ considerably. One of the reasons is that the techniques of contrastive linguistics are not well enough developed, and the criteria that are relevant to such an analysis not clear. Often, languages have been compared in terms of their inventories and not their rules. One component of the grammar that has been consistently neglected is the lexicon.

Progress in this field can only be made when work is done within an explicit grammatical theory. Lack of theoretical sophistication, and unsystematic organization of the data has lessened the importance of much earlier research into pidgin languages. The definition of certain terms as parts of an explicit theory was therefore necessary. Such definitions were given above for pidgin, creole, pidginization, creolization, 
simplification and impoverishment. At the same time terminological inconsistencies and differences in earlier work have been pointed out in order to facilitate the understanding of some otherwise valuable work. All these definitions deal with the linguistic aspect of pidgins; it has been maintained that a characterization of pidgins in purely linguistic terms is possible in principle. At the same time, the importance of extralinguistic factors for the understanding of the phenomenon 'pldgin' has been stressed. However, the lack of a theoretical framework in which the sociolinguistic parameters could be incorporated, as well as the general lack of rellable data, resulted in a merely pre-theoretical classification of some sociolinguistic data, whose relevance and relative importance must be determined in further research.

Simplification is one of the universal features of any language transmission; pidgins are, however, more simplified than other languages, although one must think of a scale of simplification rather than an invariable quantity.

The term simplification is used to refer to those processes that introduce greater regularity into language. It is strictly separated from descriptive simplicity. The uncritical use of both terms has led to certain confusion in recent literature on pidgins. Simplicity and simplification are related only in a very indirect way and I have pointed out instances where such parallelism may be found.

Simplification can be found in all components of a grammar. The mechanism that operates in simplification is one that expands the domain of grammatical rules. Simplification is optimalization of rules and not loss of rules. Languages without grammar cannot be simple. There is a relationship between lexicalization and the use of rules for pairing sound with meaning. Pldgin languages tend to prefer rules to lexical1zation: semantically similar items are generally expressed by phonetically similar items. Zero-derivation in connection with meaningful sequence of surface structure elements is the most common mechanism. This does not mean, however, that statements such as the following are valid: "The flexional neutrality is so typical...that it has led to many comments on the common structure of these languages, (pidgins and creoles). In the grammatical field, if this common feature is subtracted, there remains only word-order as a potential differential between Creole speeches" (Richardson 1963: p. 7). Word order, as well as other salient features of pidgins such as inflectional poverty and reduplication, is on 1ts own not a sufficlent, though in all likelihood a necessary, condition for a language to qualify as a pidgin. Other factors, mainly the organization of the lexicon, must be considered at the same time. 
A comparison of different pidgins should not rely too heavily on surface sequence of elements: there are good reasons to expect that the surface structure of most pidgins is very similar. One reason is that, due to the loss of inflectional categorles, meaning is partly carried by sequence. A second reason that follows from the first, is that deletion and permutation transformations cannot be expected to play an important part. The 1dentity of surface sequence should not be taken as a strong argument for relexification theory. Even the 1dentity of certain items in the lexicon is not a strong argument. The differences between pidgins, creoles, and their lexically related standard languages lie in the organization of the lexicon. This again will not prove conclusively that two pidgins are related by relexification: there are language-independent principles for the optimalization of a lexicon. The only evidence that could support relexification theory is sociolinguistic historical evidence. A few cases of relexification are known (e.g. replacement of a Dutch-based vocabulary by an English-based vocabulary in Negerengels) and the evidence from these is that relexification is gradual, random, and dependent on phonological similarity as well as meaning of lexical 1tems.

Intuition about simplification, language-independent tendencies towards simplification, and possibly some prejudices about what constitutes simplification in languages are the most important factors that account for the structure of pidgins. Substratum influences and other factors are secondary to this.

In the last part of my thesis I tried to demonstrate some implications for grammatical theory of the findings concerning simplification. Whereas transformational generative theory has developed a mechanism that can cope with the problems of lexical organisation, the relationship between lexical and grammatical items, especially the 'parts of speech' remalns unclear.

Parts of speech, such as $\mathrm{N}$ and $\mathrm{V}$ are part of practically every transformational approach to language. Nevertheless these concepts are not well defined within the model, or, at least, the relation of lexical items to these grammatical categories has not yet been satisfactorily formalized. I believe that one must insist that $\mathrm{N}, \mathrm{V}, \mathrm{Adv}$, and other traditional categories are surface structure phenomena. There is no way of deciding on the categorial status of semantic or deep elements.

It is, however, not obvious that these categories are very useful concepts for surface analysis either. They are not universals, and to say that a language has a category $N$ in fact says little. Their usefulness for the description of individual languages is limited as well: the 1tems that are classified as members of one of these categories are frequently not homogeneous with regard to their transformational, 
Inflectional or semantic properties. Subclassification that starts with maln categorles will only lead to multiple listing resulting from crossclassification on the one hand, and overlapping classes on the other hand.

The solution for this dilemma is, to abandon the 1dea of pre-existent classes and let the grammar (Including the lexical rules) decide on classification. Instead of postulating substantive universals grammatical theory should lay down princlples for the classification of grammatically relevent 1tems.

Surface structure function can be taken as one of the main criteria for the establishment of classes. Grammar should specify the functional possibllities of every lexical 1tem, partly by means of redundancy rules, the semantic and morphological consequences of the appearance of lexical 1tems in certain functions, transformational relations that hold between these functions and other grammatical rules. Th1s would mean that the categorlal component of the grammar would be replaced by a functional component, the functions being possibly universal.

Many, perhaps most, 1tems would appear in more than one function. An approach that expresses functional information in features would avold double listing and class-overlap.

Semantic properties of lexical 1tems are only partly and indirectly relatable to thelr grammatical properties. Pldgins make use of this principle, assoclating different grammatical information with the same semantic and phonological 1tem. The resulting multifunctionality is most likely a universal of pldgins, although some of the deeper regularities are not yet well understood.

Simplification can mean ultimately that the language is neutral in what 1 expresses. Functional slots in the surface structure are not places where additional obligatory semantic information is accommodated. It is sald that languages differ most, not in what they can express, but what they must express. Pldgins must express little or nothing obligatorily. Again, this is a question of degree, and the expansion or creolization of pidgins is normally accompanied by the introduction of obligatory semantic information such as time/tense information.

One of the alms of this thesis was to discuss and evaluate a representative sample of studies of pldgin languages. The state of the art in this relatively young fleld of linguistics is confusing for laymen. as well as spectalists. Most of the work that has been done is purely pretheoretical; the high quality of some of the pretheoretical work, as well as some recent work within tine framework of one or another grammatical theory, gives reason for the hope that a theoretical framework can be developed to account for both linguistic and non-linguistic 
properties of pidgins. In many ways, the multitude of observations that are already avallable will make this task a difficult one. The facts that can be found in pidgins can be seen as a challenge to grammatical theory and as a field where sociolinguistic theory may find its most rewarding subject matter. Pidgins may cast light on some basic principles of human communication, on adult language learning and optimalization of grammar.

For reasons already pointed out, the results of this thesis are tentative in many regards. The justification for the proposals made will lie in their sultability for handling a large corpus of data. More than in most other fields of linguistic research the lack of reliable data is the main barrier to advancement in our knowledge of pidgins. 



\section{BIBLIOGRAPHY}

Part I: Pidgin and Creole Languages

ALGEO, J.T.

1960 Korean Bamboo English, American Speech 55: 117-123. ALLEYNE, MERVYN C.

1971 Acculturation and the Cultural Matrix of Creoliaation, Hymes 1971: 169-186.

BAILEY, BERYZ̈ L.

1966 Jamaican Creole Syntax, New York, Cambridge University Press. Review: Wölk, Wolfgang 1968, J Eng L: 142-145.

1971 Jamaican Creole: Can Dialect Boundaries be Defined?, Hymes 1971: $341-348$.

BAKER, S.J.

1953 Australia Speaks, Sydney.

BARRENA, NATALIO

1957 Grammatica Annobonesa Madrid, Instituto de Estudios Africanos.

BAUSANI, A.

1970 Geheim-und Universalsprachen, Stuttgart, Kohlhammer. BERRY, J.

1971a Pidgins and Creoles in Africa, Current Trends in Linguistics $7:$ : $10-536$.

1971b Tone and intonation in Sierra Leone Krio, Hymes 1971: 285.

BICKERTON, D. and ESCALANTE, E.

1970 Palanquero: A Spanish-based Creole of Northern Columbia, Lingua 24: 254-267. 
BOLD, J.D.

1968 FANAGALO Phrasebook, Grammar and Dictionary.

Johannesburg, Keartland.

BORCHARDT, P.K.m.s.c.

1926 Tok-Boi Woerterbuch, typescript.

BOS, A.

1880 Note sur le Créole que Z'on Parle à l'Ile Maurice, Romania 9: 571-578.

BOSMAN, D.B.

1962 Oor die Ontstaan van Afrikaans, Amsterdam.

BOUMAN, A.C.

1962 Some Remarks on the Language of a Book of Verse in

Afrikaans, Lingua 11: 55-66.

BRUNOT, F.

Histoire de la Langue Francaise des Origines à 2900, VIII, 3.

BURLING, R.

1970 Man's many voices, New York, Holt, Rinehart \& Winston.

CARRINGTON, L.D.

1969 Deviations from Standard English in the Speech of Primary

School Children in St Lucia and Dominica: A Preliminary

survey, IRAL VII, 3 \& 4 .

CASSIDY, F.G.

1962 Toward the Recovery of Early English-African Pidgin, in

(Symposium): 267-277.

1970 Teaching Standard English to Speakers of Creole in Jamaica, 20th Georgetown Round Table Meeting: 203-214, Washington

D.C., Georgetown University Press.

1971 Tracing the Pidgin Element in Jamaican Creole in Hymes 1971: 203-222.

CHATAIGNER, A.

1963 Le Créole Portugais du Sénégal, Journal of African Languages

2, 1: 44-71.

CHATTERTON, P.

1970 The Origin and Development of Police Motu, K1vung 3, 2: 83-92.

CHURCHILL, W.

1911 Beach-La-Mar, Washington D.C., Carnegie Institution. 
CHRISTOPERSEN, P.

1953 Some Special West African English Words, English Studies $34: 282-291$.

1959 A Note on the Words 'Dash' and 'Ju-Ju' in West African English, English Studies 40: 115.

CLYNE, M.

1968 Zum Pidgin - Deutsch der Gastarbeiter, Ze1tschrift für Deutsche Mundartforschung 35: 130-139.

COLE, D.T.

1964 Fanagalo and the Bantu Languages in South Africa, in Hymes 1964: 547-554.

CONFERENCE

1971

Study Conference on Police Motu, Port Moresby, Department of Information.

D'ANS, A.M.

1968

Le Créole Francais d'Haiti, The Hague, Mouton

reviews: Goodman 1970 Lingua 25: 446.

Valdman 1971 IJAL : 203.

DeCAMP, D.

1967 African Day Names in Jamaica, Language 43: 139-149.

1968 The field of Creole Language Studies, Studia Anglica Posnaniensia I: 29-52.

1971a The Study of Pidgin and Creole Languages in Hymes 1971: $13-41$.

1971b Toward a Generative Analysis of a Post-Creole Speech Continuum, in Hymes 1971: 349-370.

DILLARD, J.L.

1967 Negro Children's Dialect in the Inner City, The Florida FL Reporter.

1968 Non Standard Negro Dialects: Convergence or Divergence?, The Florida FL Reporter.

1970 Principles in the History of American English-Paradox Virginity and Cafeteria, The Florida FL Reporter.

1971 The Creolist and the Study of Negro Non-Standard Dialects in the Continental United States, in Hymes 1971: 393-408. 
DONICIE, A. and VOORHOEVE J.

1967 De Creolentaal van Suriname, Paramaribo, Radhakishun.

De Saramakaanse Voordenschat, Amsterdam, Bureau voor Taalonderzoek in Suriname.

DUTTON, T.E.

1969 The Informal English Speech of Palm Island Aboriginal

Children, J Eng L 3: 18-36.

\section{EERSEL, CHRISTIAN}

1971 Prestige in Choice of Language and Linguistic Form, in Hymes 1971: 317-322.

ERVIN, SUSAN, M.

1961 Semantic Shift in Bilingualism, American Journal of Psychology 74: 233--241.

FERGUSON, C.A.

1959 Diglossia. Word 15: 325-340.

1971 Absence of Copula and the Notion of Simplicity: a Study of Normal speech, Baby Talk, Foreigner Talk, and Pidgins, in Hymes 1971: 141-150.

FISCHER, H.

1966 Cargo-Ideen, Anthropos LKI: 49-97.

FISHMAN, J.A. (ed.)

1968 Readings in the Sociology of Language. The Hague, Mouton.

FRAKE, CHARLES, 0 .

Lexical Origins and Semantic Structure in Philippine Creole Spanish, in Hymes 1971: 223-242.

FRENCH, A.

1953 Pidgin English in New Guinea, Australian Quarterly, 23; 4 : 57-60.

GÁLDI , GÖBL- , L.

1934 Esquisse de la Structure Grammaticale des Patois Francais-Creoles, Ze1tschrift für Französische Sprache und Literatur 58: 257-295.

1938 La Structure Grammaticale des Parlers Francais-Creoles, 2nd Cong. Internat. des Sclences Anthropologiques et Ethnologiques, Comptes Rendus, Copenhagen: 371-372.

1969 Le système du Verbe dans les Parlers Francais-Creoles, Acta Linguistica Academiae Scientiarum Hungaricae, Tomus 19: $121-125$. 
GOILO, E.R.

1964 Papiaments Leerboek, Aruba, Aruba Drukkerij.

GOODMAN, J.S.

1967 The Development of a Dialect of English-Japanese Pidgin. Anthropological Linguistics 9: 43-55.

GOODMAN, M.J.

1964 A Comparative Study of Creole French Dialects, The Hague, Mouton

reviews: 1965 IJAL XXXI: 363-370 (Taylor)

1966 Lingua XVI: $421-426$ (Voorhoeve)

1966 African Studies XXV: 161-163 (Valkhoff).

GRADE, P.

1892 Das Negerenglisch an der Westküste von Afrika, Anglia

XIV: $362-393$.

GRIMSHAW, ALLAN, D.

1971 Some Social Forces and Some Social Functions of Pidgin and Creole Languages, in Hymes 1971: 427-446.

GRANT, RENA, V.

1945 Chinook Jargon, IJAL II: 225-233,

GRIMES, J.E. and GLOCK, N.

1970 A Saramaccan Narrative Pattern, Language 46, 1: 408-425.

V. HAERINGEN

19

Neerlandica, p. 22: De Taaie Levenskracht van het Sterke werkwoord.

HALL, ROBERT, A. Jr.

1943 Melanesian Pidgin English: Grammar, Texts, Vocabulary, Linguistic Society of America review : 1944 Language 20: 168-171 (McDavid).

1944 Chinese Pidgin English, Grammar and Texts, Journal of the American Oriental Society 64: 95-113.

1948 The Linguistic Structure of Taki-Taki, Language 24: 92-116.

1952 Pidgin English and Linguistic Change, LIngua III, 2: $138-146$.

1954 Hands off Pidgin English, Sydney, Paclfic Publications.

1956 Innovations in Melanesian Pidgin (Neo-Melanesian), Oceania: 91-109.

1959 Colonial Policy and Neomelanesian, Anthropological Linguistics 1,3: 22-27. 
HALL, ROBERT, A. Jr.

1962 The Determination of Form Classes in Haitian Creole, Ze1tschrift für Romanische Philologie LXXXVIII: 172-177.

1966 Pidgin and Creole Languages, Ithaca, Cornell University Press.

review: Lingua 18 (1967): 101-105 (Voorhoeve).

HANCOCK, I.F.

1971a West Africa and the Atlantic Creoles in: Spencer (ed.) 1971 .

1971b A Provisional Comparison of the English-Derived Atlantic Creoles, in Hymes 1971: 287-292.

HARRISON, J.A.

1884 Negro English, Anglia VII: 232-279.

HARTIG, M. and KURZ, U.

1971 Sprache als soziale Kontrolle, Frankfurt, Suhrkamp.

HEINE, B.

1970 Status and Use of African Lingua Francas, Munich, Weltforum Verlag.

HEMPL, G.

1898 Language-rivalry and Speech Differentiation in the Case of Race Mixture, Transactions of the American Philological Association XXIX: 31-47.

HESSELING, D.C.

1905 Het Negerhollandsch der Deense Antillen, Leiden.

1923 Het Afrikaansch, 2nd ed., Le1den.

HJELMSLEV, L.

1938 Caractères Grammaticaux des Langues Créoles, $2 \mathrm{e}$ Congres

International des Sclences Anthropologiqus et Ethnologiques, Comptes Rendus, Copenhagen.

HOOLEY, B.A.

1962 Transformations in Neomelanesian, Oceania 33: 166-127.

HYMES, D.

1959 Genetic Classification: Retrospect and Prospect, Anthropological Linguistics I: 56-66.

1964 (ed.) Language and Society, New York, Harper and Row.

1971 (ed.) Pidginization and Creolization of Languages, Cambridge University Press.

review: 1971 TLS 3 December 1529. 
JACOBS, M.

1932 Notes on the Structure of Chinook Jargon, Language 8:

27-50.

JERNUDD, B.H.

1971 Social Change in Aboriginal speech Variation in Australia, Anthropological Linguistics 13: 16-32.

JONES, E.

1971 Krio, an English-based Language of Sierra Leone, in Spencer (ed.) 1971: 66-94.

Joos, $M$.

1971 Hypotheses as to the Origin and Modification of Pidgins, in Hymes 1971: 187.

JOURDAIN, ELODIE

1956 Du Francais aux Parlers Créoles, Paris, Klincksiek.

reviews: 1957 Language 33: 226-231 (Hall).

1957 Word 13: 357-368 (Taylor).

KOCHAN, D.C. (ed.)

1971 Stilistik und Soziolinguistik (Beiträge der Prager Schule zur strukturelien sprachbetrachtung und Spracherziehung), München, List.

LABOV, W.

1971a On the Adequacy of Natural Languages, (draft).

1971b The Notion of 'System' in Creole Languages, in Hymes 1971: 447-472.

LADO, R.

1968a Memory Span as a Factor in Second Language Learning;

IRAL III:123-129.

1968b Contrastive Linguistics in a Mentalistic Theory of Language Learning, 19th Georgetown Round Table Meeting, Washington D.C., Georgetown University Press.

LAYCOCK, D.

1970 Materials in New Guinea Pidgin, Pac1fic Linguistics, Series D, No.5, Canberra.

LAWTON, D.

1971 The Question of Creolization in Puerto Rico Spanish, in Hymes 1971: 193-196.

LENZ , R.

1928

El PAPIAMENTO. La Lengua Creolza de Curacao, la Gramatica mas sencilla, Anales de $l a$ Universidad de Chile IV-V Santiago de Chile. 
LePAGE, R.B.

1957, 1958 General Outlines of English Creole Dialects, Orb1s 6: 373-391; Orbis 7: 54-64.

1961 (ed.) Proceedings of the Conference on Creole Language Studies, London, MacMillan.

LOUW, S.A.

1948 Dialekvermenging en Taalontwikkeling, Cape Town.

MACKAY, W.F .

1968 The Description of Bilingualism, in Fishman 1968.

MAFENI, B.

1971 Nigerian Pidgin, in Spencer 1971: 95-112.

MCDAVID, RAVEN I.

1967 Historical, Regional and Social Variation, Journal of English Linguistics I: 24-40.

MCQUOWN, N.A.

1964 A Planned Auxiliary Language, in Hymes 1964: 555-564.

MIDGETT, D.

1970 Bilingualism and Linguistic Change in St. Lucia, Anthropological Linguistics 12: 158-170.

MIHALIC, F.

1971 The Jacaranda Dictionary and Grammar of MeZanesian Pidgin, Jacaranda Press.

MURPHY, J.J .

1966 The Book of Pidgin English, Brisbane.

NEUMANN, G.

1965 Russennorwegisch und Pidginenglisch: Beobachtungen zum

Bau von Behelfssprachen, Nachrichten der Glessener

Hochschulgesellschaft XXXIV: 219-232.

1966 Zur Chinesisch-Russischen Behelfssprache von Kjachta, Sprache XII: 237-251.

NIDA, E.A. and FEHDERAU R.W.

1970 Indigenous Pidgins and Koinés, IJAL 36: 146-155.

NOCKLER, HERBERT

1963 Sprachmischung in Südwestafrika, München, Hueber.

NEVERMANN, H.

1929 Das Melanesische Pidgin-English, Englische Studien:

252-258. 
ODENDAL, F.F.

1961 The Structure of the Afrikaans Root Morpheme, Lingua $\mathrm{X}: 38-56$.

POMPILUS, PRADEL

1961 De Quelques Influences du Créole sur le Francais Officiel D'Haiti, in LePage 1961: 91-98.

POLOMÉ, EDGAR

1971 The Katanga (Lubumbashi) Swahili Creole in Hymes 1971: 57-60.

PONELIS, F.

1968 Grondtrekke van die Afrikaanse Sintaksis, Pretorla

Van Schaik.

PRICK van WELY, F.F.H.

1912 Das Alter des Pidgin Englisch, Englische Studien: 298-299.

RAIDT, E.H.

1967 Oor die skeiding van die Sinchroniese en Diachroniese Taalstudie, Taalfasette 3, Pretoria.

REINECKE, J.E.

1964 Trade Jargons and Creole Dialects as Marginal Languages, in Hymes 1964: 534-546.

1971a Tây Bôi: Notes on the Pidgin French spoken in Vietnam, in Hymes 1971: 47-56.

1971b Some Suggested Fields for Research, in Hymes 1971: 499-502.

REED, S.W.

1943 The Making of Modern New Guinea, New York.

RICE, F.A. (ed.)

1962 Study of the Role of Second Languages, Washington.

RICHARDSON, I.

1961 Some Observations on the Status of Town Bemba in Northern Rhodesia, African Language Studies 2: 25-36.

1962 Linguistic Change in Africa with special Reference to the Bemba-Speaking Area in Northern Rhodesia, in Symposium: 189-196.

1963 Examples of Deviation and Innovation in Bemba, African Language Studies 4: 138-145.

1963a Evolutionary Factors in Mauritian Creole, Journal of African Languages 2, 1: 2-14. 
ROBERTSON, F .

1971 Comic-Opera Talk-Talk, New As1a Magazine, August 22: $13-16$.

ROGGE, HEINZ

1957 Pidgin English: Eine Lingua Franca Ostasiens, Zeitschrift fur Anglistik und Amerikanistik: 32l-326.

ROSS, A.S.C.

1964 The Pitcairness Language, London, Deutsch.

SAMARIN, W.J.

1955 Sango, An African Lingua Franca. Word II: 254-267.

1958 The Phonology of Pidgin Sango. Word 14: 62-70.

1966 Self-Annulling Prestige Factors among Speakers of a creole Language, in Bright: Sociolinguistics, The Hague, Mouton.

1968 Lingua Francas of the World, in Fishman 1968: 660-672.

1971 Salient and Substantive Pidginization, in Hymes 1971: 117-140.

SAYER, E.S.

1943 Pidgin English, Toronto.

1944 review: Language 20:171-174 (Hall).

SCHLAUCH, M.

1968 The English Language in Modern Times, London, Oxford University Press.

SCHNEIDER, G.D.

1966 West African Pidgin English, Athens, Ohio

review: 1971 Lingua 28: 185-196 (Todd)

1971 Language Sc1ences 17: 60-62 (Spears).

1967 West African Pidgin English - An Overview, Journal of English Linguistics I: 49-56.

SCHOLTZ, J. du P.

1941 Uit die Geskiedenis van die Naamgewing aan Plante en Diere in Afrikaans, Cape Town.

1965 Afrikaans uit die Vroëe Tyd, Cape Town.

SCHUCHARDT, H.

1881 Beiträge zur Kenntnis des Kreolischen Englisch, Englische Studien 15: 286-305. 
SCHUCHARDT, $\mathrm{H}$.

1889 Beiträge zur Kenntnis des Englischen Creolisch II:

Melaneso-Englisches Englische Studien: 158-162.

1909 Die Lingua Franca, Ze1tschrift für Romanische Philologie 33: $441-461$.

SILVERSTEIN, M.

1971 Language Contact and the Problem of Convergent

Generative Systems, in Hymes 1971: 191-192.

SOUTHWORTH, F.C.

1971 Detecting Prior Creolization: An Analysis of the

Historical Origins of Marathi, in Hymes 1971: 255-274.

SPENCER, J. (ed.)

1971 The English Language in West Africa, London, Longman. STEWART, W.A.

1962a An Outline of Linguistic Typology for Describing Multilingualism, in Rice 1962: 15-25.

1962b Creole Languages in the Caribbean, in Rice 1962: 34-53.

1963 Relexification as a Factor in the Evolution of Creole Languages, Paper read at the Thirty-Eighth Annual Meeting of the Linguistic Society of America.

(SYMPOSIUM)

1964 Symposium on Multilingualism, Brazzaville 1962, CSA/CCTA Publication No. 87, London.

TAYLOR, DOUGLAS

1947 Phonemes of Caribbean Creole, Word 3: 173-179.

1951 Structural Outlines of Caribbean Creole, Word 7: 43-59.

1956 Language Contacts in the West Indies, Word 12: 399-414.

1959 On Function Versus Form in Non-Traditional Languages Word 15: 485-488.

1960 Language Shift or Changing Relationship. IJAL 26: 155-161.

1961 New Languages for old in the West Indies, in Fishman 1968: 607-619.

1961a Some Dominican-Creole Descendants for the French Definite Article in LePage (ed.) 1961: 85-90.

THOMAS, J.J.

1969 (reprint) The Theory and Practice of Creole Grammar, London \& Port of Spain, New Beacon. 
THOMPSON, R.W.

1961 A Note on Some Possible Affinities between the Creole Dialects of the old. World and those of the New in LePage 1961 (ed.): 107-112.

TODD, LORETO

1971 West Cameron Pidgin Proverbs, Journal for West African Languages VII, 2: 85-100.

TONKIN, E.

1971 Some Coastal Pidgins of West Africa in Spencer (ed.)

1971: 129-153.

TROST, P.

1971 Zu den Ursachen des Sprachwandels, in Kochan 1971.

TSUZAKI

1971 Coexistent Systems in Language Variation: the Case of Hawaian English, in Hymes 1971: 327-340.

TURNER, G.W.

1966 The English Language in Australia and New Zealand, London, Longmans.

TURNER, L.D.

1949 Africanisms in the Guzlah Dialeat, University of Chicago Press,

reviews: Language 27 (1950): 326-332 (MacDavid) Lingua VIII (1959): 306-321 (Blok).

VALDMAN, A.

1964 Du Créole au Francais en Haiti, Linguistics 8: 84-94. VALKHOFF, M.F.

1966 Studies in Portuguese and Creole with Special Reference to South Africa, Johannesburg, Witwatersrand, University Press, reviews: 1967 Standpunte 71 and 73: The Diachronics of Afrikaans (L.C. Eksteen) 1968 Language 44: 654-659 (Taylor).

1971 Descriptive Bibliography of the Linguistics of Afrikaans: A Survey of Major Works and Authors, Current Trends in Linguistics $7:$ 455-500.

deVILLIERS, M.

1960 Nederlands en Afrikaans, Cape Town, Nasou. 
VOORHOEVE, JAN

1957

The Verbal System of Sranan, Lingua 6: 374-369.

1959 An Orthography for Saramaccan, Word 15: 436-445.

1961 la Ton et le Grammaire Dans le Saramaccan, Word 17: 146-163.

196la Linguistic Experiments in Syntactic Analysis, in LePage (ed.) : 27-60.

$196 \mathrm{lb}$ A Project for the Study of Creole Language History in Surinam, 1bidem: pp.99-106.

1962 Creole Languages and Communication, in Symposium: 233-242.

1970 The Regularity of Sound Correspondences in a Creole Language: IJAL: 51-69.

1971a A Note on Reduction and Expansion in Grammar in Hymes 1971: 189 .

1971b Church Creole and Pagan Cult Languages, in Hymes 1971: 305-316.

WEINREICH U.

1958 On the Compatibility of Genetic Relationship and Convergent Development, Word 14: 374-379.

1964 Languages in Contact, The Hague, Mouton.

WHINNOM, KEITH

1956 Spanish Contact Vernaculars in the Philippine Islands, London \& Hong Kong, Hong Kong University Press, reviews: 1957 Word 13: 489-499 (Taylor).

1965 The Origin of the European-based Creoles and Pidgins, Orb1s XIV, 2: 509-527.

1971 Linguistic Hybridization and the 'Special Case' of Pidgins and Creoles, in Hymes 1971: 91-116.

WILSON, W.A.A.

1962 The Crioulo of Guiné, Johannesburg, Witwatersrand University Press,

Review: Journal of African Languages 1965: 76-77.

WINFORD, D.

1972 A Sociolinguistic Description of two Communities in Trinidad, Unpublished Ph.D. Thesis, University of York. 
WOLFERS, E.

1971 A Report on Neo-Melanesian, in Hymes 1971: 413-419.

WURM, S.A. and HARRIS, J.B.

1963 Police Motu, Linguistic Circle of Canberra Publications, Series B, Monograph No.1, review: 1965 Language 41: 168-170 (Hooley).

WURM, S.A.

1968 Papua-New Guinea Nationhood: The Problems of a National Language: in Fishman 1968: 346-364.

197la New Guinea Highlands Pidgin: Course Materials, Paciflc Linguistics, Series D, No.3, Canberra.

1971b Pidgins, Creoles and Lingue Franche in Current Trends in Linguistics 8: 999-1021.

ZETTERSTEN, A.

1969 The English of Tristan da Cunha, Lund Studies in Engl1sh 37 , review: 1970 Lingua 26: 328-332 (LePage).

ZUMTHOR, P.

1957 review and discussion: Hall, Haitian Creole Zeitschrift für Romanische Ph1lologie 73: 513-517. 
Part II: Linguistic Theory and General Works

ANDERSON,

1971 Dependency and Grammatical Functions, Foundations of Language $7: 30-37$.

BABCOCK, S.S.

1972 Paraphrastic Causatives, Foundations of Language 8: $30-43$.

$\mathrm{BACH}, \mathrm{E}$.

1962 The Order of Elements in a Transformational Grammar of German, Language 38: 263-269.

BACH, E. and HARMS, R.T. (eds.)

1970 Universals in Linguistic Theory, London, Holt, Rinehart and Winston.

BALLY, C.

1950 Linguistique Générale et Linguistique Francaise, Berne, Francke.

BAUMGÄRTNER, K.

1970 Konstituen $z$ und Dependenz, in Steger (ed.) 1970: 52-77.

BAZELL, C.E.

1958 Linguistic Typology, Inaugural Lecture, London, School of African and Oriental Studies.

BAZELL et al (eds.)

1966 In Memory of J.R. Firth London, Longmans.

BELLUGI, U.

1971 Simplification in Childrens' Language, in Huxley and Ingram 1971: 95-116.

BIERWISCH, M.

1962 Uber den Theoretischen Status des Morphems, Studia Grammatica I: 51-89.

1966 Strukturalismus: Geschichte, Probleme und Methoden Kursbuch 5: 77-152, Frankfurt, Suhrkamp.

1971 Grammatik des Deutschen Verbs, Studia Grammatica II, Berlin, Akademie Verlag.

BLOOMFIELD, J.

1969 Language, London, Allan and Unwin. 
BOAS, F.

1966 Introduction: Handbook of American Indian Languages, Lincoln, University of Nebraska Press.

BOLINGER， D.

1968 Aspects of Language, New York Harcourt, Brace and World.

BOTHA, R.P.

1968 The Function of the Lexicon in Transformational Generative Grammar, The Hague, Mouton.

CAIRNS, C.E.

1969 Markedness, Neutralization and Universal Redundancy Rules, Language 45: 863-885.

CAROLL, J.B.

1968 Contrastive Analysis and Interference Theory, 19th Round Table Conference, Washington.

CHAFE, W.

1968 The Ordering of Phonological RuZes, IJAL XXXIV: 115-136.

1970 Meaning and the Structure of Language, New York, review: 1971 Lingua 28: 124-130 (N1lson).

CHOMSKY, N.

1957 Syntactic Structures, The Hague, Mouton.

1965 Aspects of the Theory of Syntax, Cambridge, Mass.

1966 Topics in the Theory of Generative Grammar, The Hague, Mouton.

1970 Remarks on Nominalization, In Jacobs and Rosenbaum (eds.).

1971 Deep Structure, Surface Structure and Semantic Interpretation, in Steinberg and Jakobovits (eds.).

CRYSTAL, D.

1966 Word Classes in English, Lingua 17: 24-56.

1971 Linguistics, Pelican Books.

COSERIU, E.

1969 Einführung in die Strukturelzs Linguistik, Tüb1ngen.

1970 Einführung in die Transformationelze Grammatik, Tübingen.

Di PIETRO, R.J.

1968 Contrastive Analysis and the Notions of Deep and Surface Structure, 19th Round Table Conference, Washington. 
DIXON, R.M.W.

1965 What is Language?, London, Longmans.

1968 Noun CZasses LIngua XXI: 104-125.

1971 A Method of Semantic Description, in: Steinberg and Jakobovits (eds.).

ERVIN, S.M.

1961 Semantic shift in Bilingualism, American Journal of Psychology $74: 233-241$.

1964 Imitation and Structural Change in Childrens' Language, in Lenneberg (ed.).

FILLMORE, CHARLES, J.

1970 The Case for Case, in: Bach and Harms (1970).

FODOR, J.A. and KATZ, J.J. (eds.)

1964 The Structure of Language, Prentice Hall, New Jersey.

GAUGER, H.M.

1970 Wort und Sprache, Tübingen.

GRACE, G.W.

1970 Oceanic Linguistics Tomorrow, In Wurm and Laycock (eds.). GREENBERG, J.H.

1970 Language Universals, in Current Trends in Linguistics III: $61-112$.

GRUNIG, B.

1965-66 Les Théories Transformationnelles, La Linguistique 1965: 1-24 and 1966; 1: 31-101.

HALLIDAY, M.A.K.

1961 Categories of the Theory of Grammar, Word 17: 241-292.

1966 Lexis as a Linguistic Level, in Bazell et al (eds.).

HEMP, E.B. et al (eds.)

1966 Readings in Linguistics II, Chicago, University Press.

HAYS, D.G.

1964 Dependency Theory: A Formalism and Some observations, Language 40: 511-525.

HAWKEY, H.L.

1970 A Critique of Certain Basic Theoretical Notions in Chomsky's Syntactic Structures, Folio Linguistics IV: pp. 195-209. 
HERINGER, H.J .

1970 Theorie der Deutschen Syntax, München Hueber.

HOCKETT, C.F.

1968 A Course in Modern Linguistics, New York, Macmillan. HOUSEHOLDER, F.W.

1971 Linguistic Speculations, Cambridge University Press.

ISENBERG,

1968 Das Direkte Objekt im Spanisch, Studia Grammatica 9, Berlin, Akademie Verlag.

JACOBS, R.A. and ROSENBAUM, F. (eds.)

1970 Readings in English Transformational Grammar, Waltham, Mass.

KATZ, J.J.

1967 Recent Issues in Semantic Theory, Foundations of Language 3: $124-194$.

KEMPEN , W.

1964 Woordvorming en Funksiewisseling in Afrikaans, Cape Town, Nasionale Boekhandel.

KING, R.D.

1969 Historical Linguistics and Generative Grammar, New Jersey, Prentice $\mathrm{Hall}$.

KIPARSKY, P.

1970 Linguistic Universals and Linguistic Change in Bach and Harms (eds.).

1970a Historical Linguistics, in Lyons (ed.).

LAKOFF， G.

1965 On the Nature of Syntactic Irregularity, Report No. NSF-16, Mathematical Linguistics and Automatic Translation.

1968 Instrumental Adverbs and the Concept of Deep Structure, Foundation of Language 4: 4-29.

LANGENDOEN, D.T.

1971 The Study of Syntax, London, Holt International.

LYONS, J .

1966 Towards a Notional Theory of the Parts of Speech, Journal of Linguistics 2: 209-236.

1968 Introduction to Theoretical Linguistics, Cambridge University Press. 
LYONS, J. (ed.)

1970 New Horizons in Linguistics, Pellcan Books.

MCCAWLEY, J.D.

1971 Where do Noun Phrases Come From?, in Steinberg and Jakobovits (eds.).

MARCHAND, H.

1963 Die Ableitung Desubstantivischer Verben mit Nullmorphem im Französischen und die Entsprechenden Verhältnisse im Englischen und im Deutschen, Zeitschrift f. Französ1sche Sprache und Literatur 73: 164-179.

MARTINET, A.

1966 Elements of General Linguistics, London, Faber and Faber. MATTHEWS, P.H.

1967 Word Classes in Latin, Lingua 17: 163-187.

1970 The Adequacy of Grammars, Supplementary Volume XLIV, The Aristotelian Society.

1970a Recent Developments in Morphology, in Lyons (ed.) 1970. NEWMEYER, F.J.

1971 The Source of Derived Nominals in English, Language 47: 786-796.

NIDA, A.

1967 Morphology, Ann Arbor, University of Michigan Press.

1969 Science of Translation, Language 45: 483-498.

PALMER, F.R.

1964 Sequence and Order, Fifteenth Round Table Meeting, Washington: 123-132.

1971 Grammar, Penguin Books.

PAUL, H.

1970 Prinzipien der Sprachgeschichte (reprint of the 1920 edition), Tübingen, Niemeyer.

REIBEL, D.A. and SCHANE, S.A.

1969 Modern Studies in English, New Jersey, Prentice Hall.

ROBINS, R.H.

1959 In Defence of WP, Transactions of the Phililogical Society:

$116-144$. 
ROBINS, R.H.

1961 Syntactic Analysis, Archivum Linguisticum: 78-89.

1964 General Linguistics: An Introductory Survey, London, Longmans .

1966 The Development of the Word Class System of the European Grammatical Tradition, Foundations of Language 2: 3-19.

ROSS, J.R.

1969 Adjectives as Noun Phrases, In Reibel and Schane (eds.).

RUWET, N .

1967 Introduction à la gromaire: Générative, Parls, Plon.

SCOTT, C.T.

1970 Transformational Theory and English as a Second Language/

Dialect, $20^{\text {th }}$ Round Table Meeting, Washington.

SOMMERFELT, A.

1962 Diachronic and Synchronic Aspects of Language, The Hague, Mouton.

STAAL, J.F.

Word Order in Sanskrit and Universal Grammar, Foundations of Language, Supplementary Series Vol. 5.

STEGER, H. (ed.).

1970 Vorschläge für eine strukturelle Grammatik des Deutschen, Darmstadt, Wissenschaftliche Buchgesellschaft.

STEINBERG, D.D. and JAKOBOVITS, L.A. (eds.)

1971 Semantics: An Interdisciplinary Reader in Philosophy, Linguistics and Psychology, Cambridge University Press.

STEINITZ, R.

1971 Adverbial-Syntax, Studia Grammatica 10, Berlin, Akademie Verlag.

STOCKWELL et al

1965 Grammatical Structures of English and Spanish, Chicago, University Press.

TOWNSON, M.

1971 Zur Fehleranalyse, Linguist1k und Didakt1k 7: 135-238.

TESNIËRE, L.

1939 Phonologie et Mélange de Langue, In Kamp et al. (eds.): 83-93.

1965 Eléments de Syntaxe Structurale, München, Hueber. 
ULLMANN, S.

1953 Descriptive Semantics and Linguistic Typology, Word 9 : 225-240.

1964 Semantics: The Science of Meaning, Oxford, Blackwell. Van der LUBBE, H.F.A.

1965 Woordvolgorde in het Nederlands, Assen, Van Gorcum.

VILDOMEC, $\mathrm{V}$.

1963 Multilingualism, Leyden, Sythoff.

WEINREICH, J .

1966 Explorations in Semantic Theory, in Current Trends in Linguistics III.

WUNDERLICH, D. (ed.)

1971 Probleme und Fortschritte der Transformationsgrammatik, München, Hueber.

WURM, S.A. and LAYCOCK, D.C. (eds.)

1970 Pacific Linguistic Studies in Honour of Arthur Capelz, Canberra, Linguistic Circle of Canberra Publications. 
